Outrage Fatigue? Cognitive Costs and Decisions to Blame

Veerpal Bambrah ${ }^{\mathrm{a}}$, M.A., C. Daryl Cameron ${ }^{\mathrm{b}, \mathrm{c}}$, Ph.D., and Michael Inzlicht ${ }^{\mathrm{d}, \mathrm{e}}$, Ph.D.

${ }^{a}$ Department of Psychology, Faculty of Health, York University, 4700 Keele Street, Toronto, Ontario, Canada, M3J 1P3.

${ }^{\mathrm{b}}$ Department of Psychology, Pennsylvania State University (PSU), University Park, Pennsylvania, USA, 16801.

${ }^{c}$ Rock Ethics Institute, PSU, University Park, Pennsylvania, USA, 16801.

${ }^{\mathrm{d}}$ Department of Psychology, University of Toronto, 1265 Military Trail, Scarborough, Ontario, Canada, M1C 1A4.

${ }^{\text {e }}$ Rotman School of Management, University of Toronto, 105 St. George Street, Toronto, Ontario, Canada, M5S 3E6.

All authors contributed to the conception and design of studies. Material preparation, data collection, and data analyses were performed by Veerpal Bambrah. Drafts and revisions of the manuscript were completed by Veerpal Bambrah and all authors provided feedback and commented on the manuscript. All authors read and approved the final manuscript.

Funding: This research was supported by grant 1660707 from the National Science Foundation and grant 61150 from the John Templeton Foundation to the $2^{\text {nd }}$ author, and grant 435-2014-0556 from the Social Sciences and Humanities Research Council and grant RGPIN2014-03744 from the Natural Sciences and Engineering Research Council to the $3^{\text {rd }}$ author.

Conflict of Interest: The authors have no significant interests to report. Correspondence concerning this article should be addressed to Veerpal Bambrah, Department of Psychology, Faculty of Health, York University, Behavioural Sciences Building, 4700 Keele Street, Toronto, Ontario, M3J 1P3. Email: bambrahv@yorku.ca 


\begin{abstract}
Across nine studies $(N=1,672)$, we assessed the link between cognitive costs and the choice to express outrage by blaming. We developed the Blame Selection Task, a binary free-choice paradigm that examines the propensity to blame transgressors (versus an alternative choice)either before or after reading vignettes and viewing images of moral transgressions. We hypothesized that participants' choice to blame wrongdoers would negatively relate to how cognitively inefficacious, effortful, and aversive blaming feels (compared to the alternative choice). With vignettes, participants approached blaming and reported that blaming felt more efficacious. With images, participants avoided blaming and reported that blaming felt more inefficacious, effortful, and aversive. Blame choice was greater for vignette-based transgressions than image-based transgressions. Blame choice was positively related to moral personality constructs, blame-related social-norms, and perceived efficacy of blaming, and inversely related to perceived effort and aversiveness of blaming. The BST is a valid behavioral index of blame propensity, and choosing to blame is linked to its cognitive costs.
\end{abstract}

Keywords: moral outrage, blame, choice, effort, efficacy 


\section{Outrage Fatigue? Cognitive Costs and Decisions to Blame}

Outrage often seems easy. In 2013, when Justine Sacco, a senior director of corporate communications at holding company InterActiveCorp, tweeted an acerbic joke about contracting a sexually transmitted disease in Africa, she was swiftly labeled as racist and verbally attacked by thousands of outraged strangers, making her (for a while) the No. 1 worldwide trend on Twitter (Ronson, 2015). In 2017, when over 100 travellers were detained at the United States border by an executive order blocking civilians from seven Muslim-majority countries, tens of thousands of American citizens gathered nationwide to voice their detestation towards former President Donald Trump and towards the policy (Diamond, 2017). In 2019, when Alabama citizen Marshae Jones was shot in the stomach during a dispute with another woman, it was Jones who was charged with manslaughter-a decision that prompted both national support from pro-life groups and law enforcement officials, who blamed Jones for initiating and continuing the fight that resulted in the death of her five-month old fetus, and national outcry from pro-choice groups, who blamed Alabama's racialized criminalization of women's pregnancies for Jones' sudden indictment (Silverman \& Ellis, 2019).

All of these cases are examples of moral outrage, which are feelings of anger, contempt, and disgust directed towards a third-party for violating some moral standard of fairness, justice, or care (Haidt, 2003; Salerno \& Peter-Hagene, 2013; Spring et al., 2018). As the examples above suggest, violations of fairness, justice, or care not only lead people to feel these othercondemning emotions, but to express them in different ways (Bastian et al., 2013). For example, spectators may express feelings of moral outrage by shaming or dehumanizing the individual(s) who they believe has violated moral norms (Crockett, 2017; Haslam, 2006; Viki et al., 2012). Alternatively, onlookers may call for retributive forms of punishment that are not only 
proportionate to the seriousness of moral wrong committed, but also to the intensity of their hostile affect towards the perpetrator (Carlsmith et al., 2002; Salerno \& Peter-Hagene, 2013).

Another way of demonstrating outrage is by blaming, that is, assigning moral responsibility and culpability to the individual(s) for a fault or wrong (Alicke, 2000; Bastian et al., 2011). Blaming is a particularly important form of outrage expression, as some accounts of blame (e.g., Guglielmo et al., 2009; Malle et al., 2014; Monroe \& Malle, 2017) suggest that onlookers sequentially process 'agent' causation, intent, reasons, desires, capacity/foresight, and blameworthiness for a norm-violating event before shaming, dehumanizing, and punishing the agent(s). That is, the assignment and degree of blame is said to precede (and thus, justify) other forms of outrage expression. It follows, then, that understanding the causes and consequences of expressions of moral outrage should begin with exploring blame.

Now more than ever, individuals are readily able to express their outrage. Online, users can express their outrage directly to the transgressor or to a broader audience with just a few keystrokes, anonymously or openly; and with even less work, they can simply repost or react to others' comments, fueling virality (Brady et al., 2017, 2020; Crockett, 2017). Yet, regardless of what is expressed (blaming, shaming, dehumanizing, or punishing sentiments), moral outrage has often been cast as exhausting: With the deluge of offensive news stories found online, as opposed to in-person or through traditional forms of media (Crockett, 2017; Hofmann et al., 2014), some have suggested that outrage fatigue can prevent individuals from being morally engaged and from taking pro-social or collective actions (Barberá et al., 2015; Brady et al., 2017; Crockett, 2017, Xiao \& Houser, 2005). These conflicting intuitions suggest there is a need to more completely understand the predictors and consequences of feeling and expressing moral outrage. We developed a task that uses behaviorally revealed preferences (Kool et al., 2010) to 
empirically explore the propensity to blame - that is, whether people will generate outrage and blame others (i.e., assign responsibility for a fault or wrong) when given the choice to blame against an alternative mental act. Our behavioral approach compliments recent individual differences approaches to understanding outrage/blame propensity (see Gill \& Cerce, 2021). Additionally, and crucially, in order to understand whether expressing outrage is cognitively fatiguing, we empirically examined the felt cognitive costs of blaming and how, if at all, such costs relate to people's choices to blame others.

\section{Motivations for Blame (and Other Expressions of Moral Outrage)}

Philosophers, sociologists, legal theorists, and experimental psychologists are largely in agreement as to what comprises a blameworthy act. Alicke's (2008) description of blameworthiness is representative: "A blameworthy act occurs when an actor intentionally, negligently, or recklessly causes foreseen, or foreseeable, harmful consequences without any compelling mitigating or extenuating circumstances" (p. 179). Although these experts agree about the kinds of acts that elicit blame judgments, arguably the most recurrent disagreement is the extent to which blame judgments are shaped by epistemic forces (i.e., individuals' knowledge and reasoning) or motivational forces (i.e., individuals' desires and goals). Some researchers accord inferential reasoning a central role in shaping moral judgments, whereas others assign more weight to motivated cognition in shaping such judgments.

For example, the path model of blame (Guglielmo et al., 2009; Malle et al., 2014) accords less importance to motivational factors and, instead, delineates a specific cognitive structure (or "path") that people follow to produce blame judgments. What makes judgments moral is that

they are directed at agents who are presumed, accused, or shown to have performed behaviors that caused or permitted harm to occur. Within this structure, blame judgments involve 
integrating information relevant to certain critical concepts and "testing" whether the criteria are met in a graded and systematic manner. These criteria include intentionality (whether the agent brought about the event intentionally), obligation (whether the agent should have prevented the norm-violating event), and capacity (whether the agent could have prevented the event). If the agent is judged to have acted intentionally, then the perceiver considers the agent's reasons for acting. Depending on the justification that these reasons provide, these inputs give rise to a dichotomous 'yes-or-no' and a scalar 'more-or-less' judgment of blame-minimal blame if the agent was justified in acting this way or maximal blame if the agent was not justified.

In contrast, motivated blame models suggest that the consideration of causal and mental information is secondary to and biased by early-emerging moral judgments and a general desire to blame. The various models share in the common the view that moral judgments quickly emerge in response to a norm violation, and perceivers consider the details of the event (e.g., intentionality) later, often as a post-hoc rationalization of their judgements (Alicke, 2000; Pettit $\&$ Knobe, 2009). From an attributionist perspective, the general desire to assign blame stems from a motivation to maintain a sense of predictability and control. That is, attribution processes are not only a means of providing an individual with a veridical view of his/her world, but a means of forming and maintaining one's effective exercise of control in the world (e.g., Kelley, 1971). This idea is related to the view that moral judgment is largely motivated by the need to evaluate other individuals, which allows people to navigate their social environment in more adaptive ways (Pizarro \& Tannenbaum, 2012; Tannenbaum et al., 2011).

Indeed, blaming or other expressions of outrage may allow individuals to navigate their social environment in adaptive ways if such expressions also signal positive information about oneself. For example, Jordan and colleagues (2016) tested the notion that punishing a wrongdoer 
may signal one's virtue to observers. In this work, one set of participants, the Signalers, were willing to sacrifice their own money and pay to punish a third party for selfish behavior — even though the Signalers themselves had not been personally mistreated. A second group of participants was more likely to trust Signalers who punished selfishness and were right to be trusting, as Signalers actually behaved in a more trustworthy manner. More recent studies by Jordan and Kteily (2020) found that participants expected to be evaluated more positively (by Deciders/perceivers) regardless of if they punished an unambiguous (very severe and likely to be true) or an ambiguous (less severe and less likely to be true) wrongdoing, and that participants punished at higher rates when their behavior was public. Together, these experiments underscore a "virtue-signaling" account of expressing moral outrage, such that the costs of expressing outrage may be redeemed by the social benefits of signaling one's trustworthiness and bolstering one's reputation. These studies suggests that expressing outrage is motivated by the increased ability to navigate one's social environments. This work also implies that there is a social cost to not displaying outrage, such that people are not viewed by others as trustworthy. Indeed, recent work demonstrates that people who decide to forgive wrongdoers, rather than punish them, are perceived as blameworthy and as having bad moral character (Gardner \& Monroe, 2018).

However, the act of blaming also carries substantial social costs for blamers, such as retaliation towards the blamer by the norm-violator or reputational damage for the blamer when an accusation is unsupported or unwarranted (e.g., MacCoun, 2005; Mikula et al., 1998). As such, the socially-regulated blame perspective (Monroe \& Malle, 2019) posits that the norms of moral criticism demand that individuals have warrant when they blame others. Together, the requirement for warrant and the potential social costs of blaming (for blamers) motivate individuals to be relatively careful in processing available blame-relevant information, such as an 
agent's causality and other mental states (noted above). A series of studies by Monroe and Malle (2019) found that moral perceivers do systematically grade and update blame judgements in response to the strength of new causal and mental information about an agent's intentionality, reasons, and preventability. For example, relative to initial blame for a violation whose intentionality is ambiguous, participants increased blame when they learned that a violation was intentional and decreased blame when they learned that a violation was unintentional. The authors also found that when social pressure to form fair and justified moral judgments was reduced, participants' blame judgments were no longer systematic and, instead, showed a bias towards over-blaming. Overall, the social costs of blame motivate individuals to calibrate judgements to the causal and mental information surrounding a moral violation.

\section{The Link Between Blaming and Cognitive Costs}

The above-reviewed literature underscores the role of social costs in motivating outrage and blame, and it suggests that people are less motivated to systematically update moral judgements of blame when such costs are absent. Most notably, Monroe and Malle (2019) found that systematic and graded blame updating and change occurred even when participants' cognitive resources were successfully reduced. While this finding suggests that cognitive distractions or a lack of motivation to engage in effortful cognition do not deter individuals from processing incoming morally-relevant information and altering blame decisions in a calibrated manner, what is less understood is the degree to which people's choices to express outrage and blame is linked to the felt cognitive costs of doing so. This question is relevant in modern digital contexts, where respondents are more frequently exposed to outrage-inducing stimuli, which may be fatiguing, while at the same time they are more readily able to express outrage that can 
potentially reach millions (Brady et al., 2017; Crockett, 2017). Deeper tendencies for motivated blame may be related to how cognitively taxing the act of blaming feels.

On average, individuals prefer to avoid effort (Hull, 1943; Kool \& Botvinick, 2018). There is an intrinsic, subjective cost associated with effort, such that individuals will avoid or disengage from activities that are cognitively demanding in order to avoid or reduce the inherent price of effort exertion (Kool \& Botvinick, 2013; Kool \& Botvinick, 2014; but see Inzlicht et al., 2018). Kool and colleagues (2010) have provided direct empirical support for this idea using a behavioral paradigm, called the Demand Selection Task (DST). In this task, participants face a recurring choice between two alternative lines of action, each associated with different levels of cognitive demand, and they consistently show a preference for the less effortful course of action (Kool et al., 2010). Previous accounts of mental effort have linked effort with emotional aversion (e.g., Inzlicht et al., 2015; Kurzban, 2016). In addition to effort and aversion, cognitive costs can be conceptualized as how much work is extracted from a person for a given level of achievement (Hsu et al., 2017), such that a person feels less efficacious when a task requires a lot from them in order to attain a certain goal or achievement level. Thus, in the current work, we examined felt effort, aversion, and inefficacy as aspects of cognitive costs.

\section{Current Studies: The Blame Selection Task}

Recent work suggests that individuals do in fact avoid cognitive work in moral and social contexts: People choose to avoid empathy for strangers, a preference which is linked to felt cognitive costs (Cameron et al., 2019). As its own moral emotion, the choice to feel and express outrage via blaming may be sensitive to whether it is more cognitively costly than, for example, engaging in empathy for wrongdoers or morally disengaging (being objective). In particular, the choice to blame may be sensitive to one's desire to make the most accurate or efficacious moral 
decision, stemming from social demand (e.g., rewards, norms, etc.; Jordan et al., 2016; Kundu \& Cummins, 2013) or from the fact that some moral decisions are not intuitive and, instead, require more deliberation from the perceiver (e.g., moral dilemmas; Kahane et al., 2012).

These points have the potential to be quite important for the field of moral psychology, particularly in the face of the socially-regulated blame perspective, which posits that the repeated requirement for a blame warrant makes the processing of causal and mental morally-pertinent information fast and effortless. Within moral psychology, empirical arguments for and against motivated accounts of blaming depend largely on how researchers interpret participants' judgments of agent blameworthiness, causation, intent, desire, foresight, and other factors that legal models identify as related to blame (see Ames \& Fiske, 2015). Further, the typical approach is to present participants with moral cases and to subsequently assess their ascriptions of blame via self-reports, without providing participants with the actual choice of morally engaging or disengaging in real time. This methodological innovation is important because revealed choices towards generating outrage and blaming (or not doing so) could be more consequential—and thus, potentially more costly - than self-reports of blame intentions or attitudes. To our knowledge, only one other study has directly examined choices to engage in blame (Ames \& Fiske, 2015): Participants were more likely to select a blaming task from among five options after reading about a single intentional (versus unintentional) harm. The current set of studies expand beyond this work by examining choices to engage in blaming over a series of instances, and critically, examining the associations between blaming and felt cognitive costs.

To accomplish these objectives, we developed the Blame Selection Task(BST), where respondents make a series of choices between engaging in blame and an alternative course of action. Adapted from the logic of the Demand Selection Task (Kool et al., 2010) and Empathy 
Selection Task (Cameron et al., 2019), this approach allows us to explore if respondents' baseline motivation is to feel outrage and blame individuals when presented with moral transgressions. People are well familiar with managing moral outrage; in fact, there has been much colloquial discussion of how individuals selectively choose to expose themselves to news media in order to amplify or diminish feelings of outrage (e.g., Mills, 2017; Ley, 2017). With the BST, we examine motivations towards outrage and blame through spontaneous choices, and with measures of cognitive costs, we examine whether such moralizing feels effortless or effortful.

Across studies, we examined a number of procedural variations in order to test the generalizability of our results (Yarkoni, 2019). First, in all studies, participants chose between two card decks, one of which was always a "BLAME" deck, over repeated trials. Each deck entailed different instructions on how to respond to the moral transgressions that are presented. The nature of the contrast deck differed across studies. In some studies, blaming the transgressor was contrasted against morally disengaging by objectively describing the transgressor's actions (Studies 1, 2, 4a, 5a, 5b, 6, and 7); and in other studies, blaming the transgressor was contrasted against morally engaging by empathizing with the transgressor's inner experiences (Studies 3 and $4 b$ ). We changed the contrast deck in order to examine whether blame selection motivation would be comparable even as competing courses of action changed (i.e., objective detachment or empathy for the transgressor). Second, we examined blame selection and cognitive costs in response to realistic moral transgressions that are depicted in more than one format (e.g., vignettes versus images versus images with captions). Whereas verbal descriptions of transgressions are often quite clear, images of transgressions may be more equivocal and difficult to interpret, thus leading to changes in blame choice behavior. Alternatively, images may be more effective than words in motivating onlookers' behaviors (e.g., Winkielman \& Gogolushko, 
2018), thus leading to increased blame motivation. Third, we examined whether blame motivation shifted depending on whether respondents viewed moral transgressions before making their choices (Studies 1, 2, 3, 5a, 6, and 7) or after making their choices (Studies 4a, 4b, and $5 \mathrm{~b}$ ), which allowed us to differentiate context-bound motivations to blame (in response to particular moral acts) from context-general motivations to blame. These variations are detailed both below and in the Appendices.

Our dependent variables were the choice to blame (i.e., the proportion of trials where outrage and blame are selected, compared against chance -50 percent) and the perceived cognitive costs (i.e., effort, aversion, and inefficacy) rated for each deck (the BLAME deck and the alternative deck). Across studies, we explored whether the proportion of trials that the BLAME deck was chosen significantly varied from chance, specifically whether the patterns of blame choice differed depending on the contrast deck used (objectivity or empathy), the type of moral stimuli presented (vignettes or images), and the position of the decks (deck choices before or after the moral stimuli). In keeping with the above-reviewed literature on the avoidance of cognitive work (e.g., Kool et al., 2010; Kool \& Botvinick, 2013; Kool \& Botvinick, 2014; Kool \& Botvinick, 2018), even within in socio-moral contexts (e.g., Cameron et al., 2019), we hypothesized that respondents' choice to generate outrage and blame others would negatively relate to the degree that blaming (relative to the alternative deck) felt cognitively costly (assessed via ratings of effort, aversion, and inefficacy).

\section{General Methods, Measures, and Procedures}

\section{Participants}

All studies were approved by the Research Ethics Board at the University of Toronto. Participants were voluntarily recruited for 30 minutes of participation on TurkPrime (Litman et 
al., 2016), an online data collection platform that recruits diverse research samples. All responses provided by participants were strictly anonymous. Those who failed attention checks concealed within the measures of individual differences or who failed to follow the writing prompts (e.g., entering incoherent responses or entering responses that did not match the instructions for the deck) were excluded from analyses, as they were not engaged with the task. According to a power analysis using the average effect in social psychology $(d=0.40$; Richard et al., 2003), with a one-sample $t$-test design, we could achieve $80 \%$ power in a two-tailed test with 52 participants and 90\% power in a two-tailed test with 68 participants. Study 1 included 102 participants; Study 2 included 110 participants; Study 3 included 201 participants; Study 4a included 205 participants; Study 4b included 203 participants; Study 5a included 219 participants; Study 5b included 205 participants; Study 6 included 210 participants; and Study 7 included 217 participants. The sample sizes in Studies 3 to 7 increased from Studies 1 and 2 in order to examine individual difference correlations; power analyses suggested a minimum sample size of 193 to detect a modest correlation $(r=.20)$ with $80 \%$ power in a two-tailed test. Table A1 in Appendix A presents the demographic details for each sample, including the number of people excluded in each study.

\section{The Blame Selection Task}

The Blame Selection Task (BST) was programmed on Qualtrics survey software (Qualtrics, Provo, UT). In all studies, participants chose between two card decks, one of which was always a "BLAME" deck, over repeated trials. Deck positioning was counterbalanced in Studies 1 to 6; two separate Qualtrics surveys were run sequentially, such that roughly half of the study sample completed the BST with the BLAME deck on the left or right side of the task, and the rest of the study sample subsequently completed the BST with the BLAME deck on the 
opposite side (see Table A2 in Appendix A for exact n's in each study). Given the differences in moral stimuli, deck choices, and deck position between studies, the complete pre-task and triallevel instructions of the BST varied slightly across studies and are described both below and in Appendix B. All studies first included a sample trial after the pre-task instructions to demonstrate to participants the type of moral stimuli and the decks that they would see, as well as to demonstrate sample responses for the BLAME and alternative decks. All participants then completed two practice trials to familiarize themselves with the sequence of a trial. In each study, the moral stimuli (i.e., vignettes or images) were presented in a random order. While there was no time limit for participants to choose to blame or not, a timer was implemented so that participants could not submit the written response until after a certain amount of time had elapsed (Studies 1 to $4 \mathrm{~b}=15$ seconds; Studies 5a to $6=$ eight seconds; Study $7=$ six seconds).

\section{Post-Task Assessments of Cognitive Costs and Individual Differences}

\section{Cognitive Costs}

Immediately after the BST, participants across all studies completed items adapted from the NASA Task Load Index (Hart \& Staveland, 1988), which we used to assess how cognitively costly they found each deck (i.e., BLAME and either DESCRIBE or FEEL). For each deck, participants answered four questions: "How mentally demanding was this deck?", "How hard did you have to work to accomplish your level of performance with this deck?", "How insecure, discouraged, irritated, stressed, and annoyed were you by this deck?", and "How successful were you in accomplishing what you were asked to do in this deck?" $(1=$ Very Low to $5=$ Very High $)$. For each deck, the first two items were averaged into an index of perceived effort. The third and fourth items correspond to perceived aversiveness and perceived efficacy, respectively. All three indices contributed to one's assessment of how cognitively costly they found using each deck. 


\section{Measures of Individual Differences}

Across studies, respondents completed a number of individual difference measures. First, we included three measures of moral personality, as a means to test the convergent validity of the BST. In Studies 1 to 7, the Moral Convictions Scale (Skitka, 2010) assessed the degree to which participants exhibited strong moral convictions about the transgressions they read/saw. Given that individuals with stronger convictions about moral issues prefer greater social and physical distance from attitudinally divergent others and endorse greater intolerance towards attitudinally divergent others (Skitka et al., 2005), it is expected that participants who more strongly moralize wrongdoings are more motivated to blame transgressors. In Studies 2 to 7, the Moral Identity Scale (Aquino \& Reed, 2002) assessed self-importance of moral identity. Given the links between moral identity and increased pro-social behaviors and moral emotions (e.g., Aquino \& Reed, 2002; Hardy, 2006; Stets \& Carter, 2006), participants who tie morality more closely to their self-concept might choose to blame transgressors more often. In Study 7, the Blame Intensity Inventory (Gill \& Cerce, 2021) assessed individual differences in the propensity to experience intense blame reactions; it is expected that participants with a greater tendency to have hostile affective reactions to offenders would choose to blame transgressors more frequently. Outside of moral personality, we assessed descriptive and injunctive social norms, as well as personal norms, about blaming in Studies 2 to 7 (drawing on five items from Cameron et al., 2019). Recent work (Son et al., 2019) finds that victims and jurors will reference group preferences to inform their own punitive decisions, becoming increasingly punitive as groups express a desire to punish. Thus, to the degree that participants believe that others choose blame, that others value blame, and to the degree that participants themselves view blaming as desirable, they might select into blame-eliciting contexts. Finally, the Empathy Index (Jordan et al., 2016) 
assessed trait empathy in Studies 1 to 7 , as it might be expected that highly empathetic participants would have a higher blame motivation if they are empathizing with the victim(s) of the transgression (e.g., see Leliveld et al., 2012 on the relationship between observers' empathy and punishment of offenders). Details about each measure, including how items were rated, sample items, subscales, and the Cronbach's alpha values (Table C1) and mean scores (Table C2) across all studies, are found in Appendix C. Participants in Studies 2 to 6 also completed the Ten-Item Personality Inventory (Gosling et al., 2003), but results pertaining to this measure were not of central interest in the current paper and are presented in Appendix C.

\section{Data Analyses}

Across all studies, some of the blame choice variables were non-normally distributed (i.e., possessing a slight positive or negative skew). As such, we conducted both non-parametric and parametric tests to examine the degree to which participants chose to blame compared to chance (one-sample tests), as well as the blame choice patterns based on the ambiguity of moral transgressions and on the type of moral stimuli presented (paired sample tests; described further below). It is noted that the pattern of results remained the same in all studies. We present results of non-parametric Wilcoxon tests within the main text and parametric $t$-test statistics in Appendix F. All other $t$-test assumptions, regarding the scale of measurement, random sampling, adequacy of sample size, and equality of variance in standard deviation, were met.

Across studies that used moral vignettes (Studies 1 to $4 \mathrm{~b}$ ) and moral images (Studies 5a to 6), non-parametric independent samples tests found that blame choice (i.e., the proportion of trials that participants chose the BLAME deck) of the participants who saw the BLAME deck on the left side of the BST did not significantly differ from the blame choice of the participants who saw the BLAME deck on the right side, which confirms that there was no left- or right-side bias 
for selecting the BLAME deck. See Table A2 in Appendix A for test statistics and effect sizes across all studies (vignettes and images).

\section{Studies 1 to 4b: Blame Selection Task with Moral Vignettes}

A set of 40 moral vignettes (brief written descriptions of a target individual engaging in a real-life action(s) that is morally wrong e.g., assault, robbery, infidelity, etc.) were obtained from a moral vignettes database by Knutson and colleagues (2010) and from supplementary materials published by Gill and Getty (2016). We first piloted these 40 vignettes with 109 participants, who rated each vignette on indices of Harm (low Care) and Moral Appropriateness.

Of the 40 vignettes, 26 were included in Study 1. The full procedure for selecting the 26 moral vignettes in Study 1 and the average Care and Moral Appropriateness rating for each vignette (Table D1) are in Appendix D. In Study 2 and subsequent studies using vignettes, we explored whether respondents were more likely to blame in response to certain types of moral transgressions than others. Whereas Jordan and Kteily (2020) illustrate the role of perceived reputational incentives on participants' punishment of unambiguous and ambiguous acts, we sought to explore respondents' first-person management of their choice to blame immoral acts of varying levels of severity. Based on a composite (average score) of the Care and Moral Appropriateness ratings of the 40 moral vignettes that were piloted prior to Study 1,16 vignettes were grouped and labelled as clear moral transgressions, where the action(s) was conspicuously harmful and morally inappropriate, and 16 vignettes were grouped and labelled as ambiguous moral transgressions, where the action(s) was less conspicuously harmful and morally inappropriate. See Appendix D for further details and statistical justification for this grouping procedure. Mean Care and Moral Appropriateness ratings and the composite Care-Moral Appropriateness scores of the 32 vignettes used in Studies 2, 3, 4a, 4b, and 7 are in Table D2. 


\section{Study 1 Methods}

In Study 1 , participants $(N=102)$ were instructed that they would complete a series of trials in which they would read a first-person vignette of an individual committing an action and then see two decks of cards to choose between freely. Participants were told that if they chose the BLAME deck, they would be instructed to feel moral outrage, focus on the moral details of the individual and the action(s) committed, and write one sentence about why the individual should be blamed for the sequence of events. If participants chose the objective ("DESCRIBE") deck, they would be instructed to be objectively detached, focus on the features of the individual and the action(s) committed, and write one sentence about how the individual caused the sequence of events (see Appendix B for pre-task instructions of all studies). Participants then completed 26 trials of the BST. If they chose the BLAME deck, they saw the following prompt: "Based on the scenario, try to feel moral outrage. Focus on the reasons for why the individual's action(s) is morally wrong. Please write one sentence about why the individual should be blamed for this sequence of events". If they chose the DESCRIBE deck, they saw the following prompt: "Based on the scenario, try to be objective. Focus on the details of how the individual caused the action(s) in question. Please write one sentence about how the individual caused this sequence of events". Figure 1 depicts a single trial of the BST in Study 1.

\section{Study 1 Results}

\section{Blame Choice}

Table 1 presents the descriptive and inferential statistics (medians, one-sample Wilcoxon signed-rank tests, and effect size $r^{1}$ ) for blame choice across all studies. Figure 2 depicts blame

\footnotetext{
${ }^{1}$ The interpretation values for $r$ commonly in published literature are: $0.10-<0.3$ (small effect), $0.30-<0.5$ (moderate effect) and $>=0.5$ (large effect).
} 
choice across all studies. In Study 1, although respondents chose to blame more than describe, a one-sample Wilcoxon signed-rank test found that blame choice did not significantly differ from chance (50 percent), $Z=1.55, p=.120$, with a small blame choice effect observed $(r=.15)$.

\section{Cognitive Costs}

Table 1 also presents average ratings of perceived effort, perceived aversiveness, and perceived efficacy for the BLAME and alternative decks (i.e., DESCRIBE or FEEL) across all studies $^{2}$. We report differences in these ratings between Blame and Objectivity or Empathy in each study. Paired sample $t$-tests revealed that differences between the BLAME and DESCRIBE decks in felt effort, $t(101)=1.55, p=.125,95 \% \mathrm{CI}$ of $M_{\text {difference }}=-.07, .54, d=0.16$, aversiveness, $t(101)=1.38, p=.172,95 \%$ CI of $M_{\text {difference }}=-.10, .53, d=0.14$, and efficacy, $t(101)=.48, p=.634,95 \% \mathrm{CI}$ of $M_{\text {difference }}=-.22, .35, d=0.05$, were small and not significant in Study 1 . Together, these non-significant differences in cognitive costs could account for why there was no overall motivation among respondents in this study to choose to blame wrongdoers.

\section{Study 2 Methods: Refinement of Study 1 BST}

In Study 2, participants $(N=110)$ completed a BST equivalent to what is described in Study 1. However, trial-level instructions of the BLAME deck were slightly revised to ensure that the intensity associated with the term "outrage" was not inadvertently leading respondents to choose the deck: "Based on the scenario, try to feel moral disapproval. Focus on the reasons for why the individual's action(s) is morally wrong. Please write one sentence about why the individual should be blamed for this sequence of events" (italics added to indicate revision).

\section{Study 2 Results}

\footnotetext{
${ }^{2}$ Because the NASA Task Load index was administered twice in Studies 3 and 7 (i.e., halfway through the BST and at end of the BST), we computed the average effort, aversiveness, and efficacy scores - between both time-points-for the BLAME and FEEL/DESCRIBE decks.
} 


\section{Blame Choice}

In contrast to Study 1, blame choice was significantly greater than chance in Study $2, Z=$ $4.44, p<.001$, with a moderate blame choice effect observed among participants $(r=.42)$.

\section{Cognitive Costs}

With respect to cognitive costs differences in Study 2, the BLAME deck felt significantly more aversive than the DESCRIBE deck, $t(109)=1.68, p=.048,95 \% \mathrm{CI}$ of $M_{\text {difference }}=.04, .48$, $d=0.16$, but felt no different in effort, $t(109)=.12, p=.904,95 \%$ CI of $M_{\text {difference }}=-.21, .24, d=$ 0.01 , and efficacy, $t(109)=.37, p=.712,95 \% \mathrm{CI}$ of $M_{\text {difference }}=-.16, .23, d=0.04$.

\section{Study 3 Methods: Blocking Vignettes by Moral Ambiguity with Empathy Contrast}

In Study 3, the 32 vignettes were blocked based on moral ambiguity of the transgression, which allowed us to examine participants' management of outrage and blame in response moral acts of differing levels of severity. Some respondents $(n=100)$ read all 16 clear moral transgressions first and others $(n=101)$ read all 16 ambiguous moral transgressions first. Unlike in Study 2, the contrast deck to blame was a "FEEL" deck (similar to the empathy deck used in Cameron et al., 2019), which allowed us to examine whether blame choice would change as the alternative action changed (i.e., from objective detachment to empathy). In the pre-task instructions, respondents were told that if they chose the FEEL deck, they would be instructed to have empathy and write one sentence about the feelings and experiences of the individual who committed the action(s). Trial-level instructions for the BLAME deck were revised in this study to ensure congruency in the word-count and syntax with the FEEL deck (see Appendix B). If participants chose the BLAME deck, they saw the following prompt: "Based on the scenario, try to feel moral outrage toward the individual who committed the action(s). Morally focus on the blameworthiness of this individual's actions(s). Please write one sentence about why the 
individual, who committed the action(s), should be blamed". If participants chose the FEEL deck, they saw the prompt: "Based on the scenario, try feel what the individual who committed the action(s) feels. Empathically focus on this individual's internal emotional experiences. Please write one sentence about what the individual, who committed the action(s), feels and experiences". Finally, respondents in Study 3 completed to the NASA Task Load Index twice, once after the first half of trials ("Please answer the following questions about the [BLAME or FEEL] deck, thus far.") and again after all trials ("Please answer the following questions about the [BLAME or FEEL] deck, based on your experience during the second-half of the task"), in order to collect cognitive costs ratings separately for clear and ambiguous moral transgressions.

\section{Study 3 Results}

\section{Blame Choice}

Similar to Study 2, blame choice was significantly greater than chance in Study $3, Z=$ 8.63, $p<.001, r=0.61$. Between Studies 2 and 3, there was no significant difference in blame choice, as evidenced by a Wilcoxon rank sum test, $Z=-.62, p=.537, r=-.04$. Together, these results suggest that, irrespective of the alternative deck choice (either objectivity or empathy towards transgressors), respondents displayed a moderate-to-strong motivation to feel outrage and blame individuals depicted in the moral vignettes after reading the vignettes.

\section{Blame Choice by Moral Ambiguity of Vignettes}

We computed a blame choice score (i.e., the proportion of trials that the respondent chose the BLAME deck) for the groups of clear and ambiguous moral transgressions for each participant in Studies 2 and 3, where vignettes—-labelled as either clear or ambiguous_preceded deck choice. Figure 3 depicts blame choice by the moral ambiguity of transgressions (i.e., clear versus ambiguous) across all relevant studies. 
As evidenced by paired samples Wilcoxon signed rank tests, blame choice was significantly greater for the clear moral transgressions than for the ambiguous moral transgressions within both studies [Study 2: $Z=-8.13, p<.001, r=-.78$; Study 3: $Z=-11.66, p<$ $.001, r=-.82]$, with a very robust effect of transgression ambiguity on participants' blame choices. One-sample Wilcoxon signed rank tests found that participants chose the BLAME deck at a rate significantly greater than chance (i.e., greater than 50 percent of trials) after reading the clear moral transgressions in both studies [Study 2: Median choice $=0.88, Z=6.60, p<.001, r=$ .63 ; Study 3: Median $_{\text {choice }}=0.81, Z=10.36, p<.001, r=.73$ ], but did not show a preference for selecting the BLAME deck after reading the ambiguous moral transgressions [Study 2: Median $_{\text {choice }}=0.44, Z=-.32, p=.746, r=-.03 ;$ Study 3: Median $_{\text {choice }}=0.50, Z=1.27, p=.205, r$ $=.09]$. These results suggest that, as opposed to remaining objective or empathizing, respondents chose to blame individuals who commit clearly harmful and morally inappropriate behaviors, but that this blame preference diminished for more ambiguous behaviors.

\section{Cognitive Costs}

Consistent with Study 2, the BLAME deck felt significantly more aversive than the FEEL deck in Study 3, $t(200)=2.71, p=.007,95 \%$ CI of $M_{\text {difference }}=.06, .36, d=0.19$. In Study 3 , the BLAME deck also felt significantly more efficacious than the FEEL deck, $t(200)=2.02, p=$ $.045,95 \% \mathrm{CI}$ of $M_{\text {difference }}=.01, .24, d=0.14$. In this study, the BLAME deck felt significantly less effortful than the FEEL deck, $t(200)=-2.01, p=.046,95 \%$ CI of $M_{\text {difference }}=-.27,-.01, d=-$ 0.14 , which is consistent with recent work that suggests that empathy is cognitively effortful (Cameron et al., 2019).

Notwithstanding these differences in cognitive costs between blaming and empathy, in collapsing across transgression ambiguity, the above analysis might mask differences in 
cognitive costs based upon the moral ambiguity of the action. Thus, in Study 3, we examined if differences between the BLAME and FEEL decks on perceived effort, aversiveness, and efficacy varied by the level of moral ambiguity of the action committed.

Table 2 presents the average ratings of perceived effort, perceived aversiveness, and perceived efficacy for the BLAME and FEEL deck across clear and ambiguous moral transgressions in Study 3. We conducted three 2 x 2 repeated measures ANOVAs to examine whether differences between BLAME and FEEL decks in effort, aversiveness, and efficacy were moderated by the moral ambiguity of the transgressions. There was a significant interaction between deck (BLAME, FEEL) and moral ambiguity (clear, ambiguous) on ratings of efficacy, $F(1,200)=9.01, p=.003$, partial $\eta_{\mathrm{p}}^{2}=.04$. Pairwise comparisons revealed that that BLAME deck felt significantly more efficacious than the FEEL deck in the block of clear moral transgressions $\left(M_{\text {difference }}=.24, S E_{\text {difference }}=.08, p=.003\right)$, but not in the block of ambiguous moral transgressions $\left(M_{\text {difference }}=.01, S E_{\text {difference }}=.06, p=.938\right)$. The interactions between deck and moral ambiguity on ratings of effort, $F(1,200)=.91, p=.342$, partial $\eta_{\mathrm{p}}^{2}=.01$, and aversiveness, $F(1,200)=2.14, p=.145$, partial $\eta_{\mathrm{p}}^{2}=.01$, were not statistically significant. Although these interactions were non-significant, we examined deck differences in effort and aversion separately by ambiguity level for descriptive completeness. Paired sample $t$-tests revealed that the BLAME deck felt significantly less effortful, $t(200)=-2.08, p=.039,95 \% \mathrm{CI}$ of $M_{\text {difference }}=-.71,-.02, d=-0.15$, and more aversive, $t(200)=2.90, p=.004,95 \% \mathrm{CI}$ of $M_{\text {difference }}=.09, .47, d=0.20$, than the FEEL deck for the clear moral transgressions, but no different in effort, $t(200)=-1.22, p=.222,95 \%$ CI of $M_{\text {difference }}=-.49, .12, d=-0.09$, and aversiveness, $t(200)=1.58, p=.115,95 \% \mathrm{CI}$ of $M_{\text {difference }}=-.03, .30, d=0.11$, for the ambiguous moral transgressions. Overall, these results may explain the variable differences in 
cognitive costs between the BLAME deck and alternative deck in the preceding vignette studies, in which the NASA Task Load Index was administered once and did not differentiate between clear and ambiguous transgression trials.

\section{Studies 4a and 4b Methods: Moral Vignettes After Deck Choices}

In Studies $4 \mathrm{a}(N=205)$ and $4 \mathrm{~b}(N=203)$, the card decks preceded the moral vignettes in each trial. Respondents were instructed before the task that they would complete a series of trials where they would see two decks of cards that they should choose between freely, after which they would read a first-person vignette of an individual committing an action. This design allowed us to examine context-independent motivations to blame more generally, that is, even without knowing a specific action to blame. The difference between Studies $4 \mathrm{a}$ and $4 \mathrm{~b}$ concerned the contrast deck. In 4a, the alternative deck was DESCRIBE (as in Study 2), and in 4b, the alternative deck was FEEL (as in Study 3). Study 4a used the same trial-level instructions from Study 2, but with minor changes. If participants chose the BLAME deck, they saw the following prompt: "Based on the scenario, try to feel moral outrage. Focus on the moral details of the action(s) in question. Please write one sentence to describe why the individual should be blamed". If respondents chose the DESCRIBE deck, they were told: "Based on the scenario, try to be objective. Focus on the objective details of the action(s) in question. Please write one sentence to describe how the individual caused the sequence of events" (italics added to indicate revisions). Study $4 \mathrm{~b}$ used the same trial-level prompts from Study 3. See Appendix B for details.

\section{Studies 4a and 4b Results}

\section{Blame Choice}

Blame choice was significantly greater than chance in Study $4 \mathrm{a}, Z=2.45, p=.007, r=.17$, and in Study 4b, $Z=3.60, p<.001, r=.25$ (see Table 1 and Figure 2 for more details). Between 
Studies $4 \mathrm{a}$ and 4b, there was no significant difference in blame choice, as evidenced by a Wilcoxon rank sum test, $Z=-.15, p=.883, r=-.01$. Together, these results suggest that, irrespective of the alternative deck choice (either objectivity or empathy towards transgressors), respondents displayed a comparably modest motivation to feel outrage and blame individuals depicted in the moral vignettes before reading the vignettes. That is, respondents displayed a general motivation to blame even without knowing the particular context of judgment.

\section{Cognitive Costs}

Cognitive cost differences between the decks in Study 4a and 4b were slightly consistent across the rest of the moral vignette studies (as evidenced by paired sample $t$-tests). In both Studies $4 \mathrm{a}$ and $4 \mathrm{~b}$, the BLAME deck felt significantly more efficacious than the alternative deck [Study 4a: $t(204)=3.26, p=.001,95 \%$ CI of $M_{\text {difference }}=.13, .52, d=0.23$; Study 4b: $t(202)=$ $5.83, p<.001,95 \% \mathrm{CI}$ of $\left.M_{\text {difference }}=.34, .69, d=0.41\right]$, which is consistent with the patterns found in Study 3. As with Study 3, the BLAME deck felt significantly less effortful than the FEEL deck in Study $4 b, t(202)=-5.46, p<.001,95 \%$ CI of $M$ difference $=-.67,-.31, d=-0.38$; and there were no significant differences in perceived effort between the BLAME and DESCRIBE deck in Study $4 \mathrm{a}, t(204)=.60, p=.547,95 \%$ CI of $M_{\text {difference }}=-.14, .26, d=0.04$. Unlike Study 3, the BLAME deck felt significantly less aversive than the FEEL deck in Study $4 b, t(202)=-$ $2.71, p=.007,95 \% \mathrm{CI}$ of $M_{\text {difference }}=-.47,-.07, d=-0.19 ;$ and there were no significant differences in perceived aversiveness between the BLAME and DESCRIBE deck in Study 4a, $t(204)=.62, p=.535,95 \% \mathrm{CI}$ of $M_{\text {difference }}=-.14, .27, d=0.04$

\section{Studies 5a to 6: Blame Selection Task with Moral Images}

In the next set of studies (Studies 5a to 6), we examined whether blame motivations would differ when moving to a potentially less concrete type of stimulus: moral images. Visual 
depictions of immoral acts might be more ambiguous and difficult to interpret because there is more information to parse than when presented with a verbal description of such acts. On the other hand, given that bodily responses are more easily engaged by affective information presented with pictures rather than written words (Lang et al., 2005; Larsen et al., 2003; Winkielman \& Gogolushko, 2018), respondents may be more compelled to morally engage with visual depictions of moral indiscretions. In Studies $5 \mathrm{a}$ and $5 \mathrm{~b}$, we examined blame choice in response to images of transgressions, and in Study 6, we added a caption to each image to examine how this might impact blame choice.

A total of 40 moral images were obtained from the Social-Moral Images Database (SMID; Crone et al., 2018) for the BST in Studies 5a, 5b, and 6. Crone and colleagues' (2018) normative ratings from 1812 participants were available on eight dimensions, including the level of Care and Moral Appropriateness depicted in the image. Twenty images were grouped and labelled as clear moral transgressions (i.e., the action in the image was conspicuously harmful and morally wrong), whereas 20 images were grouped and labelled as ambiguous moral transgressions. See Appendix E for the full procedure and statistical justification for the selection and grouping of the moral images. Average Care and Moral Appropriateness ratings and the composite CareMoral Appropriateness scores for all 40 moral images are presented in Table E1 (the images are labeled as found in the SMID normative ratings database; Crone et al., 2018).

\section{Studies 5a and 5b Methods}

The key difference between Study $5 \mathrm{a}$ and $5 \mathrm{~b}$ is whether the decks (BLAME versus DESCRIBE) were presented after the images (5a) or presented before the images $(5 \mathrm{~b})$; this was done to parallel the position of moral transgressions in the vignette-based studies. Respondents in Study 5a $(N=219)$ were instructed that they would complete a series of trials where they would 
first see an image of an individual who is committing an action, after which they would see and freely choose between two decks of cards. Respondents in Study $5 \mathrm{~b}(N=205)$ were instructed that they would complete a series of trials where they would first freely choose between two decks of cards, after which they would see an image of an individual who is committing an action; Figure 4 depicts a single trial of the BST in Study 5b. In both studies, respondents were given the following instructions if they picked the BLAME deck: "Try to feel moral outrage toward what you see in the image. Focus on the moral details of the individual and the action they are committing. Please write one sentence to clearly describe why the individual committing the action should be blamed". If respondents chose the DESCRIBE deck, they were given the following prompt: "Try to be objectively detached toward what you see in the image. Focus on the objective details of the individual and the action they are committing. Please write one sentence to clearly describe what the individual committing the action is doing".

\section{Studies 5a and 5b Results}

\section{Blame Choice}

Thus far, the results of the vignette studies suggest that participants show a preference towards outrage and blaming transgressors, rather than descriptively or empathically engaging with them, especially in response to clear moral transgressions. In contrast, one-sample Wilcoxon signed-rank tests revealed that blame choice in response to images (see Table 1 for descriptive statistics) was significantly less than chance in Study $5 \mathrm{a}, Z=-11.88, p<.001, r=-$ .80 , and in Study $5 b, Z=-10.80, p<.001, r=-.75$, which suggests a strong motivation to avoid blaming transgressors when wrongdoings are depicted visually.

\section{Cognitive Costs}


The patterns observed for the cognitive costs of decks in the studies with moral images were different than what was observed in the moral vignette studies (see Table 1 for descriptive statistics). The most consistent finding in the studies with moral vignettes was that the BLAME deck felt significantly more efficacious than the alternative deck choice. In contrast, in Studies 5a and $5 \mathrm{~b}$, paired sample $t$-tests found that the BLAME deck felt significantly less efficacious than the DESCRIBE deck [Study 5a: $t(218)=-8.88, p<.001,95 \%$ CI of $M_{\text {difference }}=-1.00,-.64, d=-$ 0.60; Study 5b: $t(204)=-7.30, p<.001,95 \% \mathrm{CI}$ of $\left.M_{\text {difference }}=-.89,-.51, d=-0.51\right]$, more effortful [Study 5a: $t(218)=9.86, p<.001,95 \%$ CI of $M_{\text {difference }}=.74,1.11, d=0.67$; Study $5 \mathrm{~b}$ : $t(204)=6.83, p<.001,95 \% \mathrm{CI}$ of $\left.M_{\text {difference }}=.40, .72, d=0.47\right]$, and more aversive than the DESCRIBE deck [Study 5a: $t(218)=8.79, p<.001,95 \%$ CI of $M_{\text {difference }}=.70,1.10, d=0.60$; Study $5 \mathrm{~b}: t(204)=6.84, p<.001,95 \% \mathrm{CI}$ of $\left.M_{\text {difference }}=.51, .92, d=0.48\right]$, with moderate-tolarge effects of deck choice (BLAME versus DESCRIBE) on felt cognitive costs observed. These differences in cognitive costs may account for why participants avoided blaming.

\section{Study 6 Methods}

In Study 6, respondents $(N=210)$ were instructed that a caption of what the individual was doing would accompany each image before they were to make a choice between the BLAME and DESCRIBE decks. This would allow us to examine if people's blame avoidance would diminish if visual moral content was accompanied by verbal information that elucidates the wrongdoing. Appendix E presents the caption (created by the first author) of each moral image. Study 6 used similar trial-level instructions from Studies 5a and 5b, with the addition that respondents were instructed to write the sentence in their own words (i.e., not copy the caption "Please write one sentence, in your own words, to...").

\section{Study 6 Results}




\section{Blame Choice}

Consistent with Studies 5a and 5b, blame choice in response to images and headlines was significantly less than chance in Study $6, Z=-6.21, p<.001, r=-.43$. Notably, blame choice in response to moral images and captions in Study 6 was higher than blame choice in Studies 5a, where respondents saw only moral images, $Z=-6.59, p<.001, r=-.32$, which suggests a moderate effect of captions on blame choice differences between study samples. Yet, in tandem with Studies 5a and 5b, the results suggest that people show a motivation to avoid outrage and blame when presented with visual depictions of transgressions, rather than engage in outrage.

\section{Blame Choice by Moral Ambiguity of Images}

As with Studies 2 and 3, blame choice was computed for the groups of clear and ambiguous moral transgressions in Studies 5a and 6, where images preceded deck choices (see Figure 3). Replicating results from Studies 2 and 3 (which used vignettes), paired samples Wilcoxon signed rank tests found that blame choice in Study 5a was significantly higher for clear (than ambiguous) moral transgressions, $Z=-10.89, p<.001, r=-.74$ - suggesting that the level of harm and immorality depicted in the pictures largely increases the choice to blame individuals committing such actions.

Similarly, in Study 6, blame choice was significantly greater for clear moral images accompanied by captions than for ambiguous moral images accompanied by captions, $Z=-$ 11.36, $p<.001, r=-.78$. Although this transgression ambiguity difference existed within both studies, separate one-sample Wilcoxon signed rank tests revealed that respondents in Study 5a chose to blame significantly less than $50 \%$ of the time after seeing both clear moral transgressions $\left(\right.$ Median $\left._{\text {choice }}=0.20, Z=-7.32, p<.001, r=-.49\right)$ and ambiguous moral transgressions $\left(\right.$ Median $\left._{\text {choice }}=0.05, Z=-12.95, p<.001, r=-.88\right)$. In Study 6, the rate at which 
participants chose the BLAME deck did not significantly differ from chance for the clear moral transgressions $\left(\right.$ Median $\left._{\text {choice }}=0.55, Z=-.28, p=.781, r=-.02\right)$, but was significantly less than chance for the ambiguous moral transgressions (Median choice $=0.25, Z=-11.13, p<.001, r=-$ .77). As revealed by Wilcoxon rank sum tests, blame choice for clear moral images was significantly higher among respondents in Study 6, who also read captions, than respondents in Study 5a, $Z=-5.28, p<.001, r=-.25$; and similar patterns were observed between the two study samples for ambiguous moral images, $Z=-7.80, p<.001, r=-.38$, which suggests a small-tomoderate effect of captions on blame motivation between samples. Overall, even though overall blame preferences were lower in the studies using images, there is a similar pattern within both sets of studies — blame choice tracks the moral ambiguity of the stimuli that is read or seen.

\section{Cognitive Costs}

Consistent with results from Study $5 \mathrm{a}$ and $5 \mathrm{~b}$, paired sample $t$-tests found that the BLAME deck in Study 6 felt significantly less efficacious than the DESCRIBE deck, $t(209)=-3.23, p=$ $.001,95 \% \mathrm{CI}$ of $M_{\text {difference }}=-.45,-.11, d=-0.23$, more effortful, $t(209)=6.69, p<.001,95 \% \mathrm{CI}$ of $M_{\text {difference }}=.38, .70, d=0.46$, and more aversive than the DESCRIBE deck, $t(209)=6.53, p<$ $.001,95 \% \mathrm{CI}$ of $M_{\text {difference }}=.41, .77, d=0.45$, when images were accompanied by headlines. As the NASA Task Load Index was administered only once in Studies 5a to 6, we did not examine deck differences in cognitive costs by the level of transgression ambiguity.

Across Studies 5a to 6, blaming felt more cognitively challenging in the studies using visual moral stimuli, which is opposite to what was observed in the studies using verbal moral stimuli. In Studies 5a to 6, participants had to interpret potentially unclear visual information, specifically a "snapshot" of an individual in the midst of committing an action. In contrast, the moral vignettes chronologically and explicitly outline a person's behaviors, thereby lessening the 
ambiguity and accentuating the harmfulness and moral wrongfulness of their actions. Thus, it follows that, when given the choice, respondents who view the moral images may find it less efficacious, more difficult, and more uncomfortable to blame the individual in the images (and thus, avoid blaming) because it is more challenging to construe a blameworthy action(s). While we acknowledge that images might be more emotionally evocative, the action depicted in the image is likely to be less clear than what is depicted in vignettes. This interpretation is consistent with the socially-regulated blame perspective (Monroe \& Malle, 2019), which underscores the role of morally-relevant information about a norm violation (e.g. intentionality) in the systematic and graded up- or down-regulation of blame. Notably, the blame choice effects for clear moral images and for ambiguous moral images were higher in Study 6 than in Study 5a, which suggests that the supplementing verbal information made it easier for respondents to construe moral norm violations from the images and subsequently blame wrongdoers. Together, these results suggest that the willingness to blame appears to track how cognitively costly it feels to do so.

\section{Study 7: Blame Selection Task with Moral Vignettes and Moral Images}

The final study extended upon prior studies and assessed relative differences in blame choice and cognitive costs across both moral vignettes and moral images. Whereas we observed blame choice differences between different types of moral stimuli across multiple studies, the current study allowed us to compare blame choice between vignettes and images within the same group of participants. Building on the pattern of results observed in previous studies, we anticipated that participants' blame choice would be significantly higher for vignettes than for images. We also expected that blaming would feel significantly more cognitively costly (than the alternative deck) in response to images, and in contrast, significantly less costly (specifically, more efficacious than the alternative deck) in response to vignettes. Between stimuli type, we 
anticipated that blaming would feel more cognitively costly in response to images than to vignettes. Finally, to confirm that the BST was in fact engendering feelings of outrage, we examined participants' outrage, arousal, and valence throughout the task to track with their choices to blame.

\section{Study 7 Methods}

In Study $7(N=217)$, participants saw two blocks of moral stimuli (i.e., images and vignettes) before the card decks (BLAME and DESCRIBE). The order of the blocks were randomized and counterbalanced, such that some participants $(N=109)$ first saw the block of 15 moral images and others $(N=108)$ first saw the block of 15 moral vignettes. In this study, we included only the clear moral transgressions used in prior vignette and image studies to simplify the study design. For the moral images, we used similar pre-task instructions as Study 5a. For the moral vignettes, we used similar pre-task instructions as Studies 1, 2, and 4a. See Appendix B.

For the blocks of moral images, participants saw the following trial-level instructions for the two deck choices, BLAME and DESCRIBE: "Try to feel moral outrage toward what you see in the image. Focus on the moral details of the individual and the action they are doing. Please write one sentence to clearly describe why the individual should be blamed" (BLAME); and "Try to be objectively detached toward what you see in the image. Focus on the objective details of the individual and the action they are doing. Please write one sentence to clearly describe what the individual is doing" (DESCRIBE). For the blocks of moral vignettes, participants saw the following trial-level instructions for the deck choices: "Try to feel moral outrage toward what you read in the scenario. Focus on the moral details of the individual and the action(s) they are doing. Please write one sentence about why the individual should be blamed for this sequence of events" (BLAME); and "Try to be objectively detached toward what you read in the scenario. 
Focus on the objective details of the individual and the action(s) they are doing. Please write one sentence about how the individual caused this sequence of events" (DESCRIBE). These subtle differences in trial-level instructions between the two types of moral stimuli were meant to retain the instructional sets from previous studies.

After completing the chosen deck's instructions on each trial, participants then completed outrage, arousal, and valence ratings. We included these ratings to examine whether participants felt more outrage and negative when choosing to blame transgressors, but also to determine whether participants reasonably distinguished between instructions to feel outrage against the alternative. Participants were asked "How outraged do you feel?" (1 = not at all; $9=$ extremely), "How calm/aroused do you currently feel?" (1 = calm; 9 = aroused $)$, and "How negative/positive do you currently feel?" (1 = negative; 9 = positive $)$ using self-assessment manikins (Bradley \& Lang, 1994; a similar approach was used to assess state experiences in Scheffer et al., 2021). Further, respondents in Study 7 completed to the NASA Task Load Index twice, once after the first block of trials and again after the second block of trials, in order to collect cognitive costs ratings separately for images-based and vignette-based transgressions.

\section{Study 7 Results}

\section{Blame Choice}

Collapsing across the counterbalanced conditions, a paired samples Wilcoxon signed rank test found that blame choice for the vignettes was significantly greater than blame choice for the images, $Z=-10.33, p<.001, r=-.70$, with a robust effects of stimuli modality observed. See Table 1 for descriptive statistics. Within both counterbalanced conditions, blame choice for the vignettes was significantly greater than blame choice for the images (Images presented first: Median $_{\text {choice-vignettes }}=0.47$, Median $_{\text {choice-images }}=0.20, Z=-6.71, p<.001, r=-.64$; Images 
presented second: Median $_{\text {choice-vignettes }}=0.57$, Median $_{\text {choice-images }}=0.17, Z=-7.87, p<.001, r=-$ .76), with robust effects of stimuli modality observed. Irrespective of the order of the block of moral images, image-based blame choice was significantly below chance (Images first: $Z=$ 7.46, $p<.001, r=-.71$; Images second: $Z=-7.15, p<.001, r=-.69)$, which replicates our previous image-based studies (5a to 6) and suggests a strong avoidance among participants to blame transgressors depicted visually. Among participants who saw the block of images first (before the moral vignettes), subsequent blame choice for the vignettes did not significantly differ from chance, $Z=-1.10, p=.272, r=-.11$. Among participants who saw the block of images second (after the moral vignettes), preceding vignette-based blame choice was significantly greater than chance, $Z=2.13, p=.017, r=.20$, with a small-to-moderate blame choice effect observed.

Taken together, these patterns of the blame choice results are similar to the patterns revealed in prior studies. Across previous studies, we observed that participants approached blame when moral transgressions were depicted verbally, and avoided blame when transgressions were depicted visually. The current study extends upon these patterns and shows that, among the same group of participants, the choice to blame is significantly higher for moral vignettes than for moral images. When transgressions are presented in written format, as opposed to visually, participants are more likely to approach outrage and blame. Replicating previous studies, image-based blame choice was significantly below chance, whereas vignette-based blame choice was significantly above chance.

\section{Cognitive Costs}

Table 3 presents the average ratings of perceived effort, perceived aversiveness, and perceived efficacy for the BLAME and DESCRIBE deck across the image- and vignette-based 
transgressions in Study 7. As cognitive costs were measured twice, once after each block of moral stimuli, we conducted three $2 \times 2$ repeated measures ANOVAs to examine whether differences between BLAME and DESCRIBE decks in effort, aversiveness, and efficacy were moderated by the type of moral stimuli presented to participants. There was a significant interaction between deck (BLAME, DESCRIBE) and stimuli type (images, vignettes) on ratings of efficacy, $F(1,216)=37.67, p<.001$, partial $\eta_{\mathrm{p}}^{2}=.15$, and aversiveness, $F(1,216)=4.27, p=$ .040 , partial $\eta_{\mathrm{p}}^{2}=.02$, but not effort, $F(1,216)=2.61, p=.108$, partial $\eta_{\mathrm{p}}{ }^{2}=.01$.

With respect to efficacy, follow-up pairwise comparisons revealed that the BLAME deck felt significantly more efficacious than the DESCRIBE deck after the block of vignette-based transgressions $\left(M_{\text {difference }}=.25, S E_{\text {difference }}=.08, p=.003\right)$, and felt significantly less efficacious than the DESCRIBE deck after the block of image-based transgressions $\left(M_{\text {difference }}=-.89\right.$, $\left.S E_{\text {difference }}=.09, p<.001\right)$. Also, the BLAME deck had significantly higher efficacy ratings after the vignette-based trials, compared to after the image-based trials $\left(M_{\text {difference }}=.65, S E_{\text {difference }}=\right.$ $.08, p<.001)$, whereas the DESCRIBE deck had significantly higher efficacy ratings after the image-based trials, compared to after the vignette-based trials $\left(M_{\text {difference }}=.49, S E_{\text {difference }}=.06, p\right.$ $<.001)$. For aversion, the BLAME deck felt significantly more aversive than the DESCRIBE deck after both the vignettes-block $\left(M_{\text {difference }}=.42, S E_{\text {difference }}=.09, p<.001\right)$ and images-block $\left(M_{\text {difference }}=.65, S E_{\text {difference }}=.09, p<.001\right)$, with the difference between decks being stronger for the image-based transgressions. The BLAME deck felt marginally more aversive after the images-block than after the vignettes-block $\left(M\right.$ difference $\left.=.16, S E_{\text {difference }}=.08, p=.053\right)$; the DESCRIBE deck's level of aversiveness did not significantly differ between stimuli type $\left(M_{\text {difference }}=-.07, S E_{\text {difference }}=.09, p=.423\right)$. Finally, there was a significant main effect for deck on perceived effort, $F(1,216)=11.89, p=.001$, partial $\eta_{\mathrm{p}}^{2}=.05$, such that the BLAME deck felt 
significantly more effortful than the DESCRIBE deck, irrespective of the moral stimuli shown (See Table 3 for mean estimates).

In summary, these findings are consistent with prior vignette-based and image-based studies. The BLAME deck felt significantly less costly (more efficacious) than the DESCRIBE deck when participants read the moral vignettes, but felt significantly more cognitive costly (more effortful, aversive, and inefficacious) than the DESCRIBE deck when participants saw the moral images. Moreover, between both types of moral stimuli, the BLAME felt less costly to use (specifically, more efficacious and less aversive) when people saw vignettes (as opposed to images), which suggests a greater felt cost to blaming transgressors depicted in images.

\section{Outrage and State Affect Ratings}

Finally, we examined the degree to which choosing blame influenced ratings of outrage, arousal, and valence, additionally modeling the interaction between choice and moral stimuli type (image, vignette). For this analysis, we conducted multilevel models using SPSS MIXED, nesting trials within participants. Each model $(N$ observations $=6510)$ predicted changes in state ratings (outrage, arousal or valence) from choice $($ describe $=0$, blame $=1$ ), type of moral stimuli (vignettes $=-1$, images $=1$ ), and the interactive effect of choice and type of moral stimuli. Each model included the fixed effects of intercept, choice, stimuli type, and the interaction term, as well as a random intercept. In this main analysis, we did not model repeated measure of time because of the blocking of the stimuli type manipulation (confounding stimuli condition with time) $)^{3}$. Details of these analyses are presented in Table 4 (Type III Tests of Fixed Effects) and Table 5 (Estimated Marginal Means).

\footnotetext{
${ }^{3}$ In secondary analyses, which modelled time as a repeated measure with an autoregressive covariance structure (time was coded to reflect trials 1-30, such that trials 1-15 reflect imagebased transgressions for some participants and vignette-based transgressions for other
} 
The estimates of fixed effects noted below are based on when the choice $=0$ (i.e., when the DESCRIBE deck is selected) and when stimuli type $=-1$ (when vignettes are shown). With the contrast between blame and objective detachment, there were significant effects of deck choice $(B=-2.23, S E=.08, t=-27.31, p<.001,95 \%$ CI $[-2.39,-2.07])$, moral stimuli type $(B=-.37$, $S E=.08, t=-4.53, p<.001,95 \%$ CI $[-.53,-.21])$, and the choice $\mathrm{x}$ stimuli type interaction $(B=$ $.46, S E=.10, t=4.47, p<.001,95 \%$ CI $[.26, .67])$ for changes in outrage. Similarly, there were significant effects of deck choice $(B=.85, S E=.06, t=13.75, p<.001,95 \%$ CI $[.73, .98])$, moral stimuli type $(B=.38, S E=.06, t=6.13, p<.001,95 \%$ CI $[.26, .50])$, and the choice $\mathrm{x}$ stimuli type interaction $(B=-.17, S E=.08, t=-2.15, p=.032,95 \%$ CI [-.32, -.02]) for changes in valence. Participants reported lower levels of outrage and increased positive valence after choosing the DESCRIBE deck (than after choosing the BLAME deck) and these differences were amplified on trials involving moral vignettes (compared to moral images). Put differently, participants felt more outrage and negative valence after choosing the BLAME deck (versus the DESCRIBE deck) and these differences were amplified on trials involving moral images (compared to moral vignettes). For arousal, there were significant effects for choice $(B=-1.50$, $S E=.08, t=-19.36, p<.001,95 \%$ CI $[-1.66,-1.35])$ and stimuli type $(B=-.57, S E=.08, t=-$ $7.35, p<.001,95 \% \mathrm{CI}[-.72,-.42])$, but not for the choice $\mathrm{x}$ stimuli type interaction $(B=.05, S E$ $=.10, t=.50, p=.615,95 \% \mathrm{CI}[-.14, .24])$. Likewise, participants reported higher levels of arousal after choosing the BLAME deck (than after choosing the DESCRIBE deck) and they reported higher levels of arousal after seeing the moral images (than after reading the moral vignettes). In summary, participants who chose blame felt more outraged, more negative, and 
more aroused (as opposed to calm), providing further evidence that blame regulation had consequences for generating outrage. These results also provide a manipulation check: Choosing to blame (instead of remaining objectively detached) led participants to feel more outrage towards the transgressor.

\section{Meta-analytic Associations of Blame Choice with Cognitive Costs, Social Norms, and Individual Differences}

In this section, we explored the relationships between blame choice and perceived cognitive costs measured with the NASA Task Load Index, which allowed us to test the hypothesis that to the degree that participants felt blaming (relative to the alternative deck) was cognitively costly, they would not choose to blame wrongdoers. Although overall blame choice patterns differed between studies using vignettes and studies using images, it does not preclude the possibility that blame choice would have consistent associations with other constructs across studies, such as people's felt cognitive costs. In order to garner more statistical power, we computed meta-analytic correlations across all studies of blame choice with: perceived cognitive costs measured by the NASA Task Load Index (i.e., perceived effort, aversiveness, and efficacy assigned to the BLAME deck versus the alternative deck); and with descriptive, injunctive, and personal norms about blaming (versus the alternative deck). We also computed the meta-analytic correlations of blame choice with stable individual differences measured across the studies, such as moral convictions (Moral Convictions Scale; Skitka, 2010), moral identity (Moral Identity Scale; Aquino \& Reed, 2002), and empathy (Empathy Index; Jordan et al., 2016).

For the NASA cognitive costs indices and descriptive and injunctive norms, difference scores between the BLAME deck and the alternative deck were computed (e.g., "BLAME deck Perceived Effort” minus “Alternative deck Perceived Effort”). The Hedges-Olkin method 
(Borenstein et al., 2009) calculated an overall correlation coefficient $(r)$ from the set of correlations across all studies (using Comprehensive Meta-Analysis; Borenstein et al., 2013).

Table 6 summarizes the meta-analytic effects, including the $95 \%$ confidence intervals. Table F2 in the appendices (Appendix F) presents the within-study correlations of blame choice with all of the above-noted measures (cost differences, blaming social norm differences, and individual difference measures).

First, with respect to cognitive $\operatorname{costs}^{4}$, blame choice was negatively related to perceived effort $(Z=-3.85, r=-.12, p<.001,95 \% \mathrm{CI}:-.17,-.06)$ and perceived aversion $(Z=-5.27, r=-$ $.14, p<.001,95 \% \mathrm{CI}:-.19,-.09)$, and positively related to perceived efficacy $(Z=12.64, r=.50$, $p<.001,95 \% \mathrm{CI}: .43, .56)$. In other words, respondents were less likely to choose the BLAME deck when they viewed the deck as more effortful and aversive, as well as less efficacious, than the DESCRIBE or FEEL deck. Figure 5 displays each of these associations aggregating across studies. Tests of the difference between two dependent correlations (with one variable in common; Steiger, 1980) revealed that the association of blame choice with perceived efficacy was significantly more robust than the associations of blame choice with perceived effort, $z=$ 17.51, $p<.001$, and perceived aversiveness, $z=18.08, p<.001$. Taken together, these results provide further support for our prediction that the cognitive costs of blaming-especially felt efficacy — are related with respondents' choices to blame individuals. One's choice to feel

${ }^{4}$ Given the different patterns of blame choice between the vignette and image studies, we also report separate meta-analytic correlations between blame choice and cognitive costs for the vignette and images studies, as the NASA Task Load Index items were rated based on the BST that respondents completed prior. The following patterns were observed within each study set: Vignette studies (blame choice with perceived effort: $r=-.13, p<.001$; blame choice with perceived aversiveness: $r=-.19, p<.001$; blame choice with perceived efficacy: $r=.55, p<$ .001 ) and Image studies (blame choice with effort: $r=-.05, p=.480$; blame choice with aversiveness: $r=-.05, p=.151$; blame choice with efficacy: $r=.41, p<.001$ ). 
outrage and blame transgressors is linked to the degree that doing so feels less effortful, less aversive, and more efficacious than being objective or empathizing.

Second, blame choice was positively associated with all social norms ${ }^{5}$ i.e., the descriptive norm difference score $(Z=13.67, r=.46, p<.001,95 \% \mathrm{CI}: .40, .51)$, the injunctive norm difference score $(Z=4.08, r=.10, p<.001,95 \% \mathrm{CI}: .05, .15)$, and the personal belief that blaming is more desirable than the alternative choice $(Z=7.36, r=.29, p<.001,95 \% \mathrm{CI}: .21$, .36). That is, to the degree that respondents believed that other participants choose the BLAME deck, as opposed to the DESCRIBE or FEEL deck, there was a moderate-to-large increase in respondents' own blame choice. To the extent that other participants believe that blaming, as opposed to remaining objective or empathizing, is a "good thing", there was a small increase in respondents' own blame choice. Finally, to the degree that respondents personally believed that blaming was more desirable than being objective or empathic, there was a moderate increase in their blame choice. Figure 6 displays each of these associations aggregating across studies. These correlations of blame choice and descriptive and injunctive social norms are consistent with results that highlight the signalling function of expressing moral outrage (Jordan et al., 2016), as well as results that demonstrate the link between group preferences to punish and respondents' own punitive decisions when tasked with restoring justice (Son et al., 2019). Here, the choice to blame appears to track the social value of doing so. Given that these are only correlational

\footnotetext{
${ }^{5}$ While we have presented the overall meta-analytic correlations, we also report separate metaanalytic correlations between blame choice and social norms for the vignette and images studies, as the norm items were rated based on the BST that respondents completed prior. The following patterns were observed within each study set: Vignette studies (blame choice with descriptive norms: $r=.48, p<.001$; blame choice with injunctive norms: $r=.09, p=.006$; blame choice with personal norms: $r=.29, p<.001$ ) and Image studies (blame choice with descriptive norms: $r=.39, p<.001$; blame choice with injunctive norms: $r=.11, p=.001$; blame choice with personal norms: $r=.27, p<.001)$.
} 
results, it is possible that social norm judgments reflect post-hoc justifications of blame choices made earlier in the task.

Lastly, blame choice was positively associated with moral convictions $(Z=5.61, r=.30, p$ $<.001,95 \%$ CI: .20, .40) and symbolized moral identity $(Z=4.84, r=.15, p<.001,95 \% \mathrm{CI}$ : $.09, .22)$, but not with internalized moral identity $(Z=.82, r=.03, p=.411,95 \%$ CI: $-.04, .09)$. In other words, participants who reported having stronger moral convictions engaged by the task demonstrated a moderate increase in their choice to blame; and among participants who reported engaging in actions that represent socially symbolic demonstrations of one's moral identity (i.e., behaving in ways that reflect moral traits), there was a modest increase in blame choice. Blame choice was also positively, though weakly, associated with both subscales of the Empathy Index (Empathy, $Z=2.84, r=.12, p=.005,95 \% \mathrm{CI}: .04, .20$; Behavioral Contagion, $Z=2.60, r=.09$, $p=.009,95 \% \mathrm{CI}: .02, .15)$, suggesting that participants more prone to taking on others' feelings and behaviors have a modest increase in the tendency to blame perpetrators of transgressions. Finally, blame choice was positively associated with the Blame Intensity Inventory (Gill \& Cerce, 2021) $r=.21, p=.002$ (included only in Study 7), which suggests that participants with a propensity to experience hostile affect and reactions towards wrongdoers demonstrated a smallto-moderate increase in their choice to blame wrongdoers. The correlations of blame choice with blaming norms and with multiple indices of moral personality provide evidence for the convergent validity for the Blame Selection Task.

Taken as a whole, these results suggest that respondents' felt cognitive costs, their prescribed norms about blaming, as well as their moral personality and empathic traits were related to their blame choice. The choice to blame the individuals depicted in the moral stimuli 
was most strongly linked to the perceived efficacy of the BLAME deck and the belief that others would choose the BLAME deck (as opposed to the alternative option).

\section{Discussion}

Moral norm violations cause people to experience moral outrage and to express it in various ways (Crockett, 2017), such as shaming/dehumanizing, punishing, or blaming. These forms of expressing outrage are less than moderately related to one another $(r$ 's $<.30$; see Bastian et al., 2013 for more information), which suggests that a considerable amount of variance between shaming/dehumanizing, punishing, and blaming remains unexplained and that these are distinct enough demonstrations of outrage in response to norm violations. Yet, despite its moralistic implications (see Crockett, 2017), there is still little empirical work not only on the phenomenon of outrage fatigue but also on the role of motivated cognition on expressing outrage via blame. Social costs alter blame judgments, even when people's cognitive resources are depleted (Monroe \& Malle, 2019). But how do the inherent cognitive costs of blaming relate to people's decisions towards moral outrage and blame? Here, we examined how felt cognitive costs associate with the choice to express outrage through blame.

Taking our cues from the Law of Least Effort (Hull, 1943; Kool et al., 2010), we developed a free-choice measure of blame-proneness - the Blame Selection Task - to observe how motivated respondents were to generate outrage and blame individuals committing moral transgressions. This task allows people to select whether they want to enter into situations (i.e., situation selection; Gross \& Thompson, 2007) that call for outrage cultivation and blaming, and it has parallels to everyday examples of either avoiding news about tragedies and harms or consciously "doom-scrolling” to up-regulate outrage (frequently observed on Twitter; see Miller, 2020). The BST relies on behavioral measurement of outrage and blame as people choose to 
regulate it, rather than participants' self-reports. This free-choice approach provides a novel method for understanding motivated regulation of blame and its associated cognitive costs.

With respect to blame choice patterns, participants preferred to blame at a rate greater than $50 \%$ in the studies that used moral vignettes. Most notably, when the decks preceded the vignettes, respondents displayed a small-to-moderate preference to choose the BLAME deckirrespective of if the alternative choice was to objectively write about how the individual caused the sequence of events or to empathically write about the individual's feelings and thoughts. In other words, participants made the choice to express outrage through blame, as opposed to remain objective or to feel empathy, even before reading the moral vignette and the individual's behavior(s). Irrespective of the alternative deck, participants also displayed a significant blame preference when the vignettes preceded the decks. Particularly, they displayed a significantly higher preference to choose the BLAME deck when the vignettes were blatantly harmful and immoral (clear moral transgressions) than when the moral transgressions were ambiguous, with a very large effect of moral ambiguity on blame choice observed. Whereas participants blamed significantly more than $50 \%$ of the time for the clear moral violations, with a large blame choice effect observed, they did not show a preference for blaming individuals of ambiguous moral violations, with a very small blame choice effect observed. These findings extend upon those by Jordan and Kteily (2020) by examining people's personal regulation of outrage — outside of the perceived reputational incentives of outrage — and they run parallel with literature that links observers' perceived harm of wrongdoings to the severity of their retributive punishment of transgressors (e.g., Darley \& Pittman, 2003).

In contrast, within the studies that used moral images, individuals chose to blame individuals at a rate significantly less than 50\% - irrespective of if the decks preceded or 
followed the images; here, a moderate-to-very large blame avoidance effect was observed. In studies where the decks followed the moral images (5a and 6), blame selection was significantly greater for clear moral transgressions — replicating results from the moral vignette studies_-with a very large effect of moral ambiguity on blame choice. Yet, in contrast to the vignette studies, blame choice for both clear and ambiguous moral images did not significantly exceed chance. Together, these blame choice findings suggest that the change in moral stimuli, from vignettes to images, contributed to an avoidance of blaming the people depicted in the stimuli. Indeed, Study 7 found that blame choice for vignette-based moral transgressions was significantly greater than blame choice for image-based moral transgressors among the same group of participants, suggesting a motivation towards blaming when actions are depicted verbally, as opposed to visually. Of note, blame choice for the vignette-based trials exceeded chance when these trials preceded the image-based trials, but did not exceed chance when these trials were preceded by the image-based trials. This pattern could potentially be accounted for by a "carryover effect" of blame avoidance. That is, among those who first saw the block of moral images, it is possible that these participants were less motivated to subsequently blame for the moral vignettes because they had developed a pattern of low blame choice for the images.

Notably, these studies are among the first to examine whether generating outrage and blame feels cognitively costly_without any external manipulations of effort (Ames \& Fiske, 2015). Our results are the first to examine whether and to what degree cognitive costs relate to this moralizing process. The consistent finding across the studies that used moral vignettes was that blaming felt more efficacious than the alternative choice, which could account for why participants' blame choice exceeded chance in these studies. Across the studies that used moral images, blaming felt less efficacious and more effortful and aversive than the alternative choice, 
which could account for why participants' blame choice did not exceed chance in these studies. In Study 7, blaming felt more efficacious and less aversive after the vignette-based trials than after the image-based trials, which implies that it felt more costly to generate outrage and blame when transgressions were depicted visually (versus visually). The meta-analytic associations found that people were less likely to choose the BLAME deck when it felt more cognitively effortful and aversive than the alternative deck, and more likely to choose BLAME when it felt more efficacious. Our results are the first to suggest that blaming relates to how cognitively costly it feels to do so.

Notably, of the three facets of cognitive costs measured by the NASA Task Load Index, perceived efficacy was the strongest correlate of blame choice-across all studies and within each study set (vignettes and images). Indeed, squaring each correlation suggests that respondents' perceived efficacy of the BLAME deck accounted for 16.81 -to-30.25\% of the variance in their choice to blame, compared to the 0.25 -to- $1.69 \%$ and 0.25 -to-3.61\% of perceived effort and perceived aversiveness, respectively. This indicates that one's perceived inefficacy of blaming (versus remaining objective or empathizing) is a more critical aspect of cognitive work in the choice to express outrage and blame than one's perceived effort and aversion. One might desire to avoid inaccurate moral decisions due to the social costs (Jordan et al., 2016; Kundu \& Cummins, 2013), but our results highlight the link between one's choice to blame and how inherently successful or worthwhile blaming feels. This finding is likely to have important moralistic implications, as people's perceptions of efficacy have been found to bolster their commitment to collective pro-social actions within moral contexts (Thomas \& McGarty, 2009).

Across studies and regardless of stimulus modality, participants were more likely to choose to blame for clear moral transgressions than for ambiguous transgressions, and the differences in 
felt cognitive costs across transgression type noted in Study 3 might suggest one reason why. For clear moral transgressions in Study 3, participants rated blaming as significantly more efficacious and less effortful. For ambiguous moral transgressions, where there might be conflicting ideas about how to respond, the cognitive ease of blame reduced. Moreover, when faced with more equivocal stimuli in general - the visual depictions of transgressions participants avoided blaming instead of choosing it. The cognitive cost differences between decks observed in the studies that used images, as well as the differences between the vignettesand images-based trials in blame-related efficacy and aversion found in Study 7, suggest that the uncertainty involved with interpreting visual stimuli made blaming more cognitively demanding. The socially-regulated blame perspective posits that blame must be warranted by morallyrelevant information in order for individuals to circumvent the social costs of blaming (Monroe \& Malle, 2019), and this is relevant given the meta-analytic correlations between social norms and blame choice. Across all studies, participants' responses were anonymous and their choices were not shared with others. As such, the blame choice patterns between clear versus ambiguous moral transgressions and between the studies that used vignettes versus images suggest that, even in the absence of social costs, people are sensitive to whether or not there is sufficient warrant to blame wrongdoers. This, in turn, could account for the higher cognitive costs attached to blame in the images-based studies, as well as the lower cognitive costs attached to blame for the clear transgressions in Study 3, and the larger blame avoidance.

Although much work has explored how external factors influence blame judgements (i.e., transgressor causality, intentionality, preventability, harm, other circumstances, etc.; Malle et al., 2014), very little work has examined individuals' baseline preferences to blame and how such preferences track features of the context (i.e., stimuli type, transgression ambiguity, and 
alternative deck) in interaction with individual characteristics. Supporting the claim that the Blame Selection Task captures the motivation to moralize, participants more deeply convicted in their moral principles and beliefs about fundamental right and wrong (moral convictions) showed a greater tendency to choose to blame across studies. Relatedly, Study 7 found that those prone to experiencing hostile affect towards offenders chose to blame more (blame intensity).

Moreover, blame choice appeared sensitive to social aspects of moralizing, with blame selection associating with individuals' desire to act in accordance with moral traits for its social and public consequences (symbolic moral identity). Further, participants more prone to take on the feelings (empathy) and manners (behavioral contagion) of others demonstrated higher blame preference, which suggests that, in the context of expressing outrage, empathic individuals are choosing to empathize with the victims of transgressions, not the perpetrators. As noted above, blame choice appeared sensitive to individuals' descriptive and injunctive norms about whether other people choose to blame and value blame over remaining objective or empathizing, as well personal beliefs about the appeal of blame. These results not only cohere with other results that suggest a strong signalling function for expressing outrage (e.g., Jordan et al., 2016) and a strong link between group preferences for expressing outrage one's own choices (Son et al., 2019), but also highlight another pathway through which people commit to collective moral action - group norms (Thomas \& McGarty, 2009). Taken as a whole, the associations of blame choice with all of these individual difference measures provide support for the convergent validity of the BST.

When modelling the interactive effect of choice (blame, describe) and stimuli type (vignettes and images) on changes in outrage, arousal, and valence in Study 7, the multilevel models found that participants reported higher outrage and negative valence after choosing to blame (than describe), and that these differences were most pronounced on the trials that used 
moral images. Additionally, participants' arousal levels were higher after choosing to blame (as opposed to describe) and after seeing moral images (than after reading moral vignettes). The effects of choice on increases in outrage, arousal, and negative valence provides support for the construct validity of the BST: Participants had different levels of outrage, arousal, and valence when choosing blame instead of objectivity, which suggests that the directions participants were provided, when chosen, led to different outrage responses. Interestingly, even though images provoked increases in outrage, negative valence (specifically when the BLAME deck was chosen), and arousal, participants chose to blame at a rate significantly less than chance for the image-based transgressions. We posit that the blame choice for images is lower than chance because the action depicted in the image may be more difficult to construe and hence, more difficult to blame. Given the links between affective intensity and people's level of cognitive flexibility and processing (e.g., Hsieh \& Lin, 2019; Vásquez-Rosati et al., 2019), it is additionally plausible that these engendered negative emotions (i.e., outrage) hindered respondents' ability to construe the wrongdoing and/or generate valid reasons as to why the person depicted in the image should be blamed for their actions, which, in turn, contributed to a stronger blame avoidance.

\section{Limitations and Future Directions}

We acknowledge that task demand or felt cognitive costs may not deter blaming if individuals' motivations to blame have not been satisfied. For example, intentional harm-doings elicit the motivation to blame, condemn, and punish the harm-doers, and motivated participants will initially raise their level of effort to match the increasing task demands to express outrage (Ames \& Fiske, 2015). Further, whether or not people find blaming to be demanding will likely vary depending on the context. We varied the contrast deck (i.e., objectivity or empathy) and 
whether individuals were moralizing specific actions (i.e., moral stimuli before choice) or moralizing in general (i.e., moral stimuli after choice), and these did not make a substantial impact on blame choice. Nevertheless, there could be other contextual factors, such as the amount of causal and mental information provided about the transgressions, that would matter for moral decision-making and associated felt cognitive costs. Moreover, some work finds that costly punishment can signal trust to others, but that this changes when costly helping is provided as an alternative behavioral option (Jordan et al., 2016). This finding suggests that individuals may be sensitive to the signalling value of outrage expression (versus empathy) in social interactions, and future studies might productively explore how people anticipate the social impact of effort-based choices to select or avoid blame. Importantly, we acknowledge that the results of the current study do not generalize to all demonstrations of moral outrage. Thus, future iterations of the task will want to explore participants' baseline motivations to shame/dehumanize or to punish transgressors, the felt cognitive costs associated with these different ways of expressing outrage, and if such costs differ from those observed with blaming.

In the current studies, the repeated-measures assessment of blame choice during the Blame Selection Task precluded us from examining the cognitive costs of each deck until after the task was completed and all blame choices had been made. As such, we acknowledge that this leaves open the possibility that cognitive dissonance led those participants who frequently chose to blame to perceive blaming as less cognitively costly (than the alternative deck) after the task, than those participants who did not blame as frequently. That is, participants' post-task rationalization for choosing to blame could account for the relationship between blame choice and ratings of cognitive costs. Exploratory analyses in Study 3 suggest that, among respondents who first read the block of ambiguous moral transgressions, their blame choice during the second 
half of the BST was linked to the degree to which blaming felt less aversive $(r=-.27, p=.007)$, less effortful ( $r=-.30, p=.001)$, and more efficacious $(r=.32, p=.001)$ than empathy during the first half of the BST (while statistically controlling for cognitive cost differences during the second half of the task). A similar pattern was observed between felt efficacy and subsequent blame choice $(r=.25, p=.013)$ among respondents who first read the clear transgressions. While these exploratory results suggest that people avoid blaming when it feels more cognitively costly, they also underscore the need to further explore how blame choice and perceptions of cognitive costs causally influence each other. As recent work finds that experimentally increasing felt efficacy eliminates empathy avoidance (Cameron et al., 2019), it is possible that manipulating the efficacy of blaming might similarly shape choices to blame. Future work should utilize procedures to experimentally increase or decrease the felt cognitive costs of blaming and examine how this subsequently impacts blame selection.

Finally, we acknowledge that the Blame Selection Task, in its current iterations, may have low external validity and applicability to everyday contexts of outrage, such as the kinds of outrage observed on social media (e.g., posting, reposting, 'liking', or 'reacting' to content). Although the current variations of the BST may lack some degree of external validity, there are trade-offs between external and internal validity (see Aronson et al., 1998), and we argue that this concern of external validity may still be tolerable if a research method can provide an internally valid test of the research questions of interest (i.e., by providing a structured assessment of how individuals chose to engage with outrage/blaming or not). In other words, there can, at times, be advantages of a context-limited method if such method provides a useful and valid test of psychological phenomena. Also, the repeated measurement of choices within our task only builds from previous work that uses repeated trials to establish reliable estimates of 
behavioral preferences (e.g., Kool et al., 2010). Along with the realistic examples of moral transgressions depicted verbally and visually, our task is representative of the types of moral stimuli (e.g., images, brief verbal descriptions) and moral wrongdoings (e.g., racism, infidelity) that people encounter on online platforms, as well as the frequency of the encounters that people have with such moral content on these platforms (e.g., Crockett, 2017; Hofmann et al., 2014).

Although we did not examine real-world outrage behaviors (e.g., retweeting), it is promising that our work compliments emerging work on real-world behaviors on social media. For instance, studies reveal that Twitter posts with moral outrage (Brady et al., 2020) or hostility towards perceived wrongdoers (e.g., political opponents; Rathje et al., 2021) are more frequently distributed online and that people choose to associate with others who express more extreme levels of outrage online (Goldenberg et al., 2020). To further establish the validity of the BST, future studies will want to examine the link between people's blame choice behaviors during the task and their outrage-related behaviors in real-world contexts.

\section{Conclusions}

Are feeling outrage and blaming easy and intuitive, or effortful and fatiguing? When confronted with written accounts of clear moral transgressions, participants show a preference to blame and they feel more efficacious and skilled at doing so, in comparison to objectively or empathically engaging with written indiscretions. When confronted with visual depictions of moral transgressions, participants avoid blaming and they feel less efficacious and skilled at doing so, as well as more cognitively taxed and negative. It feels cognitive easier to blame when moral wrongdoings are depicted verbally, as opposed to visually, and thus, when people encounter both types of moral content, they show a blame choice preference towards verbal information. Yet, our studies are the first to demonstrate that even as the choice to blame and its 
felt cognitive costs vary across contexts, these two experiences track together clearly: People choose to blame more often when it feels less effortful, less aversive, and particularly more efficacious. Outrage and blame may seem easy or intuitive to engage in, given the platforms and influx of offensive and immoral stories that are accessible to people. Our research advances the study of blame by suggesting that people choose to feel outrage and blame when it feels like cognitive ease, rather than cognitive work. 


\section{References}

Alicke, M. D. (2000). Culpable control and the psychology of blame. Psychological Bulletin, 126(4), 556-574. https://doi.org/10.1037/0033-2909.126.4.556

Alicke, M. D. (2008). Blaming badly. Journal of Cognition and Culture, 8(1), 179-186. https://doi.org/10.1163/156770908x289279

Ames, D. L., \& Fiske, S. T. (2015). Perceived intent motivates people to magnify observed harms. Proceedings of the National Academy of Sciences. 112(12), 3599-3605. https://doi.org/10.1073/pnas.1501592112

Aquino, K., \& Reed, A. (2002). The self-importance of moral identity. Journal of Personality and Social Psychology, 83(6), 1423-1440. https://doi.org/10.1037//0022-3514.83.6.1423

Aronson, E., Wilson, T. D., \& Brewer, M. B. (1998). Experimentation in social psychology. In D. T. Gilbert, S. T. Fiske, \& G. Lindzey (Eds.), The handbook of social psychology (4th ed., Vol. 1, pp. 99-142). Boston: McGraw-Hill.

Barberá, P., Jost, J. T., Nagler, J., Tucker, J. A., \& Bonneau, R. (2015). Tweeting from left to fight: Is online political communication more than an echo chamber? Psychological Science, 26(10), 1531-1542. https://doi.org/10.1177/0956797615594620

Bastian, B., Denson, T. F., \& Haslam, N. (2013). The roles of dehumanization and moral outrage in retributive justice. PLOS ONE, 8(4). https://doi.org/10.1371/journal.pone.0061842

Bastian, B., Laham, S. M., Wilson, S., Haslam, N., \& Koval, P. (2011). Blaming, praising, and protecting our humanity: The implications of everyday dehumanization for judgments of moral status. British Journal of Social Psychology, 50(3), 469-483.

https://doi.org/10.1348/014466610x521383 
Borenstein, M., Hedges, L. V., Higgins, J., \& Rothstein, H. R. (2009). Introduction to metaanalysis. Chichester, U.K.: John Wiley and Sons.

Borenstein, M., Hedges, L. V., Higgins, J., \& Rothstein, H. R. (2013). Comprehensive MetaAnalysis Version 3. Biostat, Englewood, NJ.

Brady, W. J., Wills, J. A., Jost, J. T., Tucker, J. A., \& Van Bavel, J. J. (2017). Emotion shapes the diffusion of moralized content in social networks. Proceedings of the National Academy of Sciences, 114(28), 7313-7318. https://doi.org/10.1073/pnas.1618923114

Brady, W. J., Crockett, M. J., \& Van Bavel, J. J. (2020). The MAD model of moral contagion: The role of motivation, attention, and design in the spread of moralized content online. Perspectives on Psychological Science, 15(4), 978-1010. https://doi.org/10.1177\%2F1745691620917336

Brady, W. J., Gantman, A. P., \& Van Bavel, J. J. (2020). Attentional capture helps explain why moral and emotional content go viral. Journal of Experimental Psychology: General, 149(4), 746-756. https://doi.org/10.1037/xge0000673

Cameron, C. D., Hutcherson, C. A., Ferguson, A. M., Scheffer, J. A., Hadjiandreou, E., \& Inzlicht, M. (2019). Empathy is hard work: People choose to avoid empathy because of its cognitive costs. Journal of Experimental Psychology: General, 148(6), 962-976. https://doi.org/10.1037/xge0000595

Carlsmith, K. M., Darley, J. M., \& Robinson, P. H. (2002). Why do we punish? Deterrence and just deserts as motives for punishment. Journal of Personality and Social Psychology, 83(2), 284-299. https://doi.org/10.1037//0022-3514.83.2.284

Crockett, M. J. (2017). Moral outrage in the digital age. Nature Human Behavior, 1(11), 769771. https://doi.org/10.1038/s41562-017-0213-3 
Crone, D. L., Bode, S., Murawski, C. \& Laham, S. (2018). The Socio-Moral Image database: A novel stimulus set for the study of social, moral and affective processes. PLoS One, 13(1). https://doi.org/10.1371/journal.pone.0190954

Darley, J. M., \& Pittman, T. S. (2003). The psychology of compensatory and retributive justice. Personality and Social Psychology Review, 7(4), 324-336.

https://doi.org/10.1207/S15327957PSPR0704_05

Diamond, J. (2017, January 29). Trump's latest executive order: Banning people from 7 countries and more. CNN. https://www.cnn.com/2017/01/27/politics/donald-trump-refugeesexecutive-order/index.html

Gardner, T \& Monroe, A. E. (2018). Blaming the blamers: People impose different obligations to punish on victims versus third parties. Poster presented at the Society of Southeastern Social Psychologists Conference, Raleigh, NC.

Gill, M. J., \& Cerce, S. C. (2021). The Blame Intensity Inventory: Assessing the propensity to blame harshly and its unique capacity to predict malicious satisfaction from offender victimization. Personality and Social Psychology Bulletin, 47(6).

https://doi.org/10.1177/0146167220985362

Gill, M. J., \& Getty, P. D. (2016). On shifting the blame to humanity: Historicist narratives regarding transgressors evoke compassion for the transgressor but disdain for humanity. British Journal of Social Psychology, 55(4), 773-791. https://doi.org/10.1111/bjso.12159

Goldenberg, A., Abruzzo, J., Willer, R., Halperin, E., \& Gross, J. (2020). Homophily and acrophily as drivers of political segregation. https://doi.org/10.31219/osf.io/9xetr 
Gosling, S. D., Rentfrow, P. J., \& Swann, W. B. (2003). A very brief measure of the Big-Five personality domains. Journal of Research in Personality, 37(6), 504-528. https://doi.org/10.1016/S0092-6566(03)00046-1

Gross, J. J., \& Thompson, R. A. (2007). Emotion regulation: Conceptual foundations. In J. J. Gross (Ed.), Handbook of emotion regulation (pp. 3-24). New York, NY: Guilford Press.

Guglielmo, S., Monroe, A. E., \& Malle, B. F. (2009). At the heart of morality lies folk psychology. Inquiry, 52(5), 449-466. https://doi.org/10.1080/00201740903302600

Haidt, J. (2003). The moral emotions. In R. J. Davidson, K. R. Scherer, \& H. H. Goldsmith (Eds.), Handbook of affective sciences (pp. 852-870). Oxford, U.K.: Oxford University Press.

Hardy, S. A. (2006). Identity, reasoning, and emotion: An empirical comparison of three Sources of moral motivation. Motivation and Emotion, 30(3), 205-213. https://doi.org/10.1007/s11031-006-9034-9

Hart, S. G., \& Staveland, L. E. (1988). Development of NASA-TLX (Task Load Index): Results of empirical and theoretical research. Advances in Psychology Human Mental Workload, 52, 139-183. https://doi.org/10.1016/S0166-4115(08)62386-9

Haslam, N. (2006). Dehumanization: An integrative review. Personality and Social Psychology Review, 10(3), 252-264. https://doi.org/10.1207/s15327957pspr1003_4

Hofmann, W., Wisneski, D. C., Brandt, M. J. \& Skitka, L. J. (2014). Replication data for: Morality in everyday life. Science, 345(6202), 1340-1343. https://doi.org/10.1126/science.1251560

Hsieh, S., \& Lin, S. J. (2019). The dissociable effects of induced positive and negative moods on cognitive flexibility. Scientific Reports, 9(1). https://doi.org/10.1038/s41598-018-37683-4 
Hsu, C.-F., Eastwood, J. D., \& Toplak, M. E. (2017). Differences in perceived mental effort required and discomfort during a working memory task between individuals at-risk and not at-risk for ADHD. Frontiers in Psychology, 8. https://doi.org/10.3389/fpsyg.2017.00407

Hull, C. L. (1943). Principles of behavior: An introduction to behavior theory. Oxford, U.K.: Appleton-Century.

Inzlicht, M., Bartholow, B. D., \& Hirsh, J. B. (2015). Emotional foundations of cognitive control. Trends in Cognitive Sciences, 19(3), 126-132.

https://doi.org/10.1016/j.tics.2015.01.004

Inzlicht, M., Shenhav, A., \& Olivola, C. (2018). The effort paradox: Effort is both costly and valued. Trends in Cognitive Science, 22(4), 337-349. https://doi.org/10.1016/j.tics.2018.01.007

Jordan, M. R., Amir, D., \& Bloom, P. (2016). Are empathy and concern psychologically distinct? Emotion, 16(8), 1107-1116. https://doi.org/10.1037/emo0000228

Jordan, J. J., Hoffman, M., Bloom, P., \& Rand, D. G. (2016). Third-party punishment as a costly signal of trustworthiness. Nature, 530(7591), 473-476. https://doi.org/10.1038/nature16981

Jordan, J. J, \& Kteily, N. (2020). Reputation drives morally questionable punishment. https://doi.org/10.31234/osf.io/97nhj

Kahane, G., Wiech, K., Shackel, N., Farias, M., Savulescu, J., \& Tracey, I. (2012). The neural basis of intuitive and counterintuitive moral judgment. Social Cognitive and Affective Neuroscience, 7(4), 393-402. https://doi.org/10.1093/scan/nsr005

Kelley, H. H. (1971). Attribution in social interaction. New York, N.Y.: General Learning Press. Kool, W., \& Botvinick, M. (2013). The intrinsic cost of cognitive control. Behavioral and Brain Sciences, 36(06), 661-698. https://doi.org/10.1017/s0140525x1300109x 
Kool, W., \& Botvinick, M. (2014). A labour/leisure tradeoff in cognitive control. Journal of Experimental Psychology: General, 143(1), 131-141. https://doi.org/10.1037/a0031048

Kool, W., \& Botvinick, M. (2018). Mental labour. Nature Human Behavior, 2(12), 899-908. https://doi.org/10.1038/s41562-018-0401-9

Kool, W., McGuire, J. T., Rosen, Z. B., \& Botvinick, M. M. (2010). Decision making and the avoidance of cognitive demand. Journal of Experimental Psychology: General, 139(4), 665-682. https://doi.org/10.1037/a0020198

Knutson, K. M., Krueger, F., Koenigs, M., Hawley, A., Escobedo, J. R., Vasudeva, V., Adolphs, R., Grafman, J. (2010). Behavioral norms for condensed moral vignettes. Social Cognitive and Affective Neuroscience, 5(4), 378-384. https://doi.org/10.1093/scan/nsq005

Kundu, P., \& Cummins, D. D. (2013). Morality and conformity: The Asch paradigm applied to moral decisions. Social Influence, 8(4), 268-279.

https://doi.org/10.1080/15534510.2012.727767

Kurzban, R. (2016). The sense of effort. Current Opinion in Psychology, 7, 67-70. https://doi.org/10.1016/j.copsyc.2015.08.003

Lang, P. J., Bradley, M. M., \& Cuthbert, B. N. (2005). International affective picture system (IAPS): Affective ratings of pictures and instruction manual. Gainesville, FL: NIMH, Center for the Study of Emotion \& Attention.

Larsen, J. T., Norris, C. J., \& Cacioppo, J. T. (2003). Effects of positive and negative affect on electromyographic activity over zygomaticus major and corrugator supercilii. Psychophysiology, 40(5), 776-785. https://doi.org/10.1111/1469-8986.00078 
Leliveld, M. C., Dijk, E., \& Van Beest, I. (2012). Punishing and compensating others at your own expense: The role of empathic concern on reactions to distributive injustice. European Journal of Social Psychology, 42(2), 135-140. https://doi.org/10.1002/ejsp.872

Ley, D. J. (2017, September 25). Coping with outrage fatigue: Are you exhausted with being upset? You're not alone. Psychology Today. Retrieved from https://www.psychologytoday.com/ca/blog/women-who-stray/201709/coping-outragefatigue

Litman, L., Robinson, J., \& Abberbock, T. (2016). TurkPrime.com: A versatile crowdsourcing data acquisition platform for the behavioral sciences. Behavior Research Methods, 49(2), 433-442. https://doi.org/10.3758/s13428-016-0727-z

MacCoun, R. J. (2005). Voice, control, and belonging: The double-edged sword of procedural fairness. Annual Review of Law and Social Science, 1, 171-201. https://doi.org/10.1146/annurev.lawsocsci.1.041604.115958

Malle, B. F., Guglielmo, S., \& Monroe, A. E. (2014). A theory of blame. Psychological Inquiry, 25(2), 147-186. https://doi.org/10.1080/1047840X.2014.877340

Mikula, G., Scherer, K. R., \& Athenstaedt, U. (1998). The role of injustice in the elicitation of differential emotional reactions. Personality and Social Psychology Bulletin, 24, 769-783. https://doi.org/10.1177/0146167298247009

Mills, E. (2017, July 7). Take a break from the world and reduce your outrage fatigue syndrome. USA Today. https://www.usatoday.com/story/opinion/columnists/emilymills/2017/07/07/mills-take-break-world-and-reduce-your-outrage-fatiguesyndrome/458879001/ 
Miller, K. (2020, July 17). What is Doomscrolling? Experts explain why we do it - and how to stop. Health. Retrieved from https://www.health.com/mind-body/what-is-doomscrolling

Monroe, A. E., \& Malle, B. F. (2017). Two paths to blame: Intentionality directs moral information processing along two distinct tracks. Journal of Experimental Psychology: General, 146(1), 123-133. https://doi.org/10.1037/xge0000234

Monroe, A. E., \& Malle, B. F. (2019). People systematically update moral judgments of blame. Journal of Personality and Social Psychology, 116(2), 215-236.

https://doi.org/10.1037/pspa0000137

Pettit, D., \& Knobe, J. (2009). The pervasive impact of moral judgment. Mind and Language, 24, 586-604. doi:10.1111/j.1468-0017.2009.01375.x

Pizarro, D. A., \& Tannenbaum, D. (2012). Bringing character back: How the motivation to evaluate character influences judgments of moral blame. In M. Mikulincer \& P. R. Shaver (Eds.) The social psychology of morality: Exploring the causes of good and evil (pp. 91108). Washington, D.C.: American Psychological Association.

Rathje, S., Van Bavel, J. J., \& van der Linden, S. (2021). Out-group animosity drives engagement on social media. Proceedings of the National Academy of Sciences, 118(26). https://doi.org/10.1073/pnas.2024292118

Richard, F. D., Bond, C. F., Jr., \& Stokes-Zoota, J. J. (2003). One hundred years of social psychology quantitatively described. Review of General Psychology, 7, 331-363. http://dx.doi.org/10.1037/1089-2680.7.4.331

Ronson, J. (2015, February 12). How one stupid tweet blew up Justine Sacco’s life. The New York Times Magazine. https://www.nytimes.com/2015/02/15/magazine/how-one-stupidtweet-ruined-justine-saccos-life.html 
Salerno, J. M., \& Peter-Hagene, L. C. (2013). The interactive effect of anger and disgust on moral outrage and judgments. Psychological Science, 24(10), 2069-2078. https://doi.org/10.1177/0956797613486988

Scheffer, J. A., Cameron, D., \& Inzlicht, M. (2021). Caring is costly: People avoid the cognitive work of compassion. https://doi.org/10.1037/xge0001073

Silverman, H., \& Ellis, R. (2019, June 30). A pregnant woman was shot, then indicted in her baby's death. Lawyers will try to get the charges dismissed. CNN. https://www.cnn.com/2019/06/30/us/alabama-pregnant-woman-lawyers-motion/index.html

Skitka, L. J. (2010). The psychology of moral conviction. Social and Personality Psychology Compass, 4(4), 267-281. https://doi.org/10.1111/j.1751-9004.2010.00254.x

Skitka, L. J., Bauman, C. W., \& Sargis, E. G. (2005). Moral conviction: Another contributor to attitude strength or something more? Journal of Personality and Social Psychology, 88(6), 895-917. https://doi.org/10.1037/0022-3514.88.6.895

Son, J., Bhandari, A., \& Feldmanhall, O. (2019). Crowdsourcing punishment: Individuals reference group preferences to inform their own punitive decisions. Scientific Reports, 9(1). https://doi.org/10.31234/osf.io/ph3wn

Spring, V. L., Cameron, C. D., \& Cikara, M. (2018). The upside of outrage. Trends in Cognitive Sciences, 22(12), 1067-1069. https://doi.org/10.1016/j.tics.2018.09.006

Steiger, J. H. (1980). Tests for comparing elements of a correlation matrix. Psychological Bulletin, 87(2), 245-251. https://doi.org/10.1037/0033-2909.87.2.245

Stets, J. E., \& Carter, M. J. (2006). The moral identity: A principle level identity. In K. A. McClelland \& T. J. Fararo (Eds.), Purpose, meaning, and action: Control system theories in sociology (pp. 293-316). New York, N.Y.: Palgrave MacMillan. 
Tannenbaum, D., Uhlmann, E. L., \& Diermeier, D. (2011). Moral signals, public outrage, and immaterial harms. Journal of Experimental Social Psychology, 47(6), 1249-1254. https://doi.org/10.1016/j.jesp.2011.05.010

Thomas, E. F., \& McGarty, C. A. (2009). The role of efficacy and moral outrage norms in creating the potential for international development activism through group-based interaction. British Journal of Social Psychology, 48(1), 115-134. https://doi.org/10.1348/014466608X313774

Vásquez-Rosati, A., Montefusco-Siegmund, R., López, V., \& Cosmelli, D. (2019). Emotional influences on cognitive flexibility depend on individual differences: A combined microphenomenological and psychophysiological study. Frontiers in Psychology, 10. https://doi.org/10.3389/fpsyg.2019.01138

Viki, G. T., Fullerton, I., Raggett, H., Tait, F., \& Wiltshire, S. (2012). The role of dehumanization in attitudes toward the social exclusion and rehabilitation of sex offenders. Journal of Applied Social Psychology, 42(10), 2349-2367. https://doi.org/10.1111/j.1559-1816.2012.00944.X

Xiao, E., \& Houser, D. (2005). Emotion expression in human punishment behavior. Proceedings of the National Academy of Sciences, 102(20), 7398-7401. https://doi.org/10.1073/pnas.0502399102

Winkielman, P., \& Gogolushko, Y. (2018). Influence of suboptimally and optimally presented affective pictures and words on consumption-related behavior. Frontiers in Psychology, 8. https://doi.org/10.3389/fpsyg.2017.02261

Yarkoni, T. (2019). The generalizability crisis. https://doi.org/10.31234/osf.io/jqw35 
Table 1

Median Blame Choice and Mean NASA Task Load Index Ratings for BLAME and Alternative decks (Studies 1 to 7)

\begin{tabular}{|c|c|c|c|c|c|c|c|c|c|}
\hline Median & Study 1 & Study 2 & Study $3 *$ & Study $4 \mathrm{a}$ & Study $4 b^{*}$ & Study $5 \mathrm{a}$ & Study $5 b$ & Study 6 & Study 7 \\
\hline Blame Choice: & 0.58 & 0.66 & 0.66 & 0.63 & 0.63 & 0.13 & 0.10 & 0.43 & 0.20 \\
\hline$Z$ & 1.55 & 4.44 & 8.63 & 2.45 & 3.60 & -11.88 & -10.80 & -6.21 & -10.28 \\
\hline$p$ & .120 & $<.001$ & $<.001$ & .007 & $<.001$ & $<.001$ & $<.001$ & $<.001$ & $<.001$ \\
\hline$r^{\mathrm{a}}$ & 0.15 & 0.42 & 0.61 & 0.17 & 0.25 & -0.80 & -0.75 & -0.43 & -0.70 \\
\hline Blame Choice: & - & - & - & - & - & - & - & - & 0.53 \\
\hline$Z$ & & & & & & & & & 0.67 \\
\hline$p$ & & & & & & & & & .505 \\
\hline$r$ & & & & & & & & & 0.05 \\
\hline$M(S D)$ & Study 1 & Study 2 & Study $3 *$ & Study $4 \mathrm{a}$ & Study $4 b^{*}$ & Study $5 \mathrm{a}$ & Study $5 b$ & Study 6 & Study 7 \\
\hline \multicolumn{10}{|l|}{ Perceived Effort: } \\
\hline BLAME & $3.38(1.18)$ & $3.47(1.07)$ & $3.30(1.07)$ & $3.43(1.14)$ & $3.24(1.16)$ & $3.80(1.02)$ & $3.76(0.99)$ & $3.59(1.07)$ & $3.54(1.11)$ \\
\hline OTHER deck & $3.14(1.16)$ & $3.46(1.12)$ & $3.44(0.97)$ & $3.37(1.20)$ & $3.73(0.99)$ & $2.88(1.24)$ & $3.20(1.08)$ & $3.05(1.18)$ & $3.29(1.07)$ \\
\hline$t(d f)$ & $1.55(101)$ & $.12(109)$ & $-2.01(200)$ & $.60(204)$ & $-5.46(202)$ & $9.86(218)$ & $6.83(204)$ & $6.69(209)$ & $3.45(216)$ \\
\hline$p$ & .125 & .904 & .046 & .547 & $<.001$ & $<.001$ & $<.001$ & $<.001$ & .001 \\
\hline Cohen's $d^{\mathrm{a}}$ & 0.16 & 0.01 & -0.14 & 0.04 & -0.38 & 0.67 & 0.47 & 0.46 & 0.24 \\
\hline \multicolumn{10}{|c|}{ Perceived Aversiveness: } \\
\hline BLAME & $2.87(1.44)$ & $2.85(1.32)$ & $2.83(1.25)$ & $2.86(1.37)$ & $2.90(1.29)$ & $3.17(1.36)$ & $3.27(1.39)$ & $2.94(1.32)$ & $3.14(1.26)$ \\
\hline OTHER deck & $2.66(1.35)$ & $2.63(1.36)$ & $2.62(1.13)$ & $2.80(1.39)$ & $3.17(1.27)$ & $2.27(1.25)$ & $2.56(1.34)$ & $2.35(1.31)$ & $2.60(1.15)$ \\
\hline$t(d f)$ & $1.38(101)$ & $1.68(109)$ & $2.71(200)$ & $.62(204)$ & $-2.71(202)$ & $8.79(218)$ & $6.84(204)$ & $6.53(209)$ & $7.48(216)$ \\
\hline$p$ & .172 & .048 & .007 & .535 & .007 & $<.001$ & $<.001$ & $<.001$ & $<.001$ \\
\hline Cohen's $d$ & 0.14 & 0.16 & 0.19 & 0.04 & -0.19 & 0.60 & 0.48 & 0.45 & 0.50 \\
\hline \multicolumn{10}{|c|}{ Perceived Efficacy: } \\
\hline BLAME & $3.76(1.08)$ & $3.86(1.04)$ & $3.96(0.87)$ & $3.86(1.01)$ & $3.97(0.84)$ & $3.40(1.25)$ & $3.45(1.27)$ & $3.79(1.09)$ & $3.61(1.04)$ \\
\hline OTHER deck & $3.70(1.09)$ & $3.83(1.00)$ & $3.84(0.88)$ & $3.54(1.23)$ & $3.46(1.08)$ & $4.22(0.92)$ & $4.15(0.89)$ & $4.06(0.91)$ & $4.18(0.69)$ \\
\hline$t(d f)$ & $.48(101)$ & $.37(109)$ & $2.02(200)$ & $3.26(204)$ & $5.83(202)$ & $-8.88(218)$ & $-7.30(204)$ & $-3.23(209)$ & $-8.27(216)$ \\
\hline$p$ & .634 & .712 & .045 & .001 & $<.001$ & $<.001$ & $<.001$ & .001 & $<.001$ \\
\hline Cohen's $d$ & 0.05 & 0.04 & 0.14 & 0.23 & 0.41 & -0.60 & -0.51 & -0.23 & -0.56 \\
\hline
\end{tabular}

Note. Study 7 presents blame choice scores for both image-based (top) and vignette-based (bottom) transgressions. Studies 3 and $4 \mathrm{~b}$ used the FEEL deck as the alternative choice to the BLAME deck. Cognitive cost differences for Studies 3 and 7 were based on the average perceived effort, perceived aversiveness, and perceived efficacy scores of the BLAME and alternative (FEEL or DESCRIBE) decks across both administrations of the NASA Task Load Index. ${ }^{\text {a }}$ The effect size $r$ and Cohen's $d$ values are specific to within-subjects effects. 


\section{Table 2}

Mean NASA Task Load Index Ratings for BLAME and Alternative decks: Split by Moral Ambiguity of Transgressions in Study 3

\begin{tabular}{lcc}
\hline$M(S D)-$ Study 3 & $\begin{array}{c}\text { Clear Moral } \\
\text { Transgression }\end{array}$ & $\begin{array}{c}\text { Ambiguous Moral } \\
\text { Transgression }\end{array}$ \\
\hline Perceived Effort: & $3.31(1.18)$ & $3.29(1.13)$ \\
BLAME deck & $3.49(1.14)$ & $3.39(1.05)$ \\
FEEL deck & & \\
Perceived Aversiveness: & $2.97(1.39)$ & $2.69(1.34)$ \\
BLAME deck & $2.69(1.28)$ & $2.55(1.28)$ \\
FEEL deck & & \\
Perceived Efficacy: & & $3.91(0.97)$ \\
BLAME deck & $4.01(0.94)$ & $3.91(0.88)$ \\
FEEL deck & $3.78(1.04)$ & \\
\hline
\end{tabular}

Table 3

Mean NASA Task Load Index Ratings for BLAME and Alternative decks: Split by Moral Stimuli depicting Transgressions in Study 7

\begin{tabular}{lcc}
\hline$M(S D)-$ Study 7 & $\begin{array}{c}\text { Moral } \\
\text { Images }\end{array}$ & $\begin{array}{c}\text { Moral } \\
\text { Vignettes }\end{array}$ \\
\hline Perceived Effort: & $3.57(1.29)$ & $3.51(1.20)$ \\
BLAME deck & $3.24(1.22)$ & $3.35(1.21)$ \\
DESCRIBE deck & & \\
Perceived Aversiveness: & $3.22(1.40)$ & $3.06(1.40)$ \\
BLAME deck & $2.57(1.29)$ & $2.64(1.33)$ \\
DESCRIBE deck & & \\
Perceived Efficacy: & & \\
BLAME deck & $3.41(1.28)$ & $4.06(0.91)$ \\
DESCRIBE deck & $4.30(0.73)$ & $3.81(1.12)$ \\
\hline
\end{tabular}




\section{Table 4}

Multilevel Models Predicting Changes in Outrage, Arousal, and Valence from Choice and Stimuli Type - Study 7

\begin{tabular}{lcccc}
\hline Outcome & Effect & $F$ & $d f$ & $p$ \\
\hline Outrage & Choice & 1248.73 & 6410.45 & $<.001$ \\
& Stimuli Type & 7.59 & 6305.84 & .006 \\
& Choice * Stimuli Type & 19.98 & 6336.11 & $<.001$ \\
Arousal & & & \\
& Choice & 755.59 & 6395.17 & $<.001$ \\
& Stimuli Type & 131.91 & 6303.62 & $<.001$ \\
Choice * Stimuli Type & .25 & 6329.50 & .615 \\
& & & \\
& Choice & 319.36 & 6392.94 & $<.001$ \\
& Stimuli Type & 60.50 & 6303.15 & $<.001$ \\
& Choice * Stimuli Type & 4.63 & 6328.46 & .032 \\
\hline
\end{tabular}

Note. The table presents Type III Tests of Fixed Effects.

Table 5

Estimated Marginal Means from Multilevel Models Predicting Changes in Outrage, Arousal, and Valence from Choice and Stimuli Type - Study 7

\begin{tabular}{lccccc}
\hline Outcome & Stimuli Type & $\begin{array}{c}\text { BLAME } \\
\text { deck } \\
M(S E)\end{array}$ & $\begin{array}{c}\text { DESCRIBE } \\
\text { deck } \\
M(S E)\end{array}$ & $p$ & $95 \%$ CI M diff \\
\hline Outrage & Vignette & $6.24(.13)$ & $4.47(.13)$ & $<.001$ & {$[1.63,1.91]$} \\
& Image & $6.61(.14)$ & $4.38(.13)$ & $<.001$ & {$[2.07,2.39]$} \\
Arousal & Vignette & $5.07(.13)$ & $3.62(.13)$ & $<.001$ & {$[1.32,1.59]$} \\
& Image & $5.65(.14)$ & $4.14(.13)$ & $<.001$ & {$[1.35,1.66]$} \\
Valence & & & & & \\
& Vignette & $2.81(.11)$ & $3.50(.11)$ & $<.001$ & {$[-0.79,-0.58]$} \\
& Image & $2.43(.11)$ & $3.29(.11)$ & $<.001$ & {$[-0.98,-0.73]$} \\
\hline
\end{tabular}




\section{Table 6}

Meta-Analytic Correlations between Blame Choice, Cognitive Costs, Social Norms and Individual Differences

\begin{tabular}{lcccccccc}
\hline Measure & Blame Choice & $p$ & Effort & $p$ & \multicolumn{1}{c}{ Aversiveness } & $p$ & Efficacy \\
\hline Blame Choice & - & & $-.12[-.17,-.06]$ & $<.001$ & $-.14[-.19,-.09]$ & $<.001$ & $.50[.43, .56]$ & $<.001$ \\
Descriptive Norm & $.46[.40, .51]$ & $<.001$ & $-.17[-.23,-.11]$ & $<.001$ & $-.14[-.19,-.09]$ & $<.001$ & $.33[.26, .39]$ & $<.001$ \\
Injunctive Norm & $.10[.05, .15]$ & $<.001$ & $-.02[-.08, .05]$ & .622 & $-.02[-.07, .03]$ & .348 & $.09[.04, .14]$ & $<.001$ \\
Personal Desire & $.29[.21, .36]$ & $<.001$ & $-.05[-.11, .02]$ & .153 & $-.11[-16, .06]$ & $<.001$ & $.23[.18, .28]$ & $<.001$ \\
Moral Convictions & $.30[.20, .40]$ & $<.001$ & $-.04[-.09, .02]$ & .157 & $-.04[-.09, .01]$ & .119 & $.17[.10, .24]$ & $<.001$ \\
Symbolization & $.15[.09, .22]$ & $<.001$ & $-.03[-.09, .03]$ & .327 & $-.04[-.10, .01]$ & .132 & $.14[.09, .19]$ & $<.001$ \\
Internalization & $.03[-.04, .09]$ & .411 & $-.03[-.07, .02]$ & .323 & $.00[-.05, .05]$ & .973 & $-.04[-.10, .03]$ & .322 \\
Empathy & $.12[.04, .20]$ & .005 & $-.02[-.09, .04]$ & .456 & $-.04[-.10, .03]$ & .242 & $.09[.03, .15]$ & .003 \\
Beh. Contagion & $.09[.02, .15]$ & .009 & $.01[-.05, .07]$ & .775 & $-.01[-.04, .06]$ & .675 & $.07[.02, .13]$ & .005 \\
\hline
\end{tabular}

Note. Meta-analytic effects reflect Pearson's $r$ correlations, with 95\% confidence intervals presented. Perceived Effort, Aversiveness, and Efficacy, as well as Descriptive and Injunctive norms, reflect difference scores (Blame deck - Alternative deck). For Blame Choice correlations involving NASA ratings of Effort, Aversiveness, and Efficacy, Moral Convictions, Empathy, Behavioral Contagion, $N \mathrm{~s}=1672$. For Blame Choice correlations involving Symbolization (moral identity subscale), Internalization (moral identity subscale), Descriptive Norm, Injunctive Norm, and Personal Desire, $N \mathrm{~s}=1570$. In Studies 3 and 7, blame choice and cognitive cost measures are averaged across the within-subjects transgression ambiguity condition (Study 3: clear, ambiguous) and stimuli type condition (Study 7: images, vignettes). 


\section{Figure 1}

Schematic Example of Blame Selection Task Trial (Studies 1 to 3)

A little while ago I had to go to the DMV to get my driver's license renewed. They told me that I had to take a written test in which I had three attempts to pass. I failed the first two times so I cheated on the final attempt.

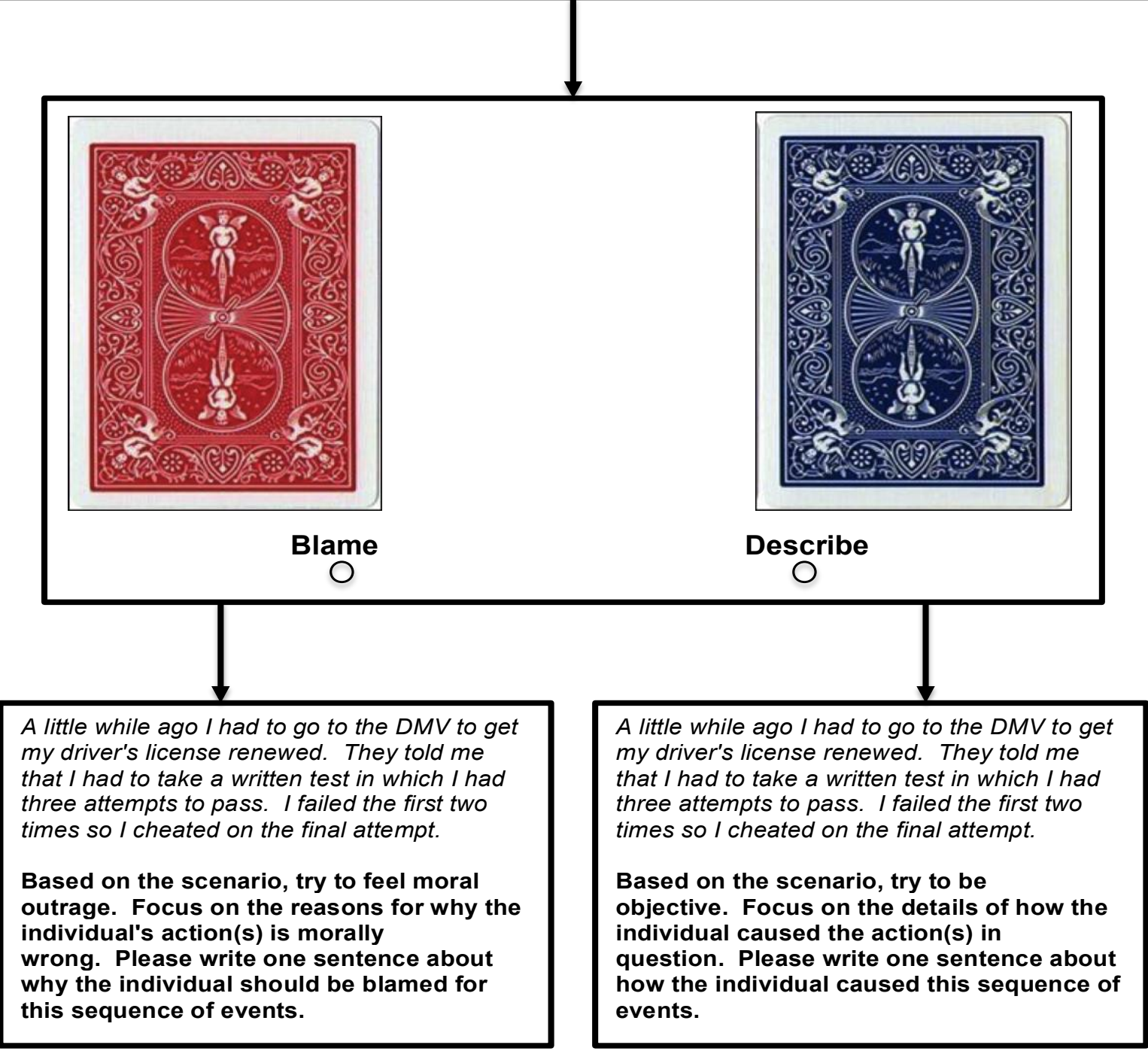

Note. Over repeated trials, respondents choose a deck after reading a first-person vignette of an individual committing an action. Based upon choice, respondents are instructed to feel moral outrage or to be objective and make a written response. The schematic includes a target stimulus used in Studies 1, 2, 3, 4a, and 4b (from the moral vignettes database; Knutson et al., 2010). See main text for modified variants in Studies 2, 3, 4a, 4b, and 7, which also used moral vignettes. 
Figure 2

Blame Choice in Studies 1 to 7 (Vignette-Based and Image-Based Studies)

\section{Blame Choice}

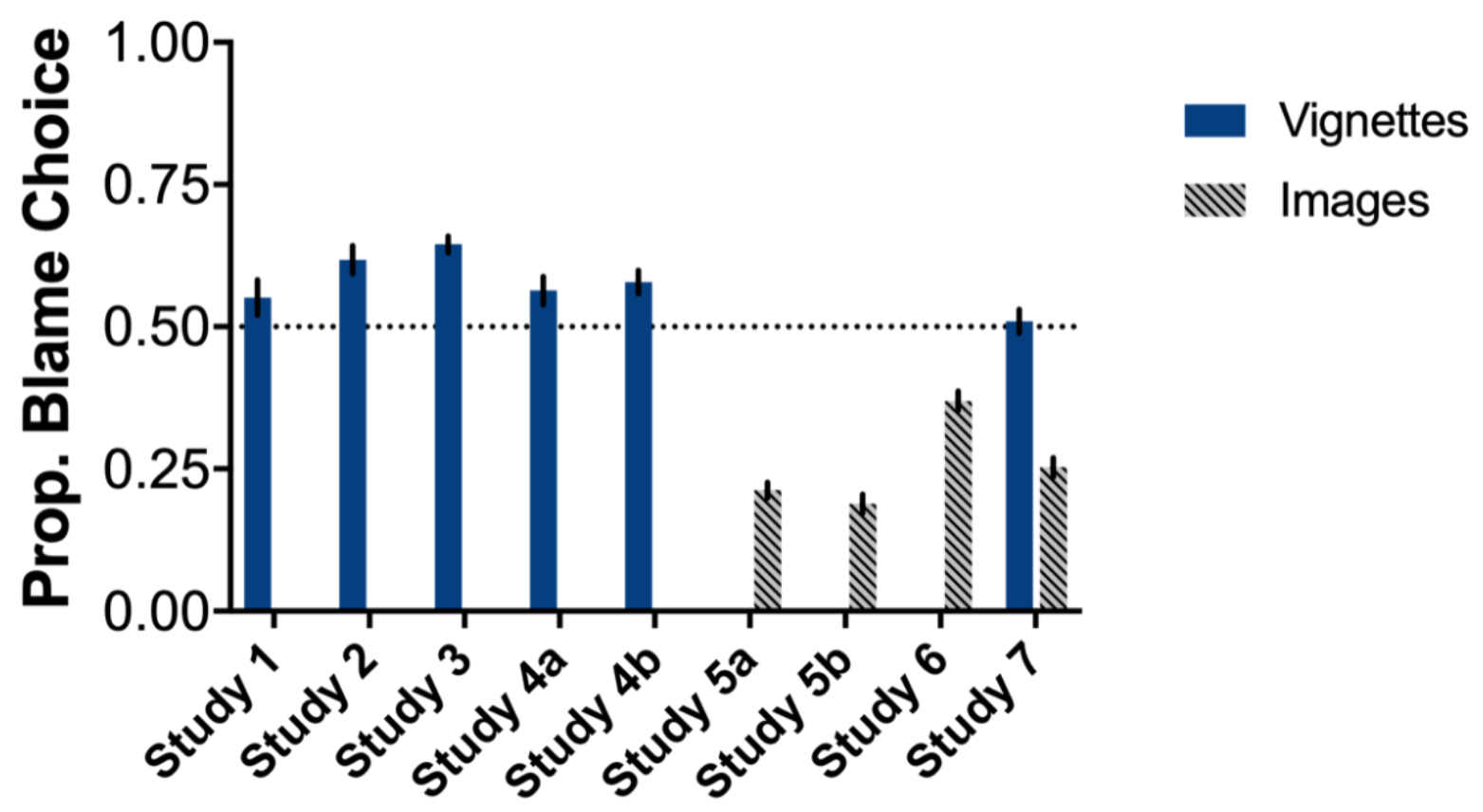

Note. Error bars reflect standard error of the mean. 
Figure 3

Blame Choice by Moral Ambiguity of Transgressions in Studies 2, 3, 5a, and 6

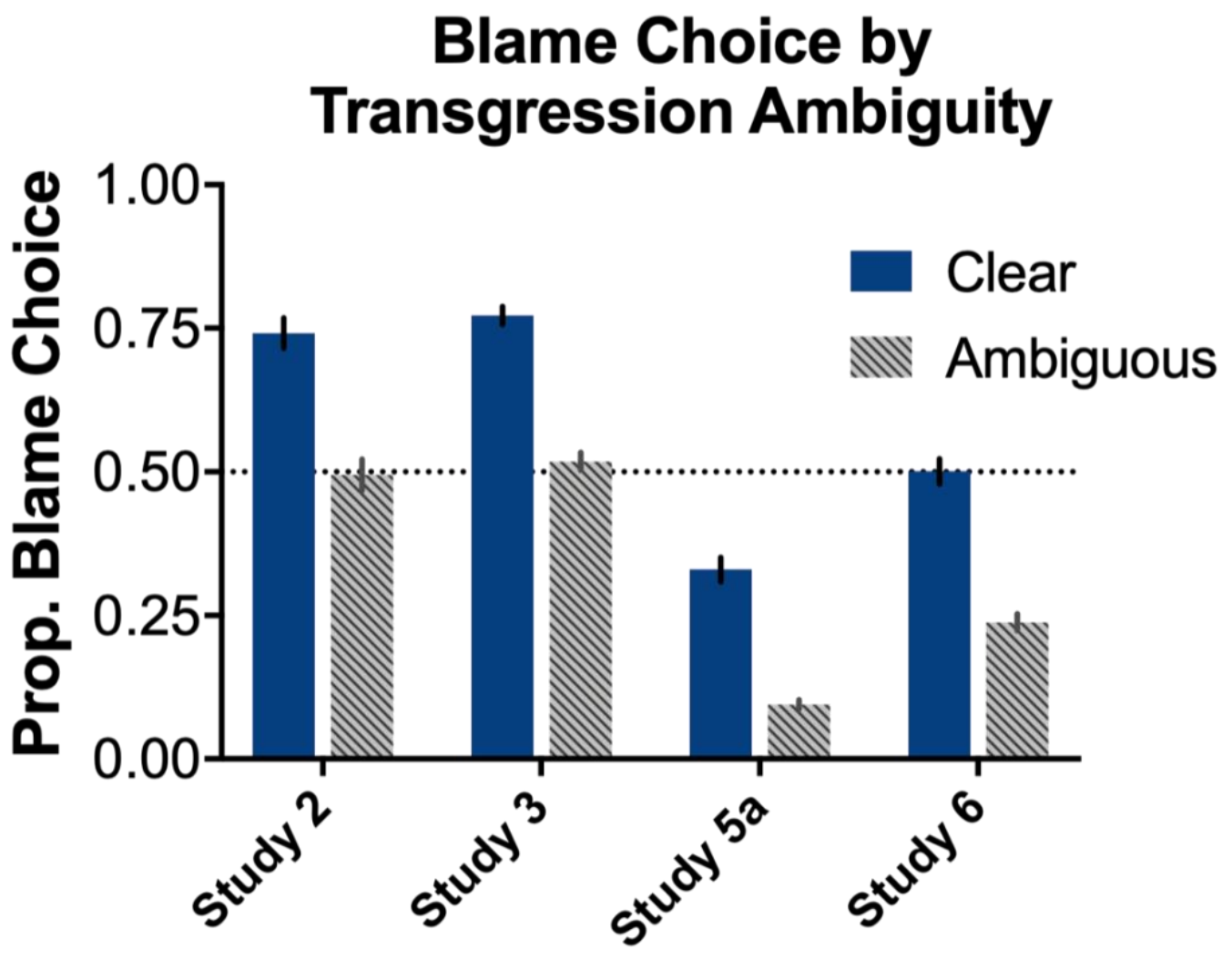

Note. Error bars reflect standard error of the mean. 


\section{Figure 4}

Schematic Example of Blame Selection Task Trial in Study $5 b$

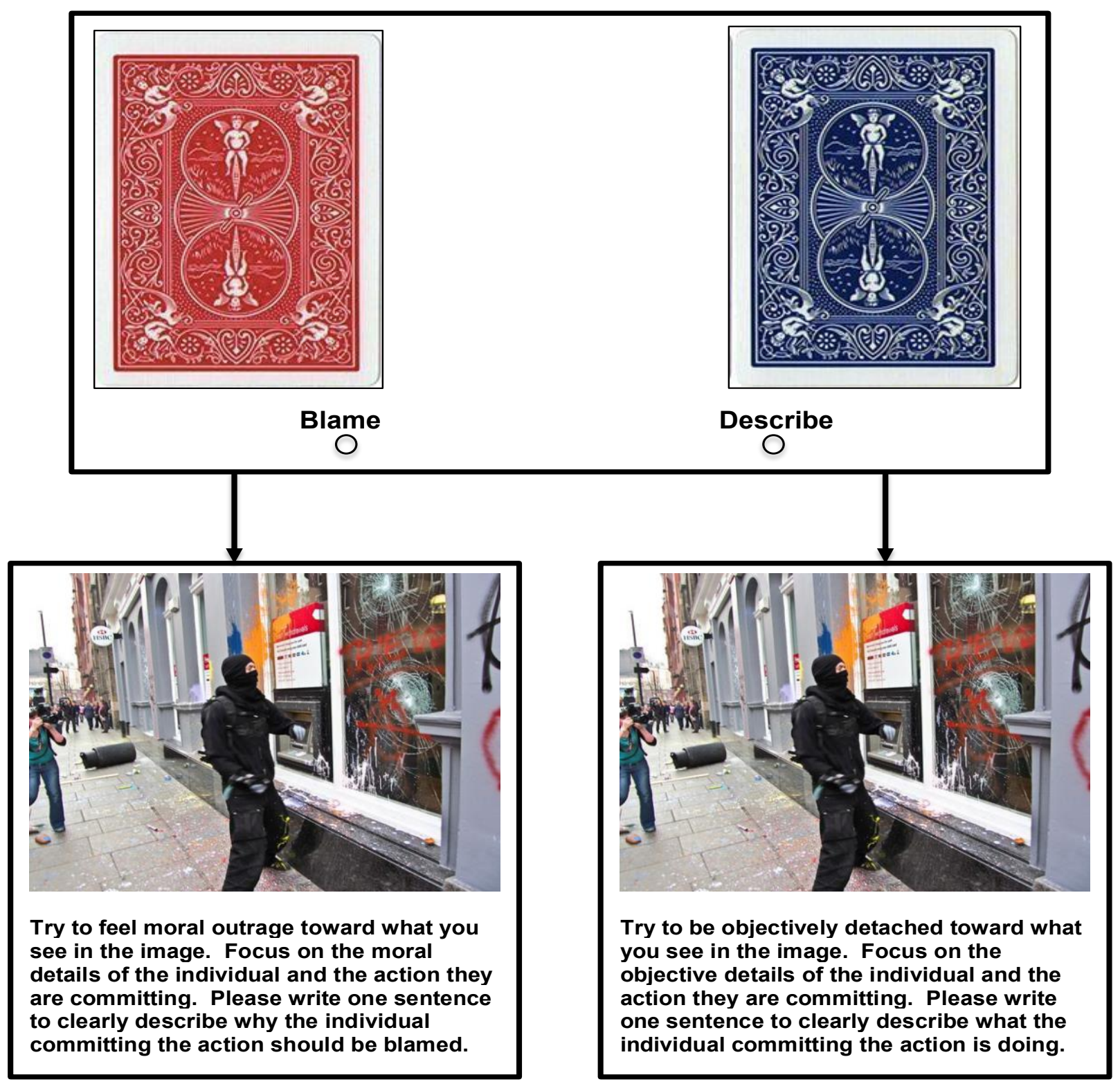

Note. Over repeated trials, respondents choose a deck before seeing an image of a person

committing an action. Based upon choice, respondents are instructed to feel moral outrage or to be objectively detached and make a written response. The schematic includes a target stimulus used in Studies 5a, 5b, 6, and 7 (from the Social-Moral Image Database; Crone et al., 2018). See main text for modified variants in Studies 5a, 6, and 7, which also used moral images. 


\section{Figure 5}

Associations of Blame Choice with NASA Task Load Index Ratings of Perceived Effort, Aversion, and Efficacy of Blaming (versus Objectivity or Empathy)
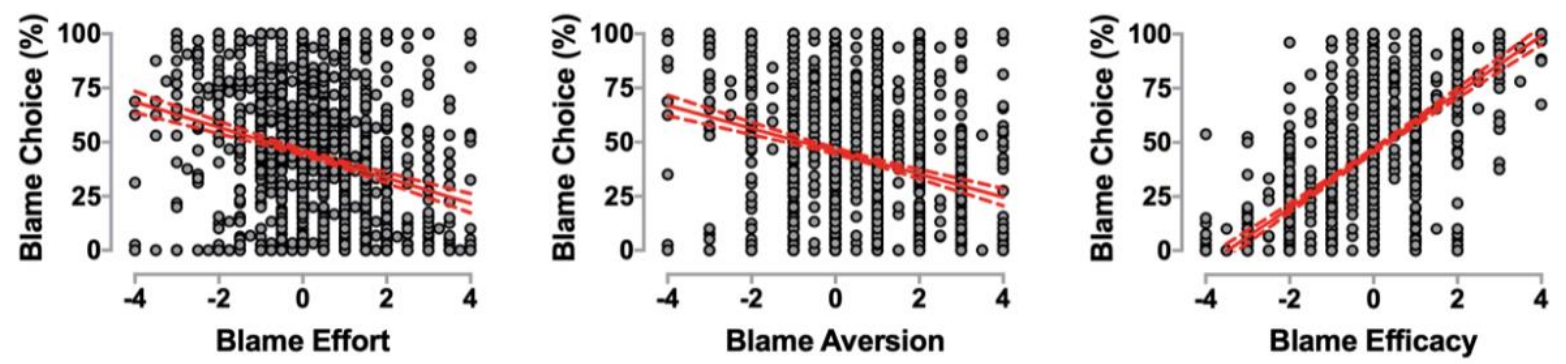


\section{Figure 6}

Associations of Blame Choice with Descriptive, Injunctive, and Personal Norms about Blaming (versus Objectivity or Empathy)
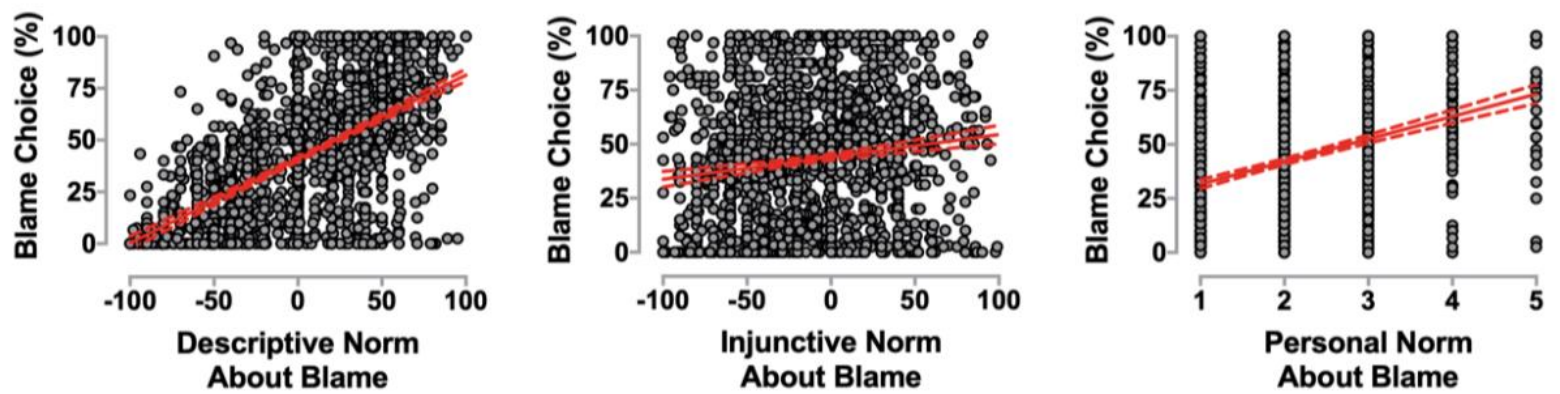
Table A1

Participant Demographic Characteristics across Studies 1 to 7

\begin{tabular}{|c|c|c|c|c|c|c|c|c|c|}
\hline & $\begin{array}{c}\text { Study } 1 \\
N=102\end{array}$ & $\begin{array}{c}\text { Study } 2 \\
N=110\end{array}$ & $\begin{array}{l}\text { Study } 3 \\
N=201\end{array}$ & $\begin{array}{c}\text { Study } 4 \mathrm{a} \\
N=205\end{array}$ & $\begin{array}{c}\text { Study } 4 \mathrm{~b} \\
N=203\end{array}$ & $\begin{array}{c}\text { Study } 5 \mathrm{a} \\
N=219\end{array}$ & $\begin{array}{c}\text { Study } 5 b \\
N=205\end{array}$ & $\begin{array}{l}\text { Study } 6 \\
N=210\end{array}$ & $\begin{array}{c}\text { Study } 7 \\
N=217\end{array}$ \\
\hline $\begin{array}{l}M_{\text {age }} \\
\left(S D_{\text {age }}\right)\end{array}$ & $\begin{array}{c}34.58 \\
(10.52)\end{array}$ & $\begin{array}{c}35.11 \\
(10.77)\end{array}$ & $\begin{array}{c}33.92 \\
(9.78)\end{array}$ & $\begin{array}{c}38.75 \\
(12.77)\end{array}$ & $\begin{array}{c}35.69 \\
(10.88)\end{array}$ & $\begin{array}{c}34.54 \\
(10.15)\end{array}$ & $\begin{array}{c}39.26 \\
(12.66)\end{array}$ & $\begin{array}{c}35.94 \\
(11.28)\end{array}$ & $\begin{array}{c}42.08 \\
(12.40)\end{array}$ \\
\hline
\end{tabular}

Gender $(n)$

$\begin{array}{lcccccccc}\text { Male } & 53 & 56 & 92 & 81 & 99 & 113 & 88 & 96 \\ \text { Female } & 49 & 54 & 109 & 124 & 102 & 104 & 116 & 114 \\ \text { Other } & - & - & - & - & 2 & 2 & 125 \\ & & & & & & 2 & - & 4\end{array}$

Race/ethnicity: \% (n)

White/Caucasian

$74.50(76)$

$77.10(155) \quad 83.40(171)$

$13.70(14)$

$7.80(8)$

$6.40(7) \quad 9.50(19)$

$9.30(19)$

$81.80(166) \quad 80.40(176)$

$77.60(159)$

$6.40(13) \quad 5.90(13)$

$13.70(28)$

$3.90(8)$

$83.80(176) 81.10(176)$

Hispanic/Latino

$12.80(13)$

$10.90(12) \quad 7.00(14)$

$4.90(10)$

- $7.30(16)$

$9.80(20)$

$7.10(15) \quad 8.80(19)$

$10.90(22) \quad 13.30(29)$

$4.80(10) \quad 7.40(16)$

$7.60(16) \quad 13.30(29)$

Political: \% (n)

Liberal

$51.80(57)$

Equally Lib. \& Cons.

Conservative

$24.50(25)$

$51.80(57) \quad 56.70(114)$

$46.80(96)$

$52.20(106)$

$53.90(118)$

$47.30(97)$

50.00 (105) $52.50(114)$

$22.60(23)$

$30.90(34) \quad 23.50(47)$

34.60

$14.80(30)$

$20.50(45)$

$25.40(52)$

$27.30(56)$

$18.60(39) \quad 16.60(36)$

$31.40(66) \quad 30.90(67)$

Religiosity: \% (n)

Not at all

Slightly

Somewhat

Very

Extremely

$\begin{array}{cccc}56.90(58) & 46.40(51) & 48.30(97) & 45.40(93) \\ 16.70(17) & 14.50(16) & 14.90(30) & 16.10(33) \\ 10.80(11) & 18.20(20) & 14.40(29) & 13.70(28) \\ 8.80(9) & 13.60(15) & 14.90(30) & 16.60(34) \\ 6.90(7) & 7.30(8) & 7.50(15 & 8.30(17)\end{array}$

$44.30(90) \quad 49.80(109)$ $21.70(44) \quad 19.20(42)$

$39.50(81)$

$17.10(35)$

$16.30(33) \quad 13.70(30) \quad 22.90(47)$

$10.80(22) \quad 14.20(31) \quad 12.70(26)$

$6.90(14) \quad 3.20(7) \quad 7.80(16)$

$47.10(99) \quad 45.60(99)$

$11.00(23) \quad 17.10(37)$

$18.60(39) \quad 12.00(26)$

$17.60(37) \quad 16.60(36)$

$5.70(12) \quad 8.80(19)$

Annual income: \% (n)

$$
<\$ 50,000
$$

$63.70(65)$

$56.40(62) \quad 50.30(101)$

$49.30(101)$

$53.70(109)$

$52.10(114) \quad 54.70(112)$

$52.40(110) \quad 38.70(84)$

$>\$ 50,001$

$36.20(37) \quad 43.60(48) \quad 49.80(100) \quad 50.70(104) \quad 46.30(94)$

$48.00(105) \quad 45.40(93)$

47.60 (100) 61.30 (133)

Note. The number of respondents excluded (for failing concealed attention checks and/or for failing to follow writing prompts) in each study: Study 1

$=8 ;$ Study $2=7 ;$ Study $3=15 ;$ Study $4 a=0 ;$ Study $4 b=15 ;$ Study $5 a=24 ;$ Study $5 b=13 ;$ Study $6=13 ;$ Study $7=13$. 
Table A2

Blame Choice based on Position of BLAME Deck during Blame Selection Task (Studies 1 to 6)

\begin{tabular}{|c|c|c|c|c|c|}
\hline & $\begin{array}{l}\text { Blame Choice - } \\
\text { BLAME Deck } \\
\text { = Left side }\end{array}$ & $\begin{array}{l}\text { Blame Choice - } \\
\text { BLAME Deck } \\
\text { = Right side }\end{array}$ & $Z$ & $p$ & $r$ \\
\hline & Mean Rank & Mean Rank & & & \\
\hline Study 1 & 56.65 & 46.35 & -1.76 & .079 & -0.17 \\
\hline Study 2 & 54.52 & 56.48 & -.32 & .747 & -0.03 \\
\hline Study 3 & 100.73 & 101.27 & -.07 & .948 & -0.00 \\
\hline Study $4 \mathrm{a}$ & 108.38 & 97.56 & -1.31 & .191 & -0.09 \\
\hline Study $4 b$ & 100.85 & 103.14 & -.28 & .781 & -0.02 \\
\hline Study 5a & 115.15 & 104.51 & -1.25 & .212 & -0.08 \\
\hline Study $5 b$ & 109.22 & 96.72 & -1.52 & .128 & -0.11 \\
\hline \multirow[t]{3}{*}{ Study 6} & 105.76 & 105.23 & -.06 & .949 & -0.00 \\
\hline & $\begin{array}{l}\text { Blame Choice - } \\
\text { BLAME Deck } \\
\text { = Left side }\end{array}$ & $\begin{array}{l}\text { Blame Choice - } \\
\text { BLAME Deck } \\
\text { = Right side }\end{array}$ & $t(d f)$ & $p$ & $d$ \\
\hline & $M(S D)$ & $M(S D)$ & & & \\
\hline Study 1 & $0.60(0.32)$ & $0.51(0.30)$ & $1.46(100)$ & .146 & 0.29 \\
\hline Study 2 & $0.61(0.25)$ & $0.63(0.27)$ & $-.32(108)$ & .750 & 0.08 \\
\hline Study 3 & $0.65(0.19)$ & $0.64(0.22)$ & .35 (199) & .726 & 0.05 \\
\hline Study 4a & $0.60(0.35)$ & $0.53(0.37)$ & $1.38(203)$ & .168 & 0.19 \\
\hline Study 4b & $0.57(0.30)$ & $0.58(0.29)$ & $-.23(201)$ & .822 & 0.03 \\
\hline Study $5 \mathrm{a}$ & $0.23(0.20)$ & $0.20(0.20)$ & $1.05(217)$ & .295 & 0.15 \\
\hline Study 5b & $0.22(0.27)$ & $0.15(0.19)$ & $2.20(181.81)$ & .029 & 0.30 \\
\hline Study 6 & $0.37(0.25)$ & $0.37(0.25)$ & $.01(208)$ & .990 & 0.00 \\
\hline
\end{tabular}

Note. Counterbalancing of the BLAME deck occurred between 2 separate Qualtrics surveys for each study. The top table presents non-parametric statistics and the bottom table presents parametric statistics. The number of respondents who saw the BLAME deck on the left side of the Blame Selection Task are as followed: Study $1=51$; Study $2=55$; Study $3=101$; Study $4 \mathrm{a}$ $=103 ;$ Study 4b = 101; Study 5a = 113; Study 5b=103; Study 6=107. 


\section{Appendix B: Blame Selection Task - Pre-task Instructions Across all Studies}

An algorithm on TurkPrime prevented participants who completed any one of the studies from completing any other study.

Study 1. In the pre-task instructions, participants who saw the BLAME deck on the right side of the Blame Selection Task were told:

In this task, you will complete a series of trials. On each trial, you will read a first-person account of an action committed by someone. Then, you will see two decks of cards: the deck on the left will always be labeled "DESCRIBE" and the deck on the right will always be labeled "BLAME". You should choose between these decks. Depending on which deck you have chosen, you will be given one of two possible sets of instructions.

If you choose from the deck labeled "DESCRIBE", then you will be told to be objectively detached and focus on the features of the individual and the action(s) committed. When completing this kind of trial, do not let yourself get caught up in your feelings toward the individual who committed the action(s). On these trials, write one sentence about how the person who committed the action(s) caused this sequence of events.

If you choose from the deck labeled "BLAME", then you will be told to feel moral outrage and focus on the moral details of the action(s) committed and the individual who committed the action(s). When completing this kind of trial, let yourself get caught up in your feelings towards the individual who committed the action(s). On these trials, write one sentence about why the person who committed the action(s) should be blamed for this sequence of events.

You are free to choose from either deck on any trial. Feel free to sample from both decks and move from one deck to the other whenever you choose. However, if one deck begins to seem preferable, then feel free to choose that deck more often.

This task will take the same amount of time regardless of which deck you choose.

Study 2. Pre-task instructions and details were identical to Study 1, except that participants were told to feel moral "disapproval" after choosing the BLAME deck instead of moral "outrage":

[...] If you choose from the deck labeled "BLAME", then you will be told to feel moral disapproval and focus on the moral details of the action(s) committed and the individual who committed the action(s). When completing this kind of trial, let yourself get caught up in your feelings towards the individual who committed the action(s). On these trials, write one sentence about why the person who committed the action(s) should be blamed for this sequence of events. [...]. 
Study 3. In this study, the FEEL deck was introduced, thereby requiring different information from participants. Participants who saw the BLAME deck on the right side of the Blame Selection Task received the following pre-task instructions:

In this task, you will complete a series of trials. On each trial, you will read a first-person account of an action committed by someone. Then, you will see two decks of cards: the deck on the left will always be labeled "FEEL" and the deck on the right will always be labeled "BLAME". You should choose between these decks. Depending on which deck you have chosen, you will be given one of two possible sets of instructions.

If you choose from the deck labeled "FEEL", then you will be told to have empathy and share in the emotional experience(s) of the individual who committed the action(s). When completing this kind of trial, try to feel empathy. Let yourself share in the internal emotional experiences of the individual who committed the action(s). On these trials, write one sentence about the feelings and experiences of the individual who committed the $\operatorname{action}(\mathrm{s})$.

If you choose from the deck labeled "BLAME", then you will be told to feel moral outrage and focus on the moral details of how the individual committed the action(s). When completing this kind of trial, try to feel moral outrage. Let yourself get caught up in outrage towards the individual who committed the action(s). On these trials, write one sentence about why the individual should be blamed for having committed the action(s).

You are free to choose from either deck on any trial. Feel free to sample from both decks and move from one deck to the other whenever you choose. However, if one deck begins to seem preferable, then feel free to choose that deck more often.

This task will take the same amount of time regardless of which deck you choose.

Study 4a. The card decks (BLAME and DESCRIBE) were presented prior to the moral transgressions. Participants who saw the BLAME deck on the right side of the Blame Selection Task received the following pre-task instructions:

In this task, you will complete a series of trials. On each trial, you will see two decks of cards: the deck on the left will always be labeled "DESCRIBE" and the deck on the right will always be labeled "BLAME". You should choose between these decks. Once you choose a deck, you will then read a first-person account of an action committed by someone. Depending on which deck you have chosen, you will be given one of two possible sets of instructions.

If you choose from the deck labeled "DESCRIBE", then you will be told to be objectively detached and focus on the objective details of the individual and the action(s) committed. When completing this kind of trial, do not let yourself get caught up in your feelings toward the individual who committed the action(s). On these trials, write one sentence about how the person who committed the action(s) caused this sequence of events. 
If you choose from the deck labeled "BLAME", then you will be told to feel moral outrage and focus on the moral details of the action(s) committed and the individual who committed the action(s). When completing this kind of trial, let yourself get caught up in your feelings towards the individual who committed the action(s). On these trials, write one sentence about why the person who committed the action(s) should be blamed for this sequence of events.

You are free to choose from either deck on any trial. Feel free to sample from both decks and move from one deck to the other whenever you choose. If one deck begins to seem preferable, then feel free to choose that deck more often.

This task will take the same amount of time regardless of which deck you choose.

Study $\mathbf{4 b}$. The card decks (BLAME and FEEL) were presented prior to the moral transgressions. Participants who saw the BLAME deck on the right side of the Blame Selection Task received the following pre-task instructions:

In this task, you will complete a series of trials. On each trial, you will see two decks of cards: the deck on the left will always be labeled "FEEL" and the deck on the right will always be labeled "BLAME". You should choose between these decks. Once you choose a deck, you will then read a first-person account of an action committed by someone. Depending on which deck you have chosen, you will be given one of two possible sets of instructions. [...].

The remainder of the pre-task instructions were similar to those used in Study 3.

Study 5a. Moral images were presented prior to deck choices. Participants who saw the BLAME deck on the right side of the Blame Selection Task received the following pre-task instructions:

In this task, you will complete a series of trials. On each trial, you will first see an image of a person who is committing an action - please look at the image carefully. Then, you will see two decks of cards: the deck on the left will always be labeled "DESCRIBE" and the deck on the right will always be labeled "BLAME". You should choose between these decks. Depending on which deck you have chosen, you will be given one of two possible sets of instructions.

If you choose from the deck labeled "DESCRIBE", then you will be told to be objectively detached and focus on the objective details of the individual and the action they are committing. When completing this kind of trial, do not let yourself get caught up in your feelings toward the individual committing the action. On these trials, write one sentence to clearly describe what the individual committing the action is doing.

If you choose from the deck labeled "BLAME", then you will be told to feel moral outrage and focus on the moral details of the individual and the action they are committing. When completing this kind of trial, let yourself get caught up in your feelings towards the 
individual committing the action. On these trials, write one sentence to clearly describe why the individual committing the action should be blamed.

You are free to choose from either deck on any trial. Feel free to sample from both decks and move from one deck to the other whenever you choose. If one deck begins to seem preferable, then feel free to choose that deck more often.

This task will take the same amount of time regardless of which deck you choose.

Study $5 \boldsymbol{b}$. Participants received the exact same pre-task instructions as those presented in Study $5 a$, with the exception that the moral images would follow after participants choose between the BLAME and DESCRIBE card decks:

In this task, you will complete a series of trials. On each trial, you will see two decks of cards: the deck on the left will always be labeled "DESCRIBE" and the deck on the right will always be labeled "BLAME". You should choose between these decks. Once you choose a deck, you will then see an image of a person who is committing an action. Depending on which deck you have chosen, you will be given one of two possible sets of instructions. [...].

Study 6. Moral images and accompanying headlines were presented prior to deck choices. Participants who saw the BLAME deck on the right side of the Blame Selection Task received the following pre-task instructions:

In this task, you will complete a series of trials. On each trial, you will first see an image of a person who is committing an action. A headline of what the person is doing will accompany the image. Please look at the image and read the headline carefully. Then, you will see two decks of cards: the deck on the left will always be labeled "DESCRIBE" and the deck on the right will always be labeled "BLAME". You should choose between these decks. Depending on which deck you have chosen, you will be given one of two possible sets of instructions.

If you choose from the deck labeled "DESCRIBE", then you will be told to be objectively detached and focus on the objective details of the individual and the action they are committing. When completing this kind of trial, do not let yourself get caught up in your feelings toward the individual committing the action. On these trials, write one sentence, in your own words, to clearly describe what the individual committing the action is doing.

If you choose from the deck labeled "BLAME", then you will be told to feel moral outrage and focus on the moral details of the individual and the action they are committing. When completing this kind of trial, let yourself get caught up in your feelings towards the individual committing the action. On these trials, write one sentence, in your own words, to clearly describe why the individual committing the action should be blamed.

You are free to choose from either deck on any trial. Feel free to sample from both decks 
and move from one deck to the other whenever you choose. If one deck begins to seem preferable, then feel free to choose that deck more often.

This task will take the same amount of time regardless of which deck you choose.

Study 7. Both moral images and moral vignettes were presented in separate counterbalanced blocks prior to deck choices. With the images, pre-task instructions and details were identical to Study 5a. With the vignettes, pre-task instructions and details were similar to Study 1, 2, and 4a.

Moral Vignettes:

In this task, you will complete a series of trials. On each trial, you will first read a scenario of an individual who is doing an $\operatorname{action}(\mathbf{s})$ - please read the scenario carefully.

Then, you will see two decks of cards: the deck on the left will always be labeled "DESCRIBE" and the deck on the right will always be labeled "BLAME." You should choose between these decks. Depending on which deck you have chosen, you will be given one of two possible sets of instructions.

If you choose from the deck labeled "DESCRIBE," then you will be told to be objectively detached and focus on the objective details of the individual and the action(s) they are doing. When completing this kind of trial, do not let yourself get caught up in your feelings toward the individual doing the action(s). On these trials, write one sentence about how the individual caused this sequence of events.

If you choose from the deck labeled "BLAME," then you will be told to feel moral outrage and focus on the moral details of the individual and the action(s) they are doing. When completing this kind of trial, let yourself get caught up in your feelings towards the individual doing the action(s). On these trials, write one sentence about why the individual should be blamed for this sequence of events.

You are free to choose from either deck on any trial. Feel free to sample from both decks and move from one deck to the other whenever you choose. If one deck begins to seem preferable, then feel free to choose that deck more often.

This task will take the same amount of time regardless of which deck you choose.

In all studies, participants were shown a pair of card decks during each trial. When the BLAME deck was on the right side of the task, it was blue and the DESCRIBE deck was red.

The pre-task instructions did not change for participants who completed the Blame Selection Task with the BLAME deck on the left side of the task, with the only exception that participants were informed that the deck on the left will always be labeled "BLAME" and the deck on the right will always be labeled "DESCRIBE"; and during each trial, the BLAME deck was red and the DESCRIBE deck was blue. 


\section{Appendix C: Measures of Individual Differences}

\section{Moral Convictions Scale (Skitka, 2010)}

After completing the Blame Selection Task, participants across all studies were asked:

To what extent were your choices between the DESCRIBE [or FEEL] and BLAME decks:

(a) a reflection of your core moral beliefs and convictions?;

(b) connected to your beliefs about fundamental right and wrong?;

(c) based on moral principle?; and

(d) a moral stance?

Responses were provided on a 1 (Not at all) to 5 (Very Much) rating scale, with a higher total score indicating greater moral convictions during the Blame Selection Task.

\section{Moral Identity Scale (Aquino \& Reed, 2002)}

On a 5-point rating scale $(1=$ Strongly Disagree to $5=$ Strongly Agree $)$, participants in Studies 2 to 6 completed the 11-item Moral Identity Scale, which contains two subscales that assess the extent to which a set of moral traits (i.e., caring, compassionate, fair, friendly, generous, helpful, hardworking, honest, and kind) are important to one's moral identity. The Symbolization subscale is comprised of six items that measure the degree to which the abovenoted moral traits are manifested in one's own actions in the world (e.g., I often buy products that communicate the fact that I have these characteristics). The Internalization subscale is comprised of five items that measure the extent to which the above-noted moral traits are central to one's "self-concept" (e.g., It would make me feel good to be a person who has these characteristics). Higher subscale scores indicated greater symbolization and internalization of moral traits.

\section{Empathy Index (Jordan et al., 2016)}

On a 5-point rating scale $(1=$ Does not describe me well to $5=$ Describes me very well $)$, participants across all studies completed the 14-item Empathy Index, which contains two subscales assessing individual differences in Empathy and Behavioral Contagion. The Empathy subscale is comprised of seven items that measure the degree to which respondents take on others' feelings (e.g., I sometimes find myselffeeling the emotions of the people around me, even if I don't try to feel what they're feeling). The Behavioral Contagion scale is comprised of seven items that measures the extent to which respondents engage in the same behaviors as others around them (e.g., If I see someone else yawn, I am also likely to yawn). The two subscales differ in that empathy tracks and produces affect, whereas behavioral contagion tracks and produces behaviors. Higher subscale scores indicated greater empathy and behavioral contagion.

\section{Social Norm Items (Cameron et al., 2019)}

Participants in Studies 2 to 6 were asked:

(a) What percentage of people tends to choose the BLAME deck in the task you just completed? (Descriptive norm \#1);

(b) What percentage of people tends to choose the [DESCRIBE or FEEL] deck in the task you just completed? (Descriptive norm \#2);

(c) What percentage of people thinks that blaming is a good thing? (Injunctive norm \#1); and 
(d) What percentage of people thinks that [objectivity or empathy] is a good thing? (Injunctive norm \#2).

Responses to items (a) to (d) were provided on a sliding scale, ranging from 0 to 100 percent.

Participants were also asked:

(e) According to your own personal beliefs, do you think that it more desirable to blame or to [be objective or empathize]? (Personal norm).

Answers were provided on a 5-point rating scale $(1=$ [Objectivity or Empathy] is much more desirable to $5=$ Blame is much more desirable).

\section{Ten-Item Personality Inventory (Gosling et al., 2013)}

On a 7-point rating scale ( $1=$ Disagree Strongly to $7=$ Agree Strongly), participants in Studies 2 to 6 completed the Ten-Item Personality Inventory, where they were presented with personality traits (e.g., extraverted, enthusiastic) and indicated how much each trait is related to their own personality. Two items each comprise the Extraversion, Agreeableness,

Conscientiousness, Emotional Stability, and Openness to Experience subscales, with higher subscale scores indicating greater endorsement of traits.

Table C3 presents the correlations of the Ten-Item Personality Inventory subscales with blame choice and perceived effort, perceived aversiveness, and perceived efficacy of the BLAME deck (as opposed to the alternative deck) collapsed across all studies. Blame choice was positively, though weakly, related to conscientiousness $(r=.08, p=.004)$, but was unrelated to all other personality factors. All of the subscales were unrelated to the cognitive costs of blaming.

\section{Blame Intensity Inventory (Gill \& Cerce, 2021)}

On a 7 -point rating scale $(1=$ Not very likely to $7=$ Extremely likely), participants in Study 7 completed the Blame Intensity Inventory. Participants were first presented with brief vignettes of 7 offenses (white-collar crime, street crime, physical abuse of children by a parent, terrorism, pedophilia by a religious leader, alcohol abuse with drunk driving, and violence driven by religious fundamentalism) and then asked to indicate the degree to which they would have different hostile reactions to the offenders (e.g., the likelihood of feeling anger and disgust towards the offender). 


\section{Table C1}

Cronbach's Alpha Values for Individual Difference Measures across Studies 1 to 7

\begin{tabular}{|c|c|c|c|c|c|c|c|c|c|}
\hline$\alpha$ & $\begin{array}{c}\text { Study } 1 \\
N=102\end{array}$ & $\begin{array}{l}\text { Study } 2 \\
N=110\end{array}$ & $\begin{array}{l}\text { Study } 3 \\
N=201\end{array}$ & $\begin{array}{l}\text { Study } 4 \mathrm{a} \\
N=205\end{array}$ & $\begin{array}{c}\text { Study } 4 \mathrm{~b} \\
N=203\end{array}$ & $\begin{array}{c}\text { Study } 5 \mathrm{a} \\
N=219\end{array}$ & $\begin{array}{c}\text { Study } 5 b \\
N=205\end{array}$ & $\begin{array}{l}\text { Study } 6 \\
N=210\end{array}$ & $\begin{array}{l}\text { Study } 7 \\
N=217\end{array}$ \\
\hline Moral Convictions & .97 & .95 & .95 & .97 & .95 & .96 & .96 & .95 & .96 \\
\hline Moral Identity & - & & & & & & & & \\
\hline Symbolization & & .93 & .91 & .94 & .89 & .94 & .90 & .91 & .94 \\
\hline Internalization & & .76 & .84 & .78 & .79 & .72 & .84 & .85 & .83 \\
\hline \multicolumn{10}{|l|}{ Empathy Index } \\
\hline Empathy & .78 & .85 & .83 & .83 & .82 & .85 & .81 & .80 & .83 \\
\hline Beh. Contagion & .70 & .81 & .76 & .74 & .78 & .80 & .76 & .78 & .79 \\
\hline TIPI & - & & & & & & & & - \\
\hline Extraversion & & .71 & .81 & .79 & .81 & .85 & .72 & .66 & \\
\hline Agreeableness & & .43 & .55 & .46 & .49 & .41 & .64 & .37 & \\
\hline Conscientiousness & & .63 & .60 & .58 & .66 & .69 & .57 & .71 & \\
\hline Emotional & & .76 & .70 & .77 & .81 & .82 & .78 & .71 & \\
\hline \multicolumn{10}{|l|}{ Stability } \\
\hline Openness & & .36 & .55 & .62 & .43 & .51 & .64 & .42 & \\
\hline Blame Intensity & - & - & - & - & - & - & - & - & .86 \\
\hline
\end{tabular}


Table C2

Mean Scores for Social Norms and Individual Differences Measures across Studies 1 to 7

\begin{tabular}{lccccc}
\hline$M(S D)$ & Study 1 & Study 2 & Study $3^{*}$ & Study 4a & Study 4b* \\
& $N=102$ & $N=110$ & $N=201$ & $N=205$ & $N=203$ \\
\hline Moral Convictions & $3.29(1.36)$ & $3.52(1.24)$ & $3.90(1.05)$ & $3.20(1.38)$ & $3.38(1.24)$ \\
Moral Identity & - & & & & \\
$\quad$ Symbolization & & $2.90(0.99)$ & $2.92(0.97)$ & $2.86(1.09)$ & $2.82(0.94)$ \\
Internalization & & $4.41(0.66)$ & $4.36(0.76)$ & $4.42(0.65)$ & $4.38(0.67)$ \\
Empathy Index & & & & \\
Empathy & $2.70(0.79)$ & $2.88(0.91)$ & $2.91(0.86)$ & $2.69(0.88)$ & $2.97(0.83)$ \\
Beh. Contagion & $2.93(0.75)$ & $2.99(0.85)$ & $3.11(0.77)$ & $2.93(0.74)$ & $3.14(0.78)$ \\
Social Norms & - & & & & \\
Descriptive \#1 & & $63.92(19.85)$ & $68.12(16.72)$ & $58.87(19.60)$ & $62.64(18.14)$ \\
Descriptive \#2 & & $39.70(20.85)$ & $33.50(18.11)$ & $42.90(19.91)$ & $39.92(20.34)$ \\
Injunctive \#1 & & $50.17(21.73)$ & $52.07(22.91)$ & $48.01(23.59)$ & $48.85(22.44)$ \\
Injunctive \#2 & & $53.97(20.89)$ & $57.00(23.43)$ & $57.01(21.10)$ & $59.25(21.87)$ \\
Personal Norm & & $2.39(1.09)$ & $2.38(1.06)$ & $2.18(1.10)$ & $2.15(1.04)$ \\
TIPI & - & & & & \\
Extraversion & & $3.91(1.75)$ & $3.59(1.80)$ & $3.57(1.84)$ & $3.24(1.70)$ \\
Agreeableness & & $5.61(1.15)$ & $5.42(1.33)$ & $5.33(1.31)$ & $5.40(1.22)$ \\
Conscientious & & $5.78(1.16)$ & $5.50(1.29)$ & $5.79(1.16)$ & $5.47(1.34)$ \\
Emo. Stability & & $5.31(1.46)$ & $4.97(1.52)$ & $5.16(1.52)$ & $4.71(1.58)$ \\
Openness & & $5.33(1.13)$ & $5.05(1.36)$ & $5.03(1.38)$ & $5.00(1.26)$ \\
Blame Intensity & - & - & - & - & - \\
\hline
\end{tabular}

\begin{tabular}{lcccc}
\hline$M(S D)$ & Study 5a & Study 5b & Study 6 & Study 7 \\
& $N=219$ & $N=205$ & $N=210$ & $N=217$ \\
\hline Moral Convictions & $3.00(1.32)$ & $2.77(1.25)$ & $3.27(1.19)$ & $3.24(1.18)$ \\
Moral Identity & & & & \\
Symbolization & $2.73(1.07)$ & $2.97(0.96)$ & $2.93(0.97)$ & $2.85(1.07)$ \\
Internalization & $4.29(0.66)$ & $4.32(0.72)$ & $4.29(0.79)$ & $4.42(0.71)$ \\
Empathy Index & & & & \\
Empathy & $2.85(0.88)$ & $2.73(0.80)$ & $2.88(0.81)$ & $2.74(0.84)$ \\
Beh. Contagion & $3.07(0.82)$ & $3.02(0.76)$ & $3.09(0.80)$ & $3.05(0.80)$ \\
Social Norms & & & & \\
Descriptive \#1 & $38.37(20.79)$ & $41.22(18.69)$ & $52.67(24.09)$ & $48.68(23.14)$ \\
Descriptive \#2 & $61.91(20.53)$ & $58.40(19.04)$ & $49.45(23.25)$ & $53.18(22.79)$ \\
Injunctive \#1 & $41.10(23.94)$ & $42.86(23.85)$ & $51.66(25.82)$ & $45.55(22.64)$ \\
Injunctive \#2 & $60.35(23.04)$ & $60.13(21.82)$ & $52.88(23.94)$ & $55.16(20.98)$ \\
Personal Norm & $1.81(0.90)$ & $1.80(0.83)$ & $2.21(1.05)$ & $2.02(0.95)$ \\
TIPI & & & & - \\
Extraversion & $3.69(1.89)$ & $3.59(1.66)$ & $3.65(1.61)$ & \\
Agreeableness & $5.34(1.25)$ & $5.36(1.33)$ & $5.41(1.20)$ & \\
Conscientious & $5.42(1.30)$ & $5.66(1.19)$ & $5.40(1.34)$ & \\
Emo. Stability & $4.84(1.63)$ & $5.01(1.50)$ & $4.85(1.50)$ & \\
Openness & $5.11(1.33)$ & $5.29(1.29)$ & $4.98(1.27)$ & \\
Blame Intensity & - & - & - & $5.46(1.17)$
\end{tabular}

Note. Studies 3 and $4 \mathrm{~b}$ used the FEEL deck as the alternative choice to the BLAME deck. All other studies used the DESCRIBE deck. 


\section{Table C3}

Meta-Analytic Correlations between Blame Choice, Cognitive Costs, and TIPI Subscales (Studies 1 to 6)

\begin{tabular}{lcccccccc}
\hline Measure & $\begin{array}{c}\text { Blame } \\
\text { Choice }\end{array}$ & $p$ & Effort & $p$ & Aversiveness & $p$ & Efficacy & $p$ \\
\hline Extraversion & .08 & .116 & -.04 & .203 & -.02 & .465 & .03 & .455 \\
Agreeableness & .05 & .218 & -.05 & .059 & -.02 & .464 & .00 & .988 \\
Conscientiousness & .08 & .004 & .00 & .921 & -.01 & .833 & .04 & .231 \\
Emotional Stability & .02 & .520 & .00 & .874 & -.02 & .451 & .02 & .461 \\
Openness & .04 & .377 & -.03 & .273 & -.03 & .341 & -.01 & .700 \\
\hline
\end{tabular}

Note. Meta-analytic effects reflect Pearson's $r$ correlations. Perceived Effort, Aversiveness, and Efficacy reflect difference scores

(Blame deck - Alternative deck). All Ns = 1353. 


\section{Appendix D: Moral Vignettes for Studies 1 and 2 to $4 \mathrm{~b}$}

\section{Study 1.}

Forty moral vignettes were selected from the moral vignettes database by Knutson et al. (2010) and from supplementary materials published by Gill and Getty (2016) and were piloted with 109 respondents ( 44 female, 65 male, $M_{\text {age }}=33.72$ years, $S D_{\text {age }}=10.53$ years). On a scale of 1 to 7 , respondents rated each moral vignette on indices of Harm $(1=$ no harm to others, $7=$ extreme harm to others $)$ and Moral Appropriateness $(1=$ extremely inappropriate, $7=$ extreme appropriate). We reversed the scores for the Harm index, such that lower ratings would be indicative of higher perceived Harm, or lower Care.

Of the 40 moral vignettes, 26 with the lowest average Care (i.e., $<3.88$ out of 7 ) and the lowest average Moral Appropriateness ratings (i.e., < 2.93 out of 7) were included in the Blame Selection Task of Study 1. See Table D1 for the average Care rating and Moral Appropriateness rating for each vignette.

The moral vignettes were presented in the following fixed random order to all participants in Study 1:

MV1: I committed my first assault and robbery as a teenager. Since then, I have threatened people with a knife, punched and kicked them, and broken into their homes to steal their money and valuables.

MV2: I have served in congress for years. Often, I have supported legislation that was inconsistent with my stated values. That is, there is a disconnect between what I say and what I do. For example, despite publicly advocating against abortions, I have made my wife abort her unborn child three times in the past decade, against her own wishes.

MV3: I live on the street and use drugs. I have a very young attractive girlfriend. I let her do whatever she wants to do, like prostitution and stuff like that.

MV4: I am an accountant for a large company. Over a period of years, I have faked the books and have shifted company money into my personal bank account.

MV5: My partner is very sick and has to walk very slowly. He needs a cane and can't move fast. Every day, I am very impatient with him and yell at him to move faster.

MV6: I was in a relationship with this woman named Beth for a long time. Then one night I cheated on Beth with my ex-girlfriend. The next morning my ex came by to see why I didn't stay the night at her place and she saw me with Beth.

MV7: I took my sister's ring that was given to her by our father's aunt. I had never met our father's aunt but my sister spent some time with her. I took the ring because I don't think that my sister deserves it. 
MV8: I called someone a racial name. The person I called the name was a sort of a friend of my sister's. It got back to her and she is humiliated.

MV9: I cheated on my present boyfriend. I don't understand why he does not want to get married. I feel like he doesn't want to get married because of me and because he doesn't want to be with me, so I thought it was okay to have an affair.

MV10: My family doesn't have money so I always admire jewellery on other students in school. Recently, there was this girl who would wear this necklace. One time at break she put it down and I took it.

MV11: I am responsible for the financial wellbeing of the women members in my family. They really need all the money that they have and can get. So, through a bit of creative reporting on their taxes, I have cheated the government out of about $\$ 100,000$.

MV12: I was with my mother in the mall. I decided to steal some lipstick, because one of my friends stole things all the time. The owners caught me and they thought that it was my mom who tried to get me to steal things for her. I did not refute this.

MV13: I have a friend who is incarcerated. Recently, his girlfriend was driving his car. I was driving my girlfriend's car and got into an accident. My friend's car was one of the cars that I hit, but I just drove away and has never told my friend.

MV14: As I was backing out of a parking lot I bumped a parked car and left a dent. I didn't even feel the impact when I hit the car but it left quite a bit of damage. I drove away without leaving a message or trying to contact the person.

MV15: I drink and drive a lot. Recently, I borrowed my brother's car, was drunk and had taken Valium. I sideswiped another car that had its door open. I got scared and kept driving.

MV16: I was getting a massage at the gym and the massage therapist came on to me. I was dating a guy named Brad at the time though. I was unfaithful to Brad and had sex with the man who was massaging me.

MV17: I work as a legal assistant. I lie to clients all of the time, the attorney I work for lies all the time too. We just lie to our clients so things will work out the best for us.

MV18: I work in a cosmetics department store. I steal clothes by pretending to ring them up, as if I am buying them, and then just put them in my bag. I have taken a lot of clothes and just recently the store found out.

MV19: I work for my dad in the produce business. I feel that he underpays me and I deserve more. So I self-compensate and take money from him.

MV20: A few days ago, I was driving drunk down a road. An old farm dog came out into the middle of the road and started barking. I purposely ran right over it and killed it. 
MV21: I said some bad things about this guy that I work with. He told me some secrets that I promised not to share, but I did anyway. He hasn't found out but I am afraid if he does, he might do something crazy.

MV22: A few months ago, I got my girlfriend pregnant. She told me she was pregnant and that she wanted me to be there for her. At first, I took her to her appointments and such, until I became nervous and ended the relationship.

MV23: My husband and I split up and soon after he was arrested for drug use. While he has been in jail, I have used some of his credit cards that I still have from our marriage. I do it so that he will be so upset with me that he will stop trying to contact me.

MV24: My friends and I are big shoplifters. Our favourite thing to do is go to a local drugstore and load up on candy bars. We do it quite often and no one has ever found out.

MV25: I had a friend whom I wasn't really getting along with anymore. He was coming to see me when he got into a car accident. I chose that time at the hospital to tell him our friendship was over.

MV26: I slept with one of my math teachers and I really hope nobody ever finds out about it. At the time he said he was separated from his wife, so I knew that he was married. 


\section{Table D1}

Mean Care and Moral Appropriateness Ratings for Moral Vignettes (MV) in Study 1

\begin{tabular}{lcc}
\hline Vignette Name & $\begin{array}{c}\text { Care } \\
(\text { Reverse Harm) }\end{array}$ & Moral Appropriateness \\
& $M(S D)$ & $M(S D)$ \\
\hline MV1 & $1.70(0.96)$ & $1.72(1.55)$ \\
MV2 & $2.91(1.57)$ & $2.29(1.49)$ \\
MV4 & $3.47(1.58)$ & $2.77(1.60)$ \\
MV5 & $2.98(1.35)$ & $1.92(1.21)$ \\
MV6 & $3.28(1.38)$ & $2.50(1.41)$ \\
MV7 & $3.04(1.29)$ & $2.52(1.45)$ \\
MV8 & $3.39(1.34)$ & $2.45(1.33)$ \\
MV9 & $3.50(1.32)$ & $2.75(1.36)$ \\
MV10 & $3.05(1.26)$ & $2.29(1.26)$ \\
MV11 & $3.35(1.23)$ & $2.31(1.34)$ \\
MV12 & $3.87(1.73)$ & $2.76(1.57)$ \\
MV13 & $2.80(1.43)$ & $1.99(1.24)$ \\
MV14 & $3.45(1.32)$ & $2.51(1.32)$ \\
MV15 & $3.72(1.36)$ & $2.65(1.19)$ \\
MV16 & $2.77(1.36)$ & $1.88(1.20)$ \\
MV17 & $3.22(1.42)$ & $2.24(1.11)$ \\
MV18 & $2.70(1.40)$ & $2.15(1.37)$ \\
MV19 & $3.67(1.51)$ & $2.34(1.34)$ \\
MV20 & $3.29(1.46)$ & $2.49(1.39)$ \\
MV21 & $1.99(1.13)$ & $1.63(1.36)$ \\
MV22 & $3.75(1.42)$ & $2.90(1.18)$ \\
MV23 & $2.83(1.40)$ & $2.37(1.34)$ \\
MV24 & $3.25(1.34)$ & $2.67(1.40)$ \\
MV25 & $3.85(1.49)$ & $2.41(1.30)$ \\
MV26 & $3.64(1.48)$ & $2.85(1.38)$ \\
\hline Note. The & $2.92(1.35)$ \\
\hline
\end{tabular}

Note. The vignettes (and their corresponding average Care and Moral Appropriateness scores) are listed in the fixed random order they were presented to all participants in Study 1. 


\section{Studies 2 to $4 b$, and Study 7.}

When selecting the vignettes for Study 2 and onward, we re-examined the 40 moral vignettes that were piloted prior to Study 1.

The average Care and Moral Appropriateness ratings, as well as the composite (average) Care-Moral Appropriateness scores, for the moral vignettes used in Studies 2, 3, 4a, 4b, and 7 are presented in Table D2. The first author and one research assistant first grouped each of the vignettes as a 'clear' or 'ambiguous' moral transgression based on each vignette's composite Care-Moral Appropriateness score. Sixteen vignettes with a low composite Care-Moral Appropriateness score $(M=2.57$ out of $7, S D=0.38)$ were grouped and labelled as clear moral transgressions. Sixteen vignettes with a moderate composite Care-Moral Appropriateness score $(M=3.75$ out of $7, S D=0.40)$ were grouped and labelled as ambiguous moral transgressions. The composite Care-Moral Appropriateness scores of the 16 clear moral transgressions were significantly lower than the composite scores of the 16 ambiguous moral transgressions, $t(15)=-$ $8.62, p<.001$, confirming that the former set of violations were more blatantly harmful and morally wrong than the latter.

The 32 vignettes (moral transgressions, MT) are listed below in ascending order of the Composite Care-Moral Appropriateness Scores that are presented in Table D2. The first 15 vignettes were used in Study 7.

MT1: I committed my first assault and robbery as a teenager. Since then, I have threatened people with a knife, punched and kicked them, and broken into their homes to steal their money and valuables.

MT2: A few days ago, I was driving drunk down a road. An old farm dog came out into the middle of the road and started barking. I purposely ran right over it and killed it.

MT3: I drink and drive a lot. Recently, I borrowed my brother's car, was drunk and had taken Valium. I sideswiped another car that had its door open. I got scared and kept driving.

MT4: I was with my mother in the mall. I decided to steal some lipstick, because one of my friends stole things all the time. The owners caught me and they thought that it was my mom who tried to get me to steal things for her. I did not refute this.

MT5: I work as a legal assistant. I lie to clients all of the time, the attorney I work for lies all the time too. We just lie to our clients so things will work out the best for us.

MT6: I am an accountant for a large company. Over a period of years, I have faked the books and have shifted company money into my personal bank account.

MT7: I have served in congress for years. Often, I have supported legislation that was inconsistent with my stated values. That is, there is a disconnect between what I say and what I do. For example, despite publicly advocating against abortions, I have made my wife abort her unborn child three times in the past decade, against her own wishes. 
MT8: A few months ago, I got my girlfriend pregnant. She told me she was pregnant and that she wanted me to be there for her. At first, I took her to her appointments and such, until I became nervous and ended the relationship.

MT9: I cheated on my present boyfriend. I don't understand why he does not want to get married. I feel like he doesn't want to get married because of me and because he doesn't want to be with me, so I thought it was okay to have an affair.

MT10: I was getting a massage at the gym and the massage therapist came on to me. I was dating a guy named Brad at the time though. I was unfaithful to Brad and had sex with the man who was massaging me.

MT11: I was in a relationship with this woman named Beth for a long time. Then one night I cheated on Beth with my ex-girlfriend. The next morning my ex came by to see why I didn't stay the night at her place and she saw me with Beth.

MT12: My family doesn't have money so I always admire jewellery on other students in school. Recently, there was this girl who would wear this necklace. One time at break she put it down and I took it.

MT13: My partner is very sick and has to walk very slowly. He needs a cane and can't move fast. Every day, I am very impatient with him and yell at him to move faster.

MT14: I work for my dad in the produce business. I feel that he underpays me and I deserve more. So I self-compensate and take money from him.

MT15: I took my sister's ring that was given to her by our father's aunt. I had never met our father's aunt but my sister spent some time with her. I took the ring because I don't think that my sister deserves it.

MT16: I called someone a racial name. The person I called was a sort of a friend of my sister's. It got back to her and she is humiliated.

MT17: I left my second marriage and I left my step-kids there too. My youngest stepson has some disabilities, but I left him there. I cannot cope with his druggy, drinking father and so I decided to leave everything behind.

MT18: I said some bad things about this guy that I work with. He told me some secrets that I promised not to share, but I did anyway. He hasn't found out but I am afraid if he does, he might do something crazy.

MT19: I slept with one of my math teachers and I really hope nobody ever finds out about it. At the time he said he was separated from his wife, so I knew that he was married. 
MT20: We used to have a built-in swimming pool and my cousins would come swim. One day one of my cousins was getting cold and wanted to leave, and I said that if he did he couldn't come to swim anymore. He continued swimming and the next day he got really sick.

MT21: At work, I do not follow principles of fairness in my decision making. I often give myself the easiest tasks, and give the hardest tasks to those I do not like. My friends get better raises than my enemies even when their work performance is similar.

MT22: I own this knife that is of illegal length. My next-door neighbour is a drug-dealer and one day some guy came by with a rottweiler and a pit bull that were off their leashes. My cat was outside so I went over with my knife and threatened the man to leave.

MT23: My friend has always been putting down all the men I date because she is jealous. I recently confronted her about it and said some really mean comments to her about how no man wants her. I hurt her feelings a lot.

MT24: When I was a scriptwriter in Hollywood I was in a writer's group and sold a TV show and got an agent. My friend asked if I could send his stuff to my agent. I didn't send his stuff to my agent; instead I told my friend that my agent didn't like his work.

MT25: Recently, public transportation buses in my town have started charging a dollar. So my friends and I tear the dollar into 4 pieces and fold it up so it looks like a dollar. I have used a dollar for four rides.

MT26: A little while ago I had to go to the DMV to get my driver's license renewed. They told me that I had to take a written test in which I had three attempts to pass. I failed the first two times so I cheated on the final attempt.

MT27: For the last two years, I have been dating a real fine lady. She is really serious about settling down but I'm not interested in that. But I want to keep dating so I haven't been honest to her about my feelings.

MT28: Instead of contributing more to my mother's economic stability, by helping her out monetarily in her retirement, I travel. I spend money on travel, on vacations. Some of that money could go to her.

MT29: I am untruthful to a lot of people. I spend a lot of time socializing with girlfriends after work, but tell my boyfriend I am working late. I have skipped work to spend time with my boyfriend, but tell my supervisor I am sick.

MT30: I had a party and didn't invite my friend Anna, because I didn't think that she would mix well with the other guests. The other guests were all new friends and she was an old friend. I asked one of the attendees not to mention it to her, as he is a mutual acquaintance. 
MT31: My father is manic-depressive. He is very difficult to deal with and has made life really hard and everyday situations unpleasant. I talk about him in a really negative way because it is so hard for me to deal with.

MT32: When friends ask for help, I do not respond. When people at work try to raise money for a sick co-worker, I offer nothing. I do not give presents for birthdays or holidays. I do not donate to charities or engage in volunteer activities in the community. 
Table D2

Mean Care and Moral Appropriateness Ratings and Composite Care-Moral Appropriateness Scores for Clear and Ambiguous Moral Transgressions (MT; Studies 2 to 4b, and Study 7)

\begin{tabular}{|c|c|c|c|c|}
\hline & $\begin{array}{c}\text { Care } \\
\text { (Reverse } \\
\text { Harm) } \\
M(S D)\end{array}$ & $\begin{array}{c}\text { Moral } \\
\text { Appropriateness } \\
M(S D)\end{array}$ & $\begin{array}{c}\text { Transgression } \\
\text { Ambiguity }\end{array}$ & $\begin{array}{c}\text { Composite Care-Moral } \\
\text { Appropriateness }\end{array}$ \\
\hline MT1 & $1.70(0.96)$ & $1.72(1.55)$ & Clear & 1.71 \\
\hline MT2 & $1.99(1.13)$ & $1.63(1.36)$ & Clear & 1.81 \\
\hline MT3 & $2.77(1.36)$ & $1.88(1.20)$ & Clear & 2.33 \\
\hline MT4 & $2.80(1.43)$ & $1.99(1.24)$ & Clear & 2.40 \\
\hline MT5 & $2.70(1.40)$ & $2.15(1.37)$ & Clear & 2.43 \\
\hline MT6 & $2.98(1.35)$ & $1.92(1.21)$ & Clear & 2.45 \\
\hline MT7 & $2.91(1.57)$ & $2.29(1.49)$ & Clear & 2.60 \\
\hline MT8 & $2.83(1.40)$ & $2.37(1.34)$ & Clear & 2.60 \\
\hline MT9 & $3.05(1.26)$ & $2.29(1.26)$ & Clear & 2.67 \\
\hline MT10 & $3.22(1.42)$ & $2.24(1.11)$ & Clear & 2.73 \\
\hline MT11 & $3.04(1.29)$ & $2.52(1.45)$ & Clear & 2.78 \\
\hline MT12 & $3.35(1.23)$ & $2.31(1.34)$ & Clear & 2.83 \\
\hline MT13 & $3.28(1.38)$ & $2.50(1.41)$ & Clear & 2.89 \\
\hline MT14 & $3.29(1.46)$ & $2.49(1.39)$ & Clear & 2.89 \\
\hline MT15 & $3.39(1.34)$ & $2.45(1.33)$ & Clear & 2.92 \\
\hline MT16 & $3.50(1.32)$ & $2.75(1.36)$ & Clear & 3.13 \\
\hline MT17 & $3.27(1.52)$ & $3.24(1.72)$ & Ambiguous & 3.26 \\
\hline MT18 & $3.75(1.42)$ & $2.90(1.18)$ & Ambiguous & 3.33 \\
\hline MT19 & $3.84(1.40)$ & $2.92(1.35)$ & Ambiguous & 3.38 \\
\hline MT20 & $3.63(1.36)$ & $3.21(1.15)$ & Ambiguous & 3.42 \\
\hline MT21 & $4.05(1.46)$ & $3.10(1.30)$ & Ambiguous & 3.58 \\
\hline MT22 & $3.81(1.46)$ & $3.35(1.62)$ & Ambiguous & 3.58 \\
\hline MT23 & $3.65(1.34)$ & $3.53(1.35)$ & Ambiguous & 3.59 \\
\hline MT24 & $4.03(1.43)$ & $3.31(1.10)$ & Ambiguous & 3.67 \\
\hline MT25 & $4.48(1.49)$ & $2.85(1.17)$ & Ambiguous & 3.67 \\
\hline MT26 & $4.33(1.59)$ & $3.01(1.27)$ & Ambiguous & 3.67 \\
\hline MT27 & $3.89(1.32)$ & $3.50(1.35)$ & Ambiguous & 3.70 \\
\hline MT28 & $4.13(1.47)$ & $3.65(1.51)$ & Ambiguous & 3.89 \\
\hline MT29 & $4.53(1.31)$ & $3.26(1.08)$ & Ambiguous & 3.90 \\
\hline MT30 & $4.41(1.31)$ & $3.95(1.21)$ & Ambiguous & 4.18 \\
\hline MT31 & $4.90(1.46)$ & $4.14(1.33)$ & Ambiguous & 4.52 \\
\hline MT32 & $5.38(1.32)$ & $3.96(1.22)$ & Ambiguous & 4.67 \\
\hline
\end{tabular}

Note. Some of the vignettes in Study 1 were used in Studies 2, 3, 4a, 4b, and 7, but are labelled differently; here, the vignettes are listed by the ascending order of the composite Care-Moral Appropriateness scores. Study 7 used the first 15 vignettes ("MT1" through to "MT15"). 


\section{Appendix E: Moral Images for Studies 5a to 7}

The Social-Moral Images Database (Crone et al., 2018) contains 2941 images, representing a wide range of morally (and affectively) positively, negative, and neutral content. Normative ratings from 1812 participants were available on eight dimensions, including the level of Harm $(1=$ Caring; $5=$ Harmful $)$ and Moral Wrongness $(1=$ immoral/blameworthy; $5=$ moral/praiseworthy) depicted in the image.

First, upon thorough review of all 2941 images, the first author and one research assistant selected 66 images in which a person was committing a moral norm violation (i.e., theft, rioting, vandalism, etc.). Crone and colleagues (2018) presented the average values of the Care scale as Harm, with higher scores representing high Harm/low Care for a given image. We reversed these Harm ratings for the 66 pictures, such that lower scores would be indicative of higher perceived Harm, or lower Care. Following this, we computed a composite (average) score between the average Care and Moral Wrongness (Appropriateness) scores for each picture. A total of 40 socio-moral images were then selected for the Blame Selection Task in the studies with images (Studies 5a to 7). The first author and one research assistant sorted the 40 images based on each image's composite Care-Moral Appropriateness rating: Twenty images with low composite Care-Moral Appropriateness scores $(M=1.39$ out of $5, S D=0.09)$ were grouped and labelled as clear moral transgressions, whereas 20 images with moderate composite Care-Moral Appropriateness scores $(M=2.71$ out of $5, S D=0.40)$ were grouped as ambiguous moral transgressions. The composite Care-Moral Appropriateness scores of the 20 clear moral transgressions were significantly lower than the composite scores of the 20 ambiguous moral transgressions, $t(19)=-12.73, p<.001$, confirming that the former set of violations were more blatantly harmful and morally wrong than the latter.

The average Care and Moral Appropriateness ratings, as well as the composite Care-Moral Appropriateness scores, for the 40 moral images used in Studies 5a, 5b, and 6 are presented in Table E1. The first 15 moral images were used in Study 7. 
Table E1

Mean Care and Moral Appropriateness Ratings and Composite Scores for Moral Images (Studies 5 a to 7 )

\begin{tabular}{|c|c|c|c|c|}
\hline $\begin{array}{l}\text { Image } \\
\text { Name }\end{array}$ & $\begin{array}{c}\text { Care (Reverse } \\
\text { Harm) } \\
M(S D)\end{array}$ & $\begin{array}{l}\text { Moral } \\
\text { Appr. } \\
M(S D)\end{array}$ & $\begin{array}{c}\text { Transgression } \\
\text { Ambiguity }\end{array}$ & $\begin{array}{c}\text { Composite Care-Moral } \\
\text { Appropriateness }\end{array}$ \\
\hline b11_p167_19 & $1.23(0.89)$ & $1.12(0.64)$ & Clear & 1.17 \\
\hline b11_p167_16 & $1.24(0.89)$ & $1.27(0.90)$ & Clear & 1.26 \\
\hline b11_p164_16 & $1.24(0.89)$ & $1.38(0.92)$ & Clear & 1.31 \\
\hline b10_p136_11 & $1.37(0.68)$ & $1.26(0.93)$ & Clear & 1.32 \\
\hline b15_p388_1 & $1.40(1.12)$ & $1.28(0.98)$ & Clear & 1.34 \\
\hline b11_p164_18 & $1.44(0.84)$ & $1.26(0.86)$ & Clear & 1.35 \\
\hline b10_p138_5 & $1.36(1.18)$ & $1.36(1.05)$ & Clear & 1.36 \\
\hline b15_p326_20 & $1.54(1.06)$ & $1.19(0.87)$ & Clear & 1.37 \\
\hline b15_p452_17 & $1.27(0.81)$ & $1.47(0.97)$ & Clear & 1.37 \\
\hline b999_p496_10 & $1.39(1.04)$ & $1.39(0.85)$ & Clear & 1.39 \\
\hline b999_p477_17 & $1.48(1.21)$ & $1.33(0.91)$ & Clear & 1.40 \\
\hline b14_p290_2 & $1.32(0.95)$ & $1.53(1.31)$ & Clear & 1.42 \\
\hline b14_p272_14 & $1.23(0.61)$ & 1.68 (1.29) & Clear & 1.45 \\
\hline b15_p439_12 & $1.50(1.28)$ & $1.40(1.05)$ & Clear & 1.45 \\
\hline b15_p460_10 & $1.27(0.90)$ & $1.67(1.13)$ & Clear & 1.47 \\
\hline b5_p82_6 & $1.56(1.02)$ & $1.38(0.89)$ & Clear & 1.47 \\
\hline b2_p32_20 & $1.58(1.10)$ & $1.40(0.89)$ & Clear & 1.49 \\
\hline b15_p331_3 & $1.60(1.35)$ & $1.35(0.49)$ & Clear & 1.48 \\
\hline b15_p316_8 & $1.62(1.24)$ & $1.38(0.97)$ & Clear & 1.50 \\
\hline b999_p497_11 & $1.35(1.09)$ & 1.65 (1.27) & Clear & 1.50 \\
\hline b15_p401_6 & $1.26(0.65)$ & $3.00(1.33)$ & Ambiguous & 2.13 \\
\hline b999_p479_2 & $2.94(1.59)$ & $1.37(1.01)$ & Ambiguous & 2.16 \\
\hline b15_p377_s & $2.32(1.00)$ & $2.16(0.60)$ & Ambiguous & 2.24 \\
\hline b15_p323_11 & $1.63(0.83)$ & $2.90(1.33)$ & Ambiguous & 2.26 \\
\hline b4_p53_6 & $1.96(1.33)$ & $2.64(1.00)$ & Ambiguous & 2.30 \\
\hline b999_p479_4 & $2.81(1.60)$ & $1.86(1.24)$ & Ambiguous & 2.33 \\
\hline b15_p335_4 & $2.45(1.76)$ & $2.25(1.12)$ & Ambiguous & 2.35 \\
\hline b15_p323_13 & $2.41(1.44)$ & $2.59(1.71)$ & Ambiguous & 2.50 \\
\hline b13_p224_8 & $2.75(1.53)$ & $2.52(1.18)$ & Ambiguous & 2.64 \\
\hline b15_p296_8 & $2.55(1.70)$ & $2.95(1.15)$ & Ambiguous & 2.75 \\
\hline b13_p235_1 & $3.05(1.36)$ & $2.67(1.02)$ & Ambiguous & 2.86 \\
\hline b15_p463_17 & $2.96(1.59)$ & $2.77(1.11)$ & Ambiguous & 2.86 \\
\hline b13_p230_8 & $2.91(1.45)$ & $2.81(1.12)$ & Ambiguous & 2.86 \\
\hline b14_p284_12 & $3.65(1.39)$ & $2.20(1.11)$ & Ambiguous & 2.93 \\
\hline b13_p241_13 & $2.90(1.49)$ & $3.05(0.85)$ & Ambiguous & 2.97 \\
\hline b15_p468_11 & $4.21(1.18)$ & $2.74(1.10)$ & Ambiguous & 3.47 \\
\hline b8_p119_14 & $3.08(1.56)$ & $2.96(1.16)$ & Ambiguous & 3.02 \\
\hline b13_p230_11 & $3.17(1.38)$ & $3.06(1.16)$ & Ambiguous & 3.11 \\
\hline b8_p115_10 & $3.39(1.62)$ & $2.87(1.01)$ & Ambiguous & 3.13 \\
\hline b15_p323_16 & $3.80(1.06)$ & $2.75(0.97)$ & Ambiguous & 3.28 \\
\hline
\end{tabular}

Note. The images are labelled as found in the SMID database (Crone et al., 2018) and are listed here by the ascending order of the composite Care-Moral Appropriateness scores. Study 7 used the first 15 images ("b11_p167_19" through to "b15_p460_10"). 


\section{Headlines for Clear and Ambiguous Moral Images in Study 6}

\begin{tabular}{|c|c|}
\hline Image Name & Headline \\
\hline b11_p167_19 & Guard abuses and tortures Iraqi prisoners. \\
\hline b11_p167_16 & Man beheads innocent tourist. \\
\hline b11_p164_16 & Woman uses illicit drugs in bathroom during work. \\
\hline b10_p136_11 & Man commits aggravated assault with gun. \\
\hline b15_p388_1 & Man tackles and spits on stranger during altercation. \\
\hline b11_p164_18 & Woman heats cocaine while babysitting. \\
\hline b10_p138_5 & Man throws news-stand and damages car during peaceful demonstration. \\
\hline b15_p326_20 & Men beat seals to death to obtain fur. \\
\hline b15_p452_17 & Boy bullies and punches peer at school. \\
\hline b999_p496_10 & Man ties up and waterboards refugee as onlookers take photographs. \\
\hline b999_p477_17 & Anarchist vandalizes and damages bank. \\
\hline b14_p290_2 & Man holds up and robs bank. \\
\hline b14_p272_14 & Man throws tear-gas grenade at police during riot. \\
\hline b15_p439_12 & Man strangles young child. \\
\hline b15_p460_10 & Police officer pepper-sprays peaceful protesters at nonviolent protest. \\
\hline b5_p82_6 & Man promotes neo-Nazi ideology and shares these views on social media. \\
\hline b2_p32_20 & Man sets fire on residential street during protest. \\
\hline b15_p331_3 & Teen strikes neighbour with snow-shovel. \\
\hline b15_p316_8 & $\begin{array}{l}\text { Man yells racial slurs and holds "white-pride" flag at right-wing, white } \\
\text { supremacist rally. }\end{array}$ \\
\hline b999_p497_11 & Soldier brutally beats and threatens to kill youth prisoner. \\
\hline b15_p401_6 & Soldier fires at enemy soldiers and civilians in village using M240 machine gun. \\
\hline b999_p479_2 & Prostitute solicits driver at stoplight. \\
\hline b15_p377_5 & Man yells profanities at local area senior. \\
\hline b15_p323_11 & Man cheats on girlfriend. \\
\hline b4_p53_6 & Officer twists the arm of young man during pat-down. \\
\hline b999_p479_4 & Prostitute poses provocatively at window of brothel to solicit customers. \\
\hline b15_p335_4 & Man hangs and cuts open dead pigs for meat. \\
\hline b15_p323_13 & Man is unfaithful to wife. \\
\hline b13_p224_8 & Animal trainer whips baby cheetah during training at the circus. \\
\hline b15_p296_8 & Man sheers sheep against its will. \\
\hline b13_p235_1 & Woman slams pie in the face of restaurant patron. \\
\hline b15_p463_17 & Man collects semen from farm buffalo. \\
\hline b13_p230_8 & Equestrian crashes horse into deck. \\
\hline b14_p284_12 & Drunken man passes out in kart outside local supermarket. \\
\hline b13_p241_13 & Man hunts deer with dog. \\
\hline b15_p468_11 & Man gambles away family's life savings. \\
\hline b8_p119_14 & Air traffic control gives the clear for take-off of aircraft with ballistic missile \\
\hline b13_p230_11 & Man uses baby elephant as caddie during golf game. \\
\hline b8_p115_10 & Man dumps juice on unassuming sports spectator. \\
\hline b15_p323_16 & Woman spreads gossip about co-worker. \\
\hline
\end{tabular}




\section{Appendix F: Parametric Tests for Blame Choice}

Table F1 presents the descriptive statistics and parametric inferential statistics for blame choice across all studies.

\section{Blame Choice}

\section{Results of Studies 1 to 4b: Blame Selection Task with Moral Vignettes}

In Study 1, although respondents chose to blame more than describe, a one-sample $t$-test found that blame choice did not significantly differ from chance (50 percent), $t(101)=1.65, p=.102, d=0.16$. Blame choice was significantly greater than chance in Study 2, $t(109)=4.77, p<.001, d=0.46$, and in Study $3, t(200)=10.14, p$ $<.001, d=0.75$ - suggesting that, irrespective of the alternative deck choice (either objective description or empathy), respondents displayed a moderate-to-large motivation to feel outrage and blame individuals depicted in the moral vignettes after reading the vignettes. Blame choice was significantly greater than chance in Study $4 \mathrm{a}, t(204)=2.53, p=.006, d=0.17$, and in Study $4 \mathrm{~b}, t(202)=3.76, p<.001, d=0.27$-suggesting that, irrespective of the alternative deck choice, respondents displayed a small-to-moderate motivation to feel outrage and blame individuals depicted in the moral vignettes before reading the vignettes.

\section{Blame Choice by Moral Ambiguity of Vignettes}

We computed a blame choice score (i.e., the proportion of trials for which the respondent chose the BLAME deck) for the groups of clear and ambiguous moral transgressions for each participant in Studies 2 and 3 where vignettes - labelled as clear or ambiguous - preceded deck choice. We did not do this in Studies 4a and $4 \mathrm{~b}$ because the vignettes did not precede deck choices, and so, it is unlikely that participants would have made decisions based on vignette content in the same way. As evidenced by paired samples $t$-tests, blame choice was significantly greater for the clear moral transgressions than for the ambiguous moral transgressions within both studies [Study 2: $t(109)=12.50, p<.001, d=1.19$; Study 3: $t(200)=20.86, p<.001, d=1.47$ ] . One-sample $t$ tests found that participants chose the BLAME deck at a rate significantly greater than chance (i.e., greater than 50 percent of trials) after reading the clear moral transgressions [Study 2: $M_{\text {choice }}=0.74, S D_{\text {choice }}=0.28, t(109)=$ 9.15, $p<.001, d=0.86$; Study 3: $M_{\text {choice }}=0.77, S D_{\text {choice }}=0.22, t(200)=17.26, p<.001, d=1.23$ ], but did not show a preference for selecting the BLAME deck after reading the ambiguous moral transgressions [Study 2: $M_{\text {choice }}=0.49, S D_{\text {choice }}=0.28, t(109)=-.19, p=.850, d=-0.04 ;$ Study 3: $M_{\text {choice }}=0.52, S D_{\text {choice }}=0.22, t(200)=$ $1.18, p=.241, d=0.09]$. These results suggest that, as opposed to remaining objective or empathizing, respondents chose to blame individuals who commit clearly harmful and morally inappropriate behaviors, but that this blame preference diminished for more ambiguous acts.

\section{Blame Choice}

\section{Results of Studies 5a to 6: Blame Selection Task with Moral Images}

In contrast to the vignette studies, one-sample $t$-tests revealed that blame choice in response to images ${ }^{6}$ (see Table F1 for descriptive statistics and parametric inferential statistics) was significantly less than chance in Study 5a, $t(218)=-20.90, p<.001, d=-1.45$, in Study $5 \mathrm{~b}, t(204)=-18.80, p<.001, d=-1.29$, and in Study 6 , $t(209)=-7.66, p<.001, d=-0.52$ (see Figure 2). Blame choice in response to moral images and captions in Study 6 was higher than blame choice in Studies $5 \mathrm{a}, t(405.30)=7.18, p<.001, d=0.71$, where respondents only saw moral images, with a moderate-to-large effect of captions on blame choice differences between samples. This suggests that, although blame choice is below 50\%, there is a larger likelihood to blame others when moral images are accompanied by verbal information.

\footnotetext{
${ }^{6}$ Blame choice between participants who saw the BLAME deck on the left side of the BST and participants who saw the deck on the right side of the BST did not significantly differ from one another in Study 5a and in Study 6. Blame choice was significantly higher among participants in Study 5b who saw the deck on the left side of the BST than among participants who saw the deck on the right side of the BST (see Table A2 in
} Appendix A). 


\section{Blame Choice by Moral Ambiguity of Images}

As with Studies 2 and 3, blame choice was computed for the groups of clear and ambiguous moral transgressions in Studies 5a and 6, wherein images preceded deck choices (see Figure 3). Replicating results from Studies 2 and 3 that used vignettes, blame choice in Study 5a was significantly higher for clear moral transgressions $\left(M_{\text {choice }}=0.33, S D_{\text {choice }}=0.31\right)$ than for ambiguous moral transgressions $\left(M_{\text {choice }}=0.10, S D_{\text {choice }}\right.$ $=0.12), t(218)=14.05, p<.001, d=0.96$ - suggesting that the level of harm and immorality of the pictures that precede the decks largely increases the choice to blame individuals committing such acts. Similarly, in Study 6 , blame choice was significantly greater for clear moral images accompanied by captions $\left(M_{\text {choice }}=0.50, S D_{\text {choice }}\right.$ $=0.32)$ than for ambiguous moral images accompanied by captions $\left(M_{\text {choice }}=0.24, S D_{\text {choice }}=0.21\right), t(209)=$ $17.36, p<.001, d=1.18$. Separate one-sample $t$-tests revealed that respondents in Study 5a chose to blame significantly less than $50 \%$ of the time after seeing both clear moral transgressions, $t(218)=-8.00, p<.001, d=$ -0.55 , and ambiguous moral transgressions, $t(218)=-49.44, p<.001, d=-3.33$. In Study 6 , the rate at which participants chose the BLAME deck did not significantly differ from chance for the clear moral transgressions, $t(209)=.04, p=.966, d=0.00$, but was significantly less than chance for the ambiguous moral transgressions, $t(209)=-18.28, p<.001, d=-1.24$. Blame choice for clear moral images was significantly higher among respondents in Study 6 who also read captions than respondents in Study 5a, $t(427)=5.57, p<.001, d=0.54$; and similar patterns were observed between the two samples for ambiguous moral images, $t(334.04)=8.69, p<$ $.001, d=0.82$.

\section{Blame Choice}

\section{Results of Study 7: Blame Selection Task with Moral Vignettes and Moral Images}

Collapsing across the counterbalanced conditions, blame choice for the vignettes was significantly greater than blame choice for the images, $t(216)=12.59, p<.001, d=0.87$, with a robust effects of stimuli modality observed. See Table F1 for descriptive statistics. Within both counterbalanced conditions, blame choice for the vignettes was significantly greater than blame choice for the images, (Images first: $M_{\text {choice-vignettes }}=0.46, S D_{\text {choice- }}$ vignettes $=0.31 ; M_{\text {choice-images }}=0.26, S D_{\text {choice-images }}=0.24 ; t(108)=7.94, p<.001, d=0.77 ;$ Images second: $M_{\text {choice- }}$ vignettes $\left.=0.56, S D_{\text {choice-vignettes }}=0.29 ; M_{\text {choice-images }}=0.24, S D_{\text {choice-images }}=0.27 ; t(107)=10.05, p<.001, d=0.97\right)$, with robust effects of stimuli modality observed. Irrespective of the order of the block of moral images, imagebased blame choice was significantly below chance (Images first: $t(108)=-10.52, p<.001, d=-1.00$; Images second: $t(107)=-9.92, p<.001, d=-0.96)$. Among participants who saw the block of images first (before the moral vignettes), subsequent blame choice for the vignettes did not significantly differ from chance, $t(108)=-$ $1.37, p=.175, d=-0.13$. Among participants who saw the block of images second (after the moral vignettes), subsequent vignette-based blame choice was significantly greater than chance, $t(107)=2.14, p=.017, d=0.21$, with a small-to-moderate blame choice effect observed. 


\section{Table F1}

Blame Choice (Studies 1 to 7) - Parametric One-samples t-tests

\begin{tabular}{|c|c|c|c|c|c|c|c|c|c|}
\hline$M(S D)$ & Study 1 & Study 2 & Study $3 *$ & Study $4 \mathrm{a}$ & Study $4 b^{*}$ & Study $5 \mathrm{a}$ & Study $5 b$ & Study 6 & Study 7 \\
\hline Blame Choice: & $0.55(0.32)$ & $0.62(0.26)$ & $0.65(0.20)$ & $0.56(0.36)$ & $0.58(0.30)$ & $0.21(0.20)$ & $0.19(0.24)$ & $0.37(0.25)$ & $0.25(0.25)$ \\
\hline$t(d f)$ & $1.65(101)$ & 4.77 (109) & $10.14(200)$ & $2.53(204)$ & $3.76(202)$ & $-20.90(218)$ & $-18.80(204)$ & $-7.66(209)$ & $-14.43(216)$ \\
\hline$p$ & .102 & $<.001$ & $<.001$ & .006 & $<.001$ & $<.001$ & $<.001$ & $<.001$ & $<.001$ \\
\hline Cohen's $d^{\mathrm{a}}$ & 0.16 & 0.46 & 0.75 & 0.17 & 0.27 & -1.45 & -1.29 & -0.52 & -1.00 \\
\hline $\begin{array}{l}\text { Blame Choice: } \\
\quad t(d f) \\
p \\
\text { Cohen's } d^{\mathrm{a}}\end{array}$ & - & - & - & - & - & - & - & - & $\begin{array}{c}0.51(0.30) \\
.47 \\
.638 \\
0.03\end{array}$ \\
\hline
\end{tabular}

Note. Study 7 presents blame choice scores for both image-based (top) and vignette-based (bottom) transgressions. Studies 3 and $4 \mathrm{~b}$ used the FEEL deck as the alternative choice to the BLAME deck. 
Table F2

Within-Study Correlations between Blame Choice, Cognitive Costs, Social Norms, and Individual Difference Measures

\begin{tabular}{|c|c|c|c|c|c|c|c|c|c|}
\hline Blame Choice: & Study 1 & Study 2 & Study 3 & Study $4 \mathrm{a}$ & Study $4 b$ & Study $5 a$ & Study $5 b$ & Study 6 & Study 7 \\
\hline Effort & $-.25 *$ & -.12 & -.12 & -.14 & $-.19 * *$ & -.00 & -.11 & $-.21 * *$ & .02 \\
\hline Aversiveness & $-.29 * *$ & -.09 & $-.17 *$ & $-.24 * * *$ & $-.19 * *$ & -.05 & -.11 & -.10 & -.06 \\
\hline Efficacy & $.58 * * *$ & $.49 * * *$ & $.45^{* * *}$ & $.60 * * *$ & $.58 * * *$ & $.43 * * *$ & $.31 * * *$ & $.44 * * *$ & $.56 * * *$ \\
\hline Descriptive & - & $.42 * * *$ & $.48 * * *$ & $.54 * * *$ & $.57 * * *$ & $.38 * * *$ & $.35 * * *$ & $.50 * * *$ & $.41 * * *$ \\
\hline Injunctive & - & .04 & .04 & .14 & .11 & .11 & .03 & $.18 * *$ & $.14 *$ \\
\hline Personal & - & $.26 * *$ & $.21 * *$ & $.46 * * *$ & $.22 * *$ & $.29 * * *$ & $.14 *$ & $.32 * * *$ & $.35 * * *$ \\
\hline Moral Conviction & $.46^{* * * *}$ & $.30 * *$ & $.19 * *$ & $.35 * * *$ & .13 & $.44 * * *$ & .07 & $.49 * * *$ & $.28 * * *$ \\
\hline Symbolization & - & .12 & .09 & $.21 * *$ & -.03 & $.17 *$ & $.22 * *$ & $.22 * *$ & $.21 * *$ \\
\hline Internalization & - & -.03 & .09 & .12 & .07 & $-.16^{*}$ & .07 & -.01 & .06 \\
\hline Empathy & .05 & .14 & .04 & $.30 * * *$ & -.11 & $.15^{*}$ & .10 & .12 & $.24 * * *$ \\
\hline Beh. Contagion & .07 & .12 & .07 & .12 & -.10 & .03 & .06 & $.18 *$ & $.24 * * *$ \\
\hline
\end{tabular}

Note. Perceived Effort, Aversiveness, and Efficacy, as well as Descriptive and Injunctive norms, reflect difference scores (Blame deck - Alternative deck). In Studies 3 and 7, blame choice and cognitive cost measures are averaged across the within-subjects transgression ambiguity condition (Study 3: clear, ambiguous) and stimuli type condition (Study 7: images, vignettes).

$* p<.05, * * p<.01, * * * p<.001$ 